\title{
SHORTCUT MODELING OF NATURAL GAS SUPERSONIC SEPARATION
}

\author{
A Thesis \\ by \\ WAJDI JAMAL OTHMAN AHMED ALNOUSH \\ Submitted to the Office of Graduate and Professional Studies of \\ Texas A\&M University \\ in partial fulfillment of the requirements for the degree of \\ MASTER OF SCIENCE
}

$\begin{array}{ll}\text { Chair of Committee, } & \text { Konstantinos Kakosimos } \\ \text { Co-Chair of Committee, } & \text { Marcelo Castier } \\ \text { Committee Member, } & \text { Bing Guo } \\ \text { Head of Department, } & \text { M. Nazmul Karim }\end{array}$

December 2018

Major Subject: Chemical Engineering

Copyright 2018 Wajdi Jamal Othman Ahmed Alnoush 


\begin{abstract}
Supersonic separation is a novel technology for natural gas separation. The theoretical design uniquely combines concepts from aerodynamics, thermodynamics, physical separation and fluid-dynamics resulting in an innovative gas conditioning process. It is used to condition the gas by removing condensable vapors and natural gas liquids. The supersonic separator is composed of a converging section, a Laval nozzle and a diverging section.

Natural gas flows from reservoirs with low velocity and high pressure. In the supersonic separation process, the temperature drops below the dew point of the natural gas. A multiphase flow is formed. Undesired components form liquid condensates that are centrifugally removed through side collection streams.

The goal of this work is to develop a one-dimensional thermodynamic numerical model that presents great potential as a fast and accurate tool that enables the simulation of supersonic separators with significant details. The model is to fill certain gaps found in literature with a shortcut modeling technique. This model would best fit the category of preliminary design tools with decreased computational loads.

The model was utilized to test several cases for validation. Air, 3-component natural gas and 13-component natural gas mixtures were tested as working fluids at different conditions and nozzle area ratios. Tests included nozzles with and without side streams. The shortcut model demonstrated matching results with previous models from benchmarked studies. The computational load was immensely decreased by reducing the number of locations tested in the diverging nozzle to locate the side streams and the shockwave.

The reduction of computational load was demonstrated by decreasing simulation time by $75 \%-97 \%$ depending on the nozzle geometry and conditions. The model proved to be a quick tool suitable for preliminary designs.
\end{abstract}




\section{ACKNOWLEDGEMENTS}

My sincere gratitude goes to my advisor Professor Marcelo Castier and my committee chair Dr. Konstantinos Kakosimos. Assistance, guidance, support and motivation were provided consistently by Professor Castier. Through difficult times and obstacles, his directions steered me in the right direction. Dr. Konstantinos's comments and feedback were very valuable for the presentation of this work. My thanks extended to my committee member Dr. Bing Guo and his support and facilitation of the submission of this work.

I would like to acknowledge the Office of Graduate and Professional Studies at Texas A\&M University at Qatar for their embracement of graduate students and their assistance.

I would also like to acknowledge Dr. Ricardo A. Medronho's research team at Federal University of Rio de Janeiro for their involvement in the initial stages of this work through insightful discussions.

Finally, I must express my unlimited gratitude to my family. Their encouragement and patience throughout my studies was unparalleled. This work would not have been possible without them. 


\section{CONTRIBUTORS AND FUNDING SOURCES}

This work was supervised by a thesis committee consisting of Dr. Konstantinos Kakosimos and Dr. Marcelo Castier of the Department of Chemical Engineering and Dr. Bing Guo of the Department of Mechanical Engineering. All work for the thesis was completed independently by the student.

Graduate study was partially supported by an Itochu fellowship from Texas A\&M University for the Spring 2018 semester. The student self-funded the rest of the work related to the research and compilation of this document. 


\section{TABLE OF CONTENTS}

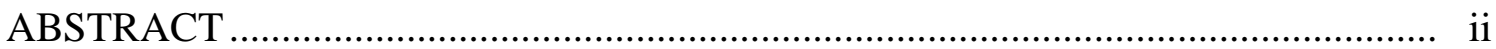

ACKNOWLEDGEMENTS _...................................................................... iii

CONTRIBUTORS AND FUNDING SOURCES ............................................... iv

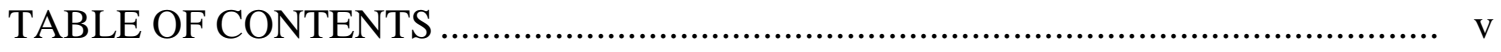

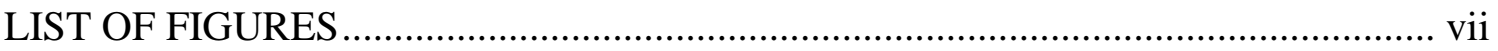

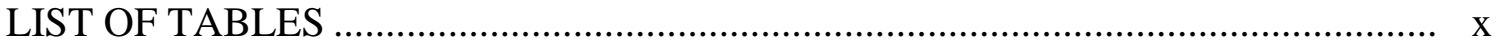

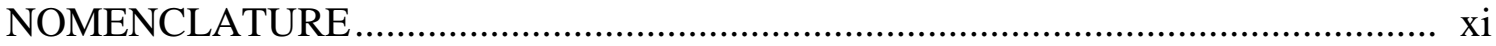

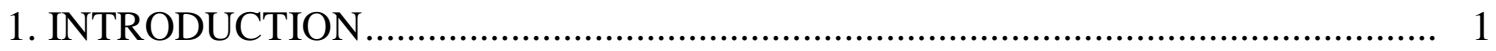

2. LITERATURE REVIEW .................................................................... 6

2.1 Thermodynamic and numerical simulation studies .................................. 6

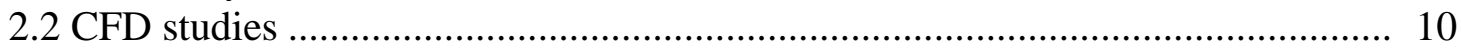

2.3 Experimental-simulation studies ............................................................ 13

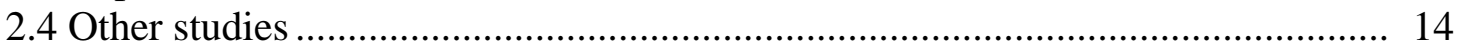

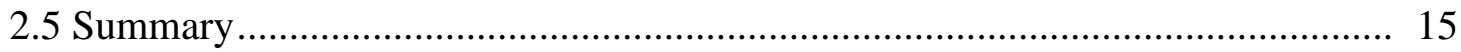

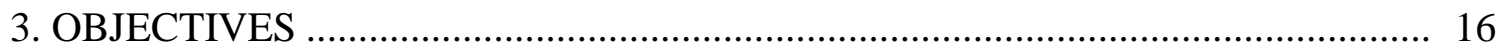

4. MODEL FORMULATION ...................................................................... 17

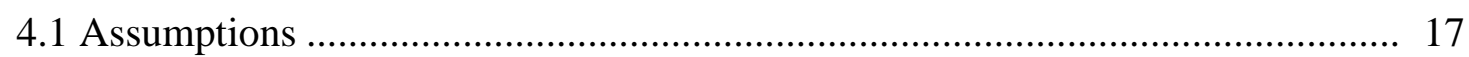




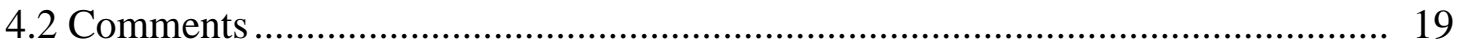

4.2.1 Thermodynamic numerical model.......................................................... 19

4.2.2 Multiphase flow........................................................................... 20

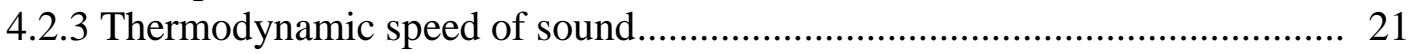

4.2.4 Side streams...................................................................................... 22

4.2.5 Shockwave location.............................................................................. 24

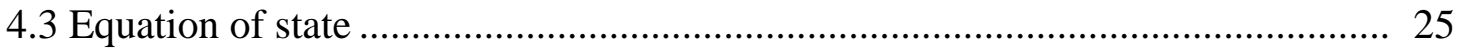

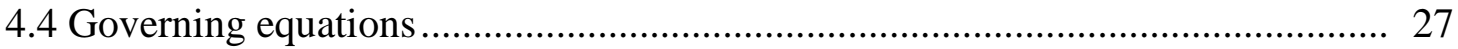

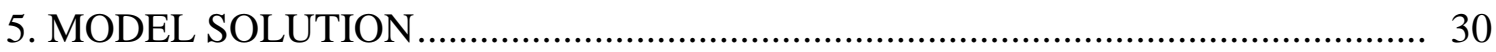

5.1 Nozzle configuration and boundary conditions ............................................... 30

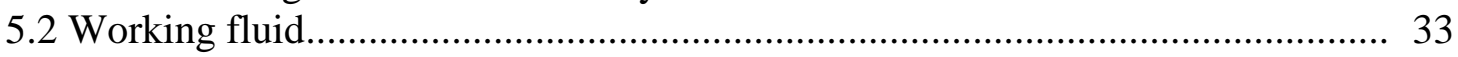

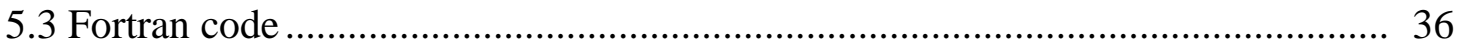

6. RESULTS AND DISCUSSION ……………………................................... 40

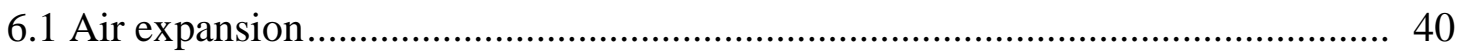

6.2 3-component natural gas............................................................................. 42

6.313 -component natural gas ........................................................................... 47

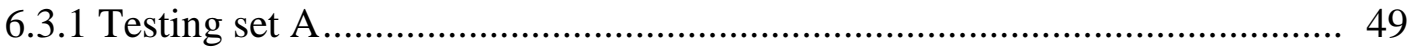

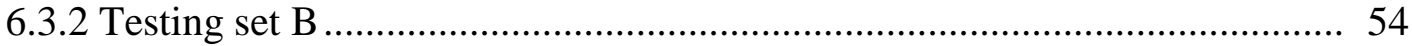

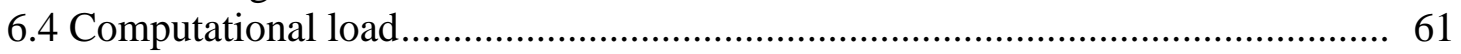

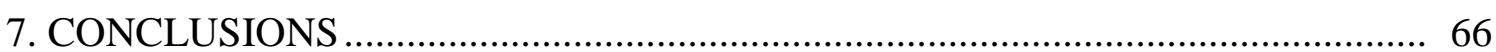

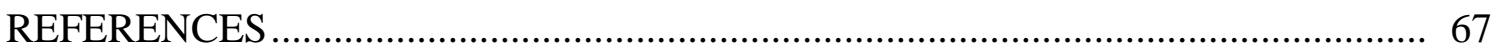

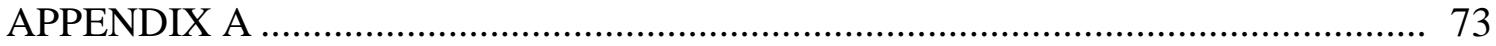

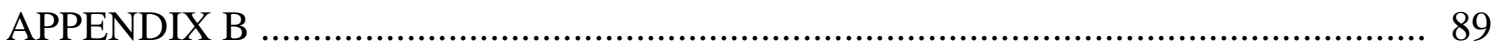




\section{LIST OF FIGURES}

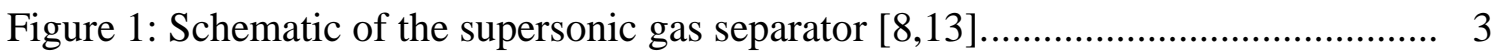

Figure 2: Sunburst supersonic flow analysis diagram.......................................... 5

Figure 3: Radial distribution of static temperature $[\mathrm{K}]$ at nozzle exit at (a) $0 \%$ swirl, (b) $48.9 \%$ swirl, (c) $90.6 \%$ swirl. [3] .................................................. 20

Figure 4: Converging-Diverging nozzle [63] ................................................ 30

Figure 5: Schematic of Twister Mark I [10,42] ................................................... 31

Figure 6: Schematic of constructed SGS device by Qingfen et al. [28]....................... 31

Figure 7: T-s diagram for raw natural gas components [17] ................................. 35

Figure 8: Pressure profile in the diverging section for air expansion. ......................... 41

Figure 9: Temperature profile in the diverging section for air expansion.................... 42

Figure 10: 3-component natural gas temperature and pressure profiles in the diverging section of a nozzle with $A_{\text {out }} / A_{t}=4.9669$ and no side streams.............. 44

Figure 11: 3-component natural gas flow speed and Mach number profiles in the diverging section of a nozzle with $A_{\text {out }} / A_{t}=4.9669$ and no side streams.

Figure 12: Profile of the ratio of mole fraction in liquid phase to the feed mole fraction along the diverging section of a nozzle with $A_{\text {out }} / A_{t}=4.9669$ for 3component natural gas mixture.

Figure 13: 13-component natural gas pressure profiles in the diverging sections of nozzles with $A_{\text {out }} / A_{t}$ ratios $(1.5,3.0$ and 4.5$)$ and no side streams.

Figure 14: 13-component natural gas temperature profiles in the diverging sections of nozzles with $A_{\text {out }} / A_{t}$ ratios $(1.5,3.0$ and 4.5$)$ and no side streams

Figure 15: 13-component natural gas temperature profiles in the diverging sections of nozzles with $A_{\text {out }} / A_{t}$ ratios $(1.5,3.0$ and 4.5$)$ and no side streams. 
Figure 16: 13-component natural gas temperature profiles in the diverging sections of nozzles with $A_{\text {out }} / A_{t}=3.0$, side stream at $166.7 \mathrm{~K}$ and liquid phase recoveries of $50 \%, 70 \%$ and $90 \%$.

Figure 17: 13-component natural gas pressure profiles in the diverging sections of nozzles with $A_{\text {out }} / A_{t}=3.0$, side stream at $166.7 \mathrm{~K}$ and liquid phase recoveries of $50 \%, 70 \%$ and $90 \%$.

Figure 18: 13-component natural gas molar entropy profiles in the diverging sections of nozzles with $A_{\text {out }} / A_{t}=3.0$, side stream at $166.7 \mathrm{~K}$ and liquid phase recoveries of $50 \%, 70 \%$ and $90 \%$.

Figure 19: 13-component natural gas temperature profiles in the diverging sections of nozzles with $90 \%$ liquid phase recovery, $A_{\text {out }} / A_{t}=3.0$ and side streams at $169.3 \mathrm{~K}, 174.8 \mathrm{~K}, 179.9 \mathrm{~K}$ and no side streams.

Figure 20: 13-component natural gas pressure profiles in the diverging sections of nozzles with $90 \%$ liquid phase recovery, $A_{\text {out }} / A_{t}=3.0$ and side streams at $169.3 \mathrm{~K}, 174.8 \mathrm{~K}, 179.9 \mathrm{~K}$ and no side streams.

Figure 21: 13-component natural gas Mach number profiles in the diverging sections of nozzles with $90 \%$ liquid phase recovery, $A_{\text {out }} / A_{t}=3.0$ and side streams at $169.3 \mathrm{~K}, 174.8 \mathrm{~K}, 179.9 \mathrm{~K}$ and no side streams.

Figure 22: 13-component natural gas mole fraction in the liquid phase profile in the diverging sections of a nozzle with $90 \%$ liquid phase recovery, $A_{\text {out }} / A_{t}=$ 3.0 and a side stream at $169.3 \mathrm{~K}$.

Figure 23: 13-component natural gas temperature profiles in the diverging sections of nozzles with $A_{\text {out }} / A_{t}=1.5$ and side streams at $210 \mathrm{~K}, 220 \mathrm{~K}$ and $230 \mathrm{~K}$.

Figure 24: 13-component natural gas pressure profiles in the diverging sections of nozzles with $A_{\text {out }} / A_{t}=1.5$ and side streams at $210 \mathrm{~K}, 220 \mathrm{~K}$ and $230 \mathrm{~K}$.

Figure 25: 13-component natural gas sound speed profiles in the diverging sections of nozzles with $A_{\text {out }} / A_{t}=1.5$ and side streams at $210 \mathrm{~K}, 220 \mathrm{~K}$ and 230 $K$.

Figure 26: 13-component natural gas Mach number profiles in the diverging sections of nozzles with $A_{\text {out }} / A_{t}=1.5$ and side streams at $210 \mathrm{~K}, 220 \mathrm{~K}$ and 230 K. 
Figure 27: 13-component natural gas molar entropy profiles in the diverging sections of nozzles with $A_{\text {out }} / A_{t}=1.5$ and side streams at $210 \mathrm{~K}, 220 \mathrm{~K}$ and 230 $K$.

Figure 28: Simulation run time comparison for nozzles at $A_{\text {out }} / A_{t}=1.5,90 \%$ liquid phase recovery and side streams at $210 \mathrm{~K}, 220 \mathrm{~K}$ and $230 \mathrm{~K}$.

Figure 29: Percentage reduction in computational time for nozzles at $A_{\text {out }} / A_{t}=1.5$, $90 \%$ liquid phase recovery and side streams at $210 \mathrm{~K}, 220 \mathrm{~K}$ and $230 \mathrm{~K}$.. 62

Figure 30: Simulation run time comparison for nozzles at $A_{\text {out }} / A_{t}=3.0$, side stream at $166.7 \mathrm{~K}$ and liquid phase recoveries of $50 \%, 70 \%$ and $90 \%$.

Figure 31: Percentage reduction in computational time for nozzles at $A_{\text {out }} / A_{t}=3.0$, side stream at $166.7 \mathrm{~K}$ and liquid phase recoveries of $50 \%, 70 \%$ and $90 \%$.

Figure 32: Simulation run time comparison for a nozzles at $A_{\text {out }} / A_{t}=4.9669,90 \%$ liquid phase recovery and no side streams. 


\section{LIST OF TABLES}

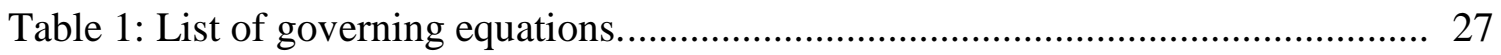

Table 2: Simulated working fluids in the works of Castier [19] and Secchi et al. [17]. 34

Table 3: Fortran code algorithms. .................................................................... 37

Table 4: Temperature and pressure changes across the shockwave and shockwave position for 3-component natural gas in a nozzle with $A_{\text {out }} / A_{t}=4.9669$...... 45

Table 5: 13-component natural gas molar composition. .......................................... 49

Table 6: Computational load comparisons............................................................ 64 


\section{NOMENCLATURE}

\section{Roman letters}

$\begin{array}{ll}a & \text { Thermodynamic sound speed } \\ a_{m} & \text { Parameter of the Peng-Robinson equation of state } \\ A_{c} & \text { Cross-sectional area } \\ b_{m} & \text { Parameter of the Peng-Robinson equation of state } \\ h & \text { Molar enthalpy } \\ k_{i j} & \text { Binary parameter for the pair of components } i-j \\ M a & \text { Mach number } \\ M & \text { Molar mass } \\ \dot{n} & \text { Molar flowrates } \\ P & \text { Absolute pressure } \\ s & \text { Molar entropy } \\ T & \text { Absolute temperature } \\ T_{C} & \text { Critical temperature } \\ T_{R} & \text { Reduced temperature } \\ u & \text { Flow velocity } \\ v & \text { Molar volume } \\ x & \text { Axial length } \\ Z & \text { Mole fractions }\end{array}$

\section{Greek letters}

$\alpha_{j} \quad$ Withdrawn fraction at side stream of phase $j$

$\beta_{j} \quad$ Fraction of the total molar flow rate present in phase $\mathrm{j}$

$\omega \quad$ Acentric factor 


\section{Subscripts}

2

Just upstream of the shock wave

$2^{*}$

Just downstream of the shock wave

$b$

Backpressure

$i$

Component

j

bss

Phase

pss

Just before side stream

in

Just post side stream

out

Nozzle's entrance

$t$

Nozzle's exit

Throat

\section{Acronyms}

CFD Computational Fluid Dynamics

LNG Liquefied Natural Gas

NGL Natural Gas Liquids

SC Shortcut model

AR Area Ratio of the nozzle

GERG Groupe européen de recherches gaziéres 


\section{INTRODUCTION}

Global energy consumption is growing fast with higher demands associated with developing economies. Natural gas serves as one of the primary energy sources and a key player in the global energy dynamics. The demand for natural gas is continually expanding. New reservoirs are being discovered continuously in remote areas that modern technologies make easily accessible. The end uses and applications of natural gas are more diverse than ever before. There is a significant expansion in the production and consumption of liquefied natural gas (LNG). Gas-To-Liquid technologies are on a parallel rising trend but with more sensitivity to the liquid oil fuels prices [1].

Natural gas coming from reservoirs is accompanied with significant quantities of impurities and heavy hydrocarbons [2]. The amount of impurities and heavy components depends on the nature of the gas reserve (associated, non-associated or shale) as well as the geographical location of wells due to unique natural formations and compositions. Typically, the bulk of extracted gas consists of mainly methane, ethane and propane. Impurity-saturated natural gas must be conditioned (dehydrated and sweetened) before proceeding to transmission lines for further processing. Water vapor and hydrogen sulfide are the essential impurities to eliminate due to the consequences of their presence. Dehydration is of extreme significance to achieve smooth transmission and processing of natural gas. Free water initiates hydrate formation which in turn can lead to a reduction of flow capacity and transmission efficiency or transmission line blockage. Water also leads to pipeline corrosion and reduction of heating value [3]. It is also pivotal for catalytic and cryogenic end processes in GTL and LNG technologies that the natural gas is dehydrated and sweetened [4].

Most applications of natural gas dictate that methane has high purity. Thus, natural gas liquids (NGLs) or heavier hydrocarbons are to be extracted through hydrocarbon dew-pointing. These liquids, depending on their quantities, are commonly sold as a side product for increased profitability. 
Traditional methods of natural gas conditioning and NGL extracting consist of high capital and operating cost facilities. Design and operation of these facilities largely depend on the nature of the natural gas and the well. Traditional dehydration and sweetening units contain rotating parts and require complex manned operations, safety considerations, frequent maintenance schedules and produce off-spec gas on start-up. The addition of chemicals in traditional methods, such as hydrate inhibitors, pose serious environmental problems [5]. A conventional method for natural gas dehydration is the use of a contactor-regenerator column set up with a liquid hygroscopic desiccant [6]. The supersonic separator is a novel technology for gas separation. The theoretical design uniquely combined concepts from aerodynamics, thermodynamics, physical separation and fluid-dynamics resulting in an innovative gas conditioning [7]. Designs for the supersonic swirling separator technology were first patented by Alferov et al. [8] and Betting et al. [9] in 2002 and 2003, respectively. However, commercially, Petronas and Sarawak Shell Berhad (SSB) were the first to start up a Twister system at the B11 offshore facility in 2003 [10,11]. Figure 1 shows a schematic of the supersonic separator design that appeared in these patents.

The technology achieves gas sweetening, hydrocarbon dew pointing, dehydration and NGL extraction simultaneously in a single process unit. It is used to condition the gas by removing condensable vapors and NGLs. The supersonic separator is composed of a converging section, a Laval nozzle and a divergent section. Natural gas flows from reservoirs with low velocity and high pressure. During the flow process, the gas pressure decreases causing an increase in speed. According to laws of thermodynamics, this decrease in pressure will be accompanied by a decrease in temperature. The temperature drops below the dew point of the natural gas. A multiphase flow is formed where the undesired components form liquid condensates are centrifugally removed through side collection streams. The dry-gas then proceeds into the transmission lines for further processes [12]. 


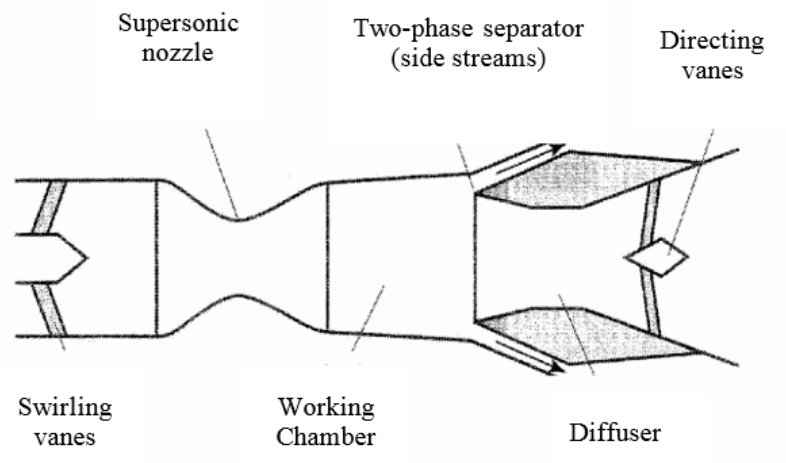

Figure 1: Schematic of the supersonic gas separator. Reprinted from $[8,13]$.

The supersonic separator poses numerous advantages when compared to traditional methods. The device contains no rotating (dynamic) parts, does not require the addition of any chemicals and presents the option for de-manned operation. Furthermore, due to the extremely high speed of flow through the device, no fouling or deposition of solids is expected. The required refrigeration is self-induced and temperatures down to $-60{ }^{\circ} \mathrm{C}$ are possible without the need of cryogenic cooling units. The chemical-free operation replaces the need for auxiliary systems such as the inhibitor injection system, inhibitor recovery system or solid adsorbent regeneration processes. Therefore, chemical disposal, environmental emission regulations, regeneration cycles and off-spec startup product are no longer operational concerns. The lack of dynamic parts decreases maintenance requirements and costs significantly. The compact size makes the device cheaper to manufacture, install and operate. One of the additional unconventional advantages it presents is the ability to operate onshore, off-shore and at subsea levels. Unlike conventional methods, the design scale and operation of the unit are not sensitive to feed gas composition or well formations $[6,14]$.

Simulation studies of supersonic separators have a lot of complications starting from defining the problem and all aspects associated with the performance. When carrying out a simulation study to design or understand the performance and conditions 
in a supersonic separator, many decisions have to made including number of phases to consider, what equation of state to choose, what type of shockwave to consider, what nozzle geometry to study, what working fluid to start with and what simulation or programming software to choose. Figure 2 represents a diagram indicating all the aspects to consider in this type of problem. It serves as a starting point to formulate the system to be studied and what assumptions and approaches to be taken.

This work aimed to develop a thermodynamic numerical model that presents great potential as a fast and accurate tool that enables simulating of supersonic separators with significant details. The model is to fill certain gaps found in literature with a shortcut modeling technique. This model would best fit the category of preliminary design tools with decreased computational loads. The purpose of the model is not produce property profiles along the diverging section except at the following 5 fundamental points:

1. The nozzle throat

2. The side stream location

3. Just before the shockwave

4. Just after the shockwave

5. The nozzle exit

Following this introduction, next chapter presents a literature review. Chapter 3 highlights the objectives of this work. Furthermore, chapter 4 and 5 detail the model formulation and solution approaches. Finally, chapter 6 presents the results of this work with detailed discussions. 


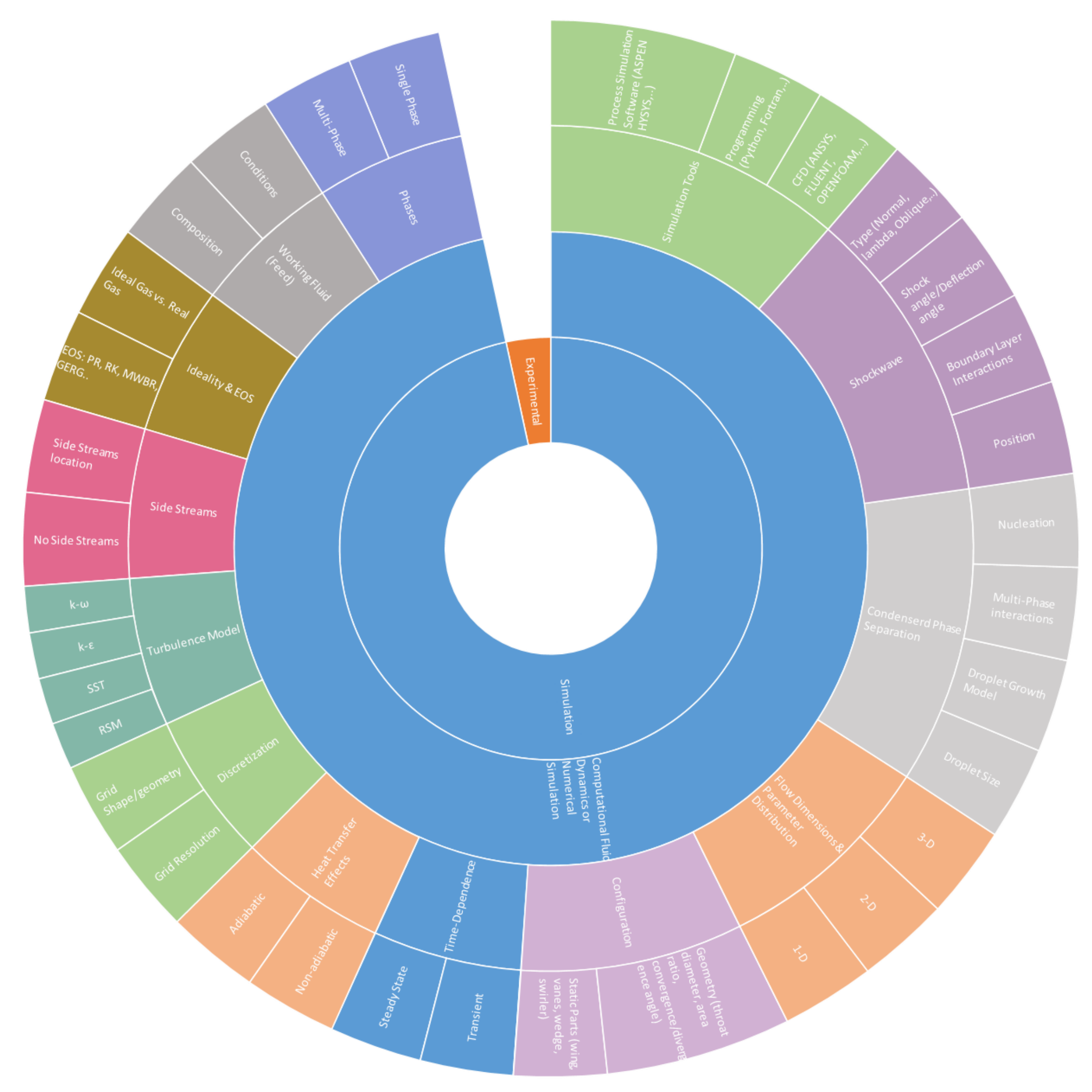

Figure 2: Sunburst supersonic flow analysis diagram 


\section{LITERATURE REVIEW}

Available literature work on the topic of natural gas supersonic separation is highly

diverse and multidisciplinary. Overall, studies are discussed according to four categories [15].

i- $\quad$ Thermodynamic approaches;

ii- $\quad$ Computational Fluid Dynamics (CFD) approaches;

iii- Experimental setups;

iv- Experimental-CFD approaches.

Although many works might cover more than one approach, the following summary of literature studies is classified, to the best degree, in accordance with these four categories.

\subsection{Thermodynamic and numerical simulation studies}

Zhao et al. [16] investigated the effect of area ratio on the performance of the supersonic separator through numerical simulation. They found that as the area ratio increased, the location of the shockwave shifted upstream closer to the throat and the shockwave intensity increased. They reported the absence of shockwave at an area ratio of 1.063 and pressure ratios in the range of 1.25-1.75. This point of no shockwave corresponds to the highest separation performance. Numerical calculation results were validated with experimental testing.

Secchi et al. [17] developed a one-dimensional thermodynamic model to simulate the supersonic gas separator. The aim of the model is to provide a reliable basic design tool with reduced computational time and satisfactory results. The Groupe Européen de Recherches Gaziéres (GERG) equation of state [18] was adopted in the thermodynamic calculations. A model for centrifugal phase separation was also developed and incorporated in the design to provide a comprehensive characterization of the phenomena involved in the supersonic separation process. Fundamental parameters such 
as distributions of Mach number, static pressure and temperature, composition of each phase and the position of the shockwave are calculated in the model.

Machado et al. [6] performed an economic and technical analysis of the Twister supersonic separation technology and compared it to the conventional water and hydrocarbon dew pointing technologies consisting of Tri Ethylene Glycol (TEG) dehydration unit and Joule-Thomson/Low-Temperature Separation. An economic comparison between the technologies was performed on the basis of net present value (NPV) after a 20-year operation. The study highlighted the fact that Twister technology considerably reduces the number of major pieces of equipment. It concluded that Twister increases the production of natural gas liquids which presents additional revenue.

Furthermore, analysis showed that Twister demonstrates lower opportunity costs when compared with conventional TEG dehydration unit and Joule-Thomson/LowTemperature Separation.

Castier [19] developed a numerical simulation technique to simulate the supersonic separator using the Peng-Robinson equation of state. The procedure calculates the thermodynamics properties along the converging-diverging nozzle of the separator, the sound speed in non-ideal multiphase systems and phase equilibrium conditions. The method is suitable for preliminary designs and yields results agreeable with computational fluid dynamics results reported in other literature studies. The technique developed here does not provide two or three-dimensional parameter profiles compared to computational fluid dynamics models. However, it provides accurate results for shockwave location, number of phases and one-dimensional property profiles and thus serves as an excellent tool for simple preliminary conceptual designs. In his work, only converging-diverging nozzles with no side streams were studied.

Wen et al. [20] designed three new separators and created an experimental set-up to measure separation efficiency using wet air. Numerical investigation showed that the separation exceeded $95 \%$ with the annular nozzle that accelerated the gas to supersonic speeds and created a centrifugal field of $640000 \mathrm{~g}$. Optimum water separation was achieved when the length of the cyclonic separation section was ten times the diameter 
of the throat. The employment of discrete particle method yielded a good agreement between the simulation and experimental results for dehydration characteristics.

Castier [21] presented a one-dimensional numerical model for steady-state supersonic separation. The model solution algorithm requires the solution for multiphase thermodynamic sound speed, isenthalpic and isentropic flash problems. The PengRobinson equation of state was employed in the evaluation of thermodynamic properties. The effect of side stream was introduced by simulating converging-diverging nozzles with side streams. Side stream locations are based on temperature specifications. Results were compared with experimental data present in literature and showed good agreement.

Wen et al. [22] numerically simulated the swirling separation of a new supersonic separator design incorporating a central body. Axial distributions of the gas flow parameters were investigated. The effect of nozzle geometry on separation performance was analyzed. Results showed distribution ranges for the centrifugal acceleration and static temperature of $220000 \mathrm{~g}-500000 \mathrm{~g}$ and $-80{ }^{\circ} \mathrm{C}$ to $-55^{\circ} \mathrm{C}$ respectively. Nozzle geometry was found to have a significant effect on the separation performance. Larger convergence angle corresponded to an improvement in the separation efficiency. Best separation performance was obtained with a divergent angle between 20 and 6o. The presence of strong swirling flow causes large gradients in temperature and velocity at wall vicinity due to non-uniformity of radial distribution. Velocity gradients near the walls could cause stirring of the boundary layer where the condensed droplets exist and thus cause impairment in the separation process.

Wen et al. [3] conducted a numerical study using the Reynolds stress model to study the effects of swirls on the temperature distribution, mass flow rate and flow velocity. The numerical analysis was coupled with experimental testing in moist air. Results indicated that strong swirls decreased mass flow rates and reduced nonuniformity of Mach number radial distribution at the nozzle exist. Moderate swirls were sufficient to produce a centrifugal field and temperature low enough to achieve condensation and separation of water and hydrocarbons from the saturated gas. 
Sun et al. [23] developed a Euler-Euler Two-Fluid model to characterize the condensation process of $\mathrm{CO}_{2}$ from a $\mathrm{CH}_{4}-\mathrm{CO}_{2}$ binary mixture in a supersonic separator. Droplet growth model and nucleation theory were utilized in the study. Results were compared to existing experimental results reported in literature. Effects of inlet conditions and composition were analyzed. Better separation of $\mathrm{CO}_{2}$ is reported at higher inlet pressure, lower inlet temperature and higher $\mathrm{CO}_{2}$ composition in the feed.

Bian et al. [24] suggested improvements in the structure of supersonic separators to improve the efficiency and refrigeration performance of the separator. Improvements were based on reducing nozzle divergence angle and increasing the length of the expanding channel. The study utilized a three-dimensional numerical simulation model.

Salikaev and Gunmerov [25] studied the effects of inlet temperature, pressure and composition as well as pressure drop across the nozzle on the flow behavior and separation performance of supersonic gas separators. The study was conducted utilizing the UniSim Design R400 software.

Mohd Hashim and Ahmad [26] carried out a preliminary design to understand the flow behavior of supersonic wet gas separators. The study incorporated numerical simulation and analysis of the flow characteristics and temperature distribution.

Arinelli et al. [15] investigated the performance of the supersonic separator for treating a natural gas with $44 \% \mathrm{~mol} \mathrm{CO}_{2}$. The performance was compared to that of conventional water and hydrocarbon dew-pointing technologies. Several configurations and combinations of the supersonic separator and the other conventional tools were considered. Supersonic separator, if used as a single unit, was able to reduce $\mathrm{CO}_{2}$ content from $44 \%$ to $22 \%$ mol, which is a sufficient option for the specifications of natural gas for power generation with a permissible limit of $20 \%$, approximately.

In Wen et al. [27] work, natural gas mass flowrate evaluation in the supersonic separator was numerically investigated via the use of several cubic equations of state. Significant discrepancies in the values of the specific heat ratio and the compressibility factor were observed when real gas models were used compared to ideal gas law. Deviations in the calculated mass flow rate exceeded $10 \%$ by using the different models. 
Shockwave location shifted upstream when the back pressure increased. The same shockwave backward shift was noticed in the results of real gas models compared to ideal gas law. Therefore, the ideal gas model overestimated the location of the shockwave location.

Qingfen et al. [28] aimed to improve separation performance of the supersonic separator though constructing a device with shorter settlement distance. The investigation employed a droplet enlargement method with an air-ethanol working fluid. Effects of temperature, swirling intensity, inlet pressure, relative humidity and mass flow rate on separation efficiency were investigated. Better separation was associated with increases in relative humidity and inlet pressure. Effect of inlet temperature on separation performance was found to be insignificant.

LingLing et al. [12] designed a numerical solution method for phase equilibrium predictions of natural gas in supersonic separation. Based on the phase equilibrium calculations, the developed model presents an analysis of separation performance. Results were cross-checked with practical measurements from the operating supersonic separator of Shengli Oil Field's Haiwu Station.

Shooshtari and Shahsavand [29] simulated supersonic separation using various structures and diffuser angles to study the effect of varying pressure recovery coefficient. Minimizing pressure loss across the separator nozzle maximizes energy recovery of the dew point correction facility. Pre-shock pressure and temperature were found to be independent of diverging angle. Maximum pressure recovery of 0.88 corresponded to minimum energy loss at a divergence angle of 80 .

\subsection{CFD studies}

Yang et al. [30] conducted a study in which they employed static vanes for the generation of swirling flow in the supersonic separator. Optimization of the static vanes structures was achieved by means of computational fluid dynamics (CFD) modeling. However, optimization of the number of vanes, swirl height and angle were achieved using a numerical model that balances the expansion characteristic and swirling separation since the two effects conflict. Results suggest that a dimensionless height of 
0.125-0.3, swirl angle at $45^{\circ}-60^{\circ}$, and a number of 8-16 vanes produce an optimized performance for the supersonic separator.

Yang et al. [31] used discrete particle method (DPM) along with a computational fluid dynamics tools to study particle behavior in the supersonic gas separator.

Jassim et al. [32] illustrated the significance of errors associated with assuming perfect or ideal gas behavior for natural gas in supersonic flow. Errors in evaluating gas thermodynamic parameters lead to incorrect predictions for shockwave location, friction losses, heat transfer effects and separation performance. Fluid behavior and shockwave position were analyzed through a computational fluid dynamics approach.

Yang et al. [33] studied real gas effects in supersonic separation utilizing a computational fluid dynamics method considering both ideal gas and real gas models. Results showed great deviation in calculated fluid properties when using ideal gas law. Deviation in gas Mach number between the two models was approximately $13.5 \%$ whereas the deviation in the density of the gas exceeded $20 \%$. The position of the shockwave predicted through real gas models was consistently upstream of that associated with the ideal gas model.

Liu et al. [34] investigated the separation efficiency of the supersonic separator utilizing the Discrete Particle Method (DPM) approach. In the study, three-dimensional computational fluid dynamics was used to characterize the flow behavior. The condensed phase was modeled with the discrete particle method assuming uniform spherical droplet shape and size, neglecting nucleation effects. The compressible NavierStokes equation was used in the gas phase with the RSM turbulence model. The effect of operating conditions and nozzle structure parameters were investigated. Results were validated through experimentation on a pilot scale supersonic separator. The study established correlations between the system parameters of pressure loss ratio, swirling intensity, mass flow rate and diameter of the particle on the separation efficiency. Maximum efficiency reached $91.6 \%$ with droplets of 25 um diameter. Separation efficiency in this study was taken as the mass fraction collected at the wet-outlet. 
Yang et al. [35] sought to understand the mechanism of pressure recovery for conditions of supersonic flow. A theoretical equation was developed for the pressure recovery coefficient using the ideal gas assumption. Results indicated that the pressure recovery coefficient is dependent on the Mach number and the adiabatic exponent upstream of the shockwave. Computational fluid dynamics showed increasing coefficient of pressure recovery with a higher adiabatic exponent. Results showed that the theoretical equation derived in this study is suitable for estimation of pressure recovery coefficient.

Xiao et al. [36] studied the wave phenomena and fluid-structure associated with the supersonic flow in the supersonic separator. Solution to the Reynolds Average Navier-Stokes equations coupled with a k- $\omega$ turbulence model was used in the investigation. The area ratio between the exit and the throat of the studied nozzle was 1.5. The selection of this geometry was for comparison with existing experimental data of nozzles of similar geometry. The pressure ratios were varied in order to understand the influence on flow structure. The effect of nozzle pressure ratio on shockwave structure and symmetry was reported in the computational results and compared with experimental values.

Yang et al. [37] carried out a study to simulate the supersonic separator and characterize the gas dynamics parameters using Redlich-Kwong (RK) equation of state and the Shear Stress Transport (SST) turbulence model. The study aimed to investigate the effect of inlet and outlet stream conditions on the gas dynamics inside the separator. The focus was to identify the relation between the position of the shockwave and the inlet and outlet conditions. It was concluded that the shockwave moves downstream as the inlet pressure increases. When the back pressure increased, however, the shockwave position shifted upstream towards the nozzle throat. The effect on the shockwave position was found to be negligible as the inlet temperature varied within the range of 10 ${ }^{\circ} \mathrm{C}$ to $70{ }^{\circ} \mathrm{C}$. 


\subsection{Experimental-simulation studies}

Cao et al. [38] designed a new supersonic separator with an ellipsoidal central body. Dehydration performance of the separator was evaluated through experimental and analytical simulation methods. Effect of inlet and outlet working conditions as well as dew point depression were analyzed. Inlet conditions were found to have a weak influence of the performance of the separator when the working requirement of the mass

flow rate is met. The primary factor that influences the performance of the separator was the pressure recovery coefficient. Increasing the pressure coefficient decreased dew point depression leading to better dehydration.

Boerner et al. [39] studied compressible swirling flow in axi-symmetric convergent-divergent nozzles both experimentally and analytically. Influence of swirl strength on velocity field and mass flow rate at the nozzle throat was investigated. Increasing swirl intensity was found to decrease the mass flow rate. A noteworthy observation was the shift of sonic line upstream of to the throat as swirl strength increased.

Ristic et al. [40] conducted a series of tests in a trisonic wind tunnel to study the supersonic two-dimensional flow in a symmetric convergent-divergent nozzle. Experimental results were compared to numerical simulations based on the solution of average Navier-Stokes equations employing a finite-volume method based on the reconstruction-evolution method of Anderson-Thomas-van Leer [41]. Flow visualization of the supersonic nozzle was demonstrated using schlieren and shadowgraphy methods as well as holographic interferometry. The advantages of holographic interferometry over other visualization methods were highlighted.

Eriqitai et al. [7] suggested a new design for the supersonic separator which includes a dual-throat device and a porous wall located at the second throat. The performance and feasibility of the device were tested experimentally and numerically. The effect of several parameters on the performance was tested including the swirl intensity, nozzle pressure ratio and the inlet temperature. The proposed technique enlarged the supersonic region. Better separation was obtained with increasing inlet 
temperature and nozzle pressure ratio. Obtained trajectories showed that most particles entered the liquid removal section and collided with the walls. The efficiency of separation exceeded $80 \%$ when with droplet diameter of $1.5 \mathrm{um}$. For higher separation efficiency, the study found the optimal length of the cyclonic section to be 16-20 times the diameter at the nozzle throat.

\subsection{Other studies}

Haghighi et al. [42] wrote a review paper in which they highlighted the developments in supersonic gas separation. The article summarized the work associated with supersonic gas separation and presented in literature. The review covered investigations on the supersonic separation and the significant findings. Specific gaps for further studies were emphasized.

Niknam et al. [43] developed an artificial neural network model for the prediction of the shockwave location inside supersonic separation nozzles. Results for shockwave location were collected from literature and a neural network self-organizing map was implemented to the dataset. The model is significantly quicker and does not require complex computations. Results show sufficient accuracy in predicting shockwave location from hydrodynamic boundary conditions. The shockwave was found to shift upstream as the inlet pressure and pressure recovery ratio increase.

Shooshtari and Shahsavand [5], developed a new theoretical approach in order to predict liquid droplet growth for binary mixtures inside the supersonic separator nozzle. The model simulates multi-component systems neglecting the interactions between condensed phases. Results concluded the ability of the $3 \mathrm{~S}$ unit to reduce hydrogen sulfide and water vapor to the tolerable values required for natural gas processing.

Titchener et al. [44] looked into the use of vortex generators to mitigate shockinduced separation. It was shown that although vortex generators could lessen shockinduced boundary layer separation, their efficiency varies significantly in practical applications. Vortex generators are considerably more successful in mitigating or decreasing shock-induced separation in transonic applications in comparison to the interactions in supersonic flows. 


\subsection{Summary}

Studies on the topic of supersonic separation show the potential of this technology as an innovative solution. All studies revolve around characterizing the performance of supersonic separator and investigating how to improve the separation. Literature works show a considerable lack of experimental studies and data. Important studies presenting numerical and CFD models only started being developed by different researchers over the last 10 years. Due to the complex nature of the system, initial studies started with simplified versions of the process. Over time, studies started filling the gaps by considering raw natural gas rather than simple working fluids as well as utilizing more complex equations of state and sound speed calculation methods. There are gaps that can still be filled. The most notable area of improvement is that associated with computational load. CFD models demand huge computational loads. Although numerical models are less computationally demanding, existing ones can be improved significantly specially for the purposes of preliminary designs. These designs should be fast, yet rigorous, with selective calculations. The aim is for these models to yield results that help in understanding the primary design performance indicators such as shockwave location, side stream location and dry gas composition after separation. 


\section{OBJECTIVES}

Based on the presented literature review, numerical models present great potential as a fast and accurate tool that enables the simulation and design of supersonic separators with significant details. Although numerical models are less comprehensive and detailed than CFD models, they proved to be able to produce accurate results comparable with those of CFD models and experimental data. Thus, these models serve as an excellent tool for preliminary designs that require less computational loads. The objective of this work is to present a rigorous one-dimensional thermodynamic model that simulates the supersonic separator. The aim is for the model to introduce improvements to certain aspects of literature work and introduce a shortcut technique to side stream and shockwave position allocation. Notable disadvantages to existing literature works include:

- Not accounting for multi-phase flow

- Modeling nozzles with no side streams

- Using simplified working fluids

- Insufficient methods for calculating the thermodynamic speed of sound which is an essential parameter for finding Mach number

- Not accounting for swirling flow

- Requiring large computational load and simulation time

Some of these aspects are treated in this work to provide a more rigorous, faster and more accurate model for supersonic separation. 


\section{MODEL FORMULATION}

The theoretical development of this work starts with framing foundational assumptions and analyzing the phenomena that occur in supersonic Laval nozzles. After presenting the methodological formulation and formulation of the problem, problem solution is detailed in chapter 5 .

\subsection{Assumptions}

Formulation of the model is based on several theoretical and empirical foundations that are discussed further in the following sections. Achieving the objective of the model, however, is based on framing the following assumptions:

- The nozzle is adiabatic and thus no heat transfer effects are considered;

- The nozzle operates at steady state with no feed fluctuations;

- The inlet temperature $\left(T_{i n}\right)$, inlet pressure $\left(P_{i n}\right)$, inlet fluid speed $\left(u_{i n}\right)$, feed composition $\left(z_{i n}\right)$ and nozzle back pressure $\left(P_{b}\right)$ are all known;

The nozzle geometry specifications and cross-sectional areas at the exit plane $\left(A_{\text {out }}\right)$ and at the throat $\left(A_{t}\right)$ are known;

- The flow is one-dimensional;

- The flow is isentropic in the converging section;

- The flow is choked at the nozzle throat;

- There is no side stream in the converging nozzle;

- Location of the side stream is specified based on a selected temperature;

- A normal shockwave occurs in the diverging nozzle with infinitesimal thickness (i.e. cross-sectional area upstream and downstream of the shockwave are equal); $[45,46]$

- The location of the shockwave is fixed since the flow is steady;

- The flow is not isentropic across the shock wave, which causes an entropy increase; 
- Abrupt changes in flow conditions across the shockwave are irreversible;

- There is no side stream after the shock wave;

- The flow is isentropic after the shock wave;

- Separation efficiency and phase carryover are specified;

- Effect of swirl is not embedded in the calculations but the swirling motion is assumed to promote phase disengagement.

These assumptions are either based on sound fundamental science or for the simplification of the problem for the scope of this study. 


\subsection{Comments}

\subsubsection{Thermodynamic numerical model}

Thermodynamic models present advantages over CFD models specifically for preliminary designs. Although the information they provide regarding flow and hydrodynamics, as well as physical property profiles is minimal, these one-dimensional numerical models allow for faster simulations that are more suitable for potential optimization studies and processes demanding repeated simulations as a recycle loop for instance [21]. Good numerical models can accurately predict thermodynamic properties of the working fluid, deal with a range of state parameters and implement time-efficient computational load as basic requirements [32].

The goal of this work is to fill some of the existing gaps on the modeling of nozzles with side streams. It builds on previous work by Castier [21]. In this work, an expansion of that one-dimensional model is to be developed with the same ability to trail condensed phase appearance and disappearance through isenthalpic and isentropic flash calculations. The one-dimensionality of the present model is assumed not to affect the accuracy of the model. This is due to the fact that at no or little swirling intensity there is little radial variation in thermodynamic parameters. The gas Mach number decreases when swirl strength is increased as stated by Wen et al. [3]. Therefore, little or medium swirl strengths are considered best to increase centrifugal force without affecting the separation performance. In Wen's study, the swirling effect on the performance of supersonic separator was investigated. A dimensionless swirl strength parameter $S$ was employed to characterize swirl strength:

$$
S=\left(\int \frac{v}{a^{*}} d A / A\right)_{t}
$$

where $v$ and $a^{*}$ are the tangential and critical velocities at the nozzle throat.

Figure 3 shows the distribution of static temperature at the exit plane of a supersonic separator with swirl strengths of $0,48.9 \%$ and $90.6 \%$ respectively. At no or little swirl 
strength, the radial temperature profiles are nearly uniform. However, radial variation is significant in tangential velocity [3]. Since this model does not aim to predict hydrodynamic flow behavior and neglects swirling effect on phase equilibrium calculations, this variation does not affect its ability to identify the essential design parameters of the nozzle such as phase segregation, shockwave location and axial property profiles.

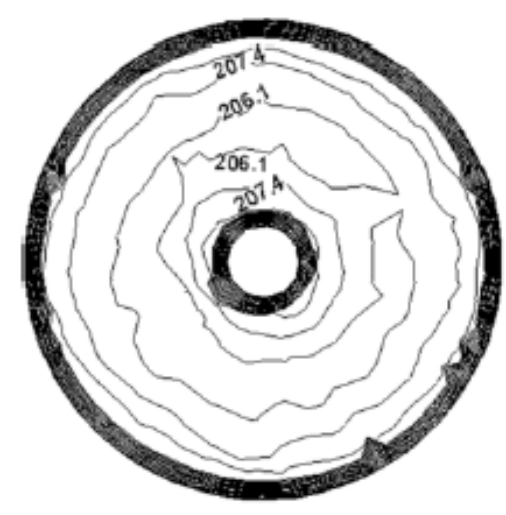

(a

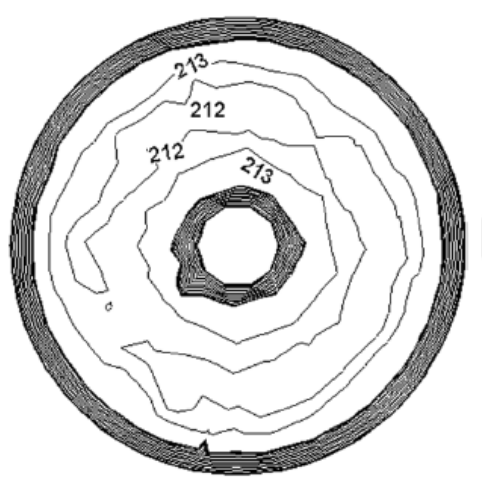

(b

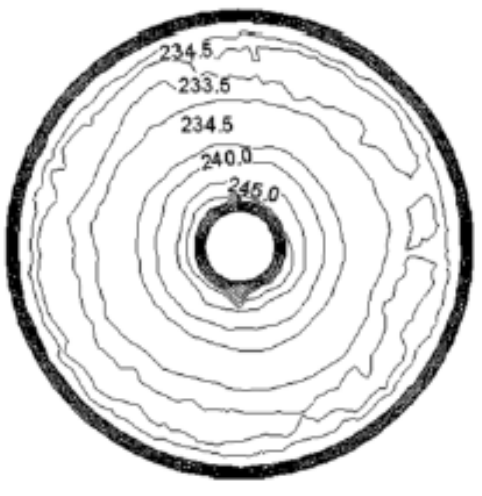

(c

Figure 3: Radial distribution of static temperature $[\mathrm{K}]$ at nozzle exit at (a) $0 \%$ swirl, (b) $48.9 \%$ swirl, (c) $90.6 \%$ swirl. [3] ${ }^{1}$

\subsubsection{Multiphase flow}

The sole purpose of supersonic separators is to condense and eliminate heavy hydrocarbons, sour gas and impurities from the bulk of the natural gas and sustain a dry gas high in the composition of $\mathrm{CH}_{4}$. Therefore, multiphase flow is a core phenomenon that dictates the performance of the separator. Often, recovered natural gas also comes

\footnotetext{
${ }^{1}$ C. Wen, X. Cao, Y. Yang, K. Zhang: Swirling effects on the performance of supersonic separators for natural gas separation. Chemical Engineering Technology. 34. 2011. 1575-1580. Copyright Wiley-VCH Verlag GmbH \& Co. KGaA. Reproduced with permission.
} 
with liquid or solid phase traces right out of reservoirs. Many of the literature work discussed present models that adopt thermodynamic modeling for ideal gas or equations of states only describing a single phase PVT behavior. In avoidance of the risk of dealing with phase-change in the supersonic region, a working fluid that is highly supercritical is chosen as dry $\mathrm{CH}_{4}$. Some other works select a full spectrum natural gas working fluid but do not deal with multi-phase flow which leads to unrealistic domains of one-phase supersonic flow [15].

With few exceptions, CFD models fail at dealing with phase-change effects occurring in supersonic separation with raw natural gas [15,32]. This leads to failure in the estimation of multi-phase thermodynamic sound speed. As listed in chapter 3, this was noted as one of the imperfections in the discussed literature studies.

This model predicts condensation rates and phase fractions by tracking phase appearance and disappearance through stability tests. Furthermore, the adopted method for speed of sound calculations works for multi-phase systems as described in the following section. Hence, multi-phase flow does not impose any fundamental limits or errors for the developed shortcut model.

\subsubsection{Thermodynamic speed of sound}

The supersonic separator works on the basis of supersonic flow that leads to a significant drop in the temperature and pressure of the stream beyond the throat. Supersonic means that the velocity of the flow exceeds a Mach number of one $(M a>1)$. This occurs when the flow at the throat becomes choked with a sonic velocity at Mach equals 1 . To determine the Mach number, the thermodynamic speed of sound is to be known.

Partial condensation can occur starting at the throat or any point along the converging and diverging nozzle depending on the conditions. Thus, it is necessary to be able to determine the thermodynamic speed of sound for multiphase flow [21]. Several notable methods exist for the determination of multi-phase thermodynamic sound speed - namely those presented by Firoozabadi and Pan [47], Nichita et al. [48], Wood [49] 
and Castier [50]. Another recent method was the extension of Wood's method for multicomponent phases using GERG EOS by Secchi et al. [17]. In this work, the method developed by Castier [50] is utilized.

\subsubsection{Side streams}

The side streams are critical for the performance of the supersonic separator. The location of side streams and the amount of condensed phase collected by them dictate the efficiency of the device. In this model, the global phase stability test by Michelsen [51,52] is employed for detecting fluid phases appearance whereas the solid phase is not considered. Similar to the approach of Castier [21], this model locates the side streams on the basis of a set temperature. The model has to solve for the conditions to determine where that temperature is achieved and place the side streams there. It also can report the condensed phase profiles.

To account for changes across the side streams, material balances are displayed below. Two positions, (bss) and (pss) are denoted to represent the positions just before and post side stream withdrawal respectively. The following equations represent the balances at those positions based on molar flowrates $(\dot{n})$, mole fractions $(z)$ based on each component $(i)$ and phase $(j)$ :

$$
\begin{gathered}
\dot{n}_{b s s}=\sum_{j=1}^{n_{\pi}} \dot{n}_{j, b s s} \\
\dot{n}_{i, b s s}=\dot{n}_{b s s} z_{i, b s s}=\sum_{j=1}^{n_{\pi}} \dot{n}_{j, b s s} z_{i, j, b s s} \\
z_{i, b s s}=\sum_{j=1}^{n_{\pi}} \beta_{j, b s s} z_{i, j, b s s}
\end{gathered}
$$


where $\beta_{j, b s s}$ is defined as the fraction of the total molar flow rate present in phase $j$ before the side stream and expressed as:

$$
\beta_{j, b s s}=\frac{\dot{n}_{j, b s s}}{\dot{n}_{b s s}}
$$

Defining $\alpha_{j}$ as the withdrawn fraction at side stream of phase $(j)$ on a molar basis, the following balances are obtained:

$$
\dot{n}_{a s s}=\dot{n}_{b s s}-\sum_{j=1}^{n_{\pi}} \alpha_{j} \dot{n}_{j, b s s}
$$

Thus,

$$
\frac{\dot{n}_{a s s}}{\dot{n}_{b s s}}=1-\sum_{j=1}^{n_{\pi}} \alpha_{j} \frac{\dot{n}_{j, b s s}}{\dot{n}_{b s s}}=1-\sum_{j=1}^{n_{\pi}} \alpha_{j} \beta_{j, b s s}
$$

Molar flowrate of component ( $i$ ) withdrawn to side stream is expressed as:

$$
\dot{n}_{i, a s s}=\dot{n}_{a s s} z_{i, a s s}=\dot{n}_{b s s} z_{i, b s s}-\sum_{j=1}^{n_{\pi}} \alpha_{j} \dot{n}_{j, b s s} z_{i, j, b s s}
$$

Then,

$$
\begin{gathered}
\frac{\dot{n}_{a s s}}{\dot{n}_{b s s}} z_{i, a s s}=z_{i, b s s}-\sum_{j=1}^{n_{\pi}} \alpha_{j} \frac{\dot{n}_{j, b s s}}{\dot{n}_{b s s}} z_{i, j, b s s}=z_{i, b s s}-\sum_{j=1}^{n_{\pi}} \alpha_{j} \beta_{j, b s s} z_{i, j, b s s} \\
\left(1-\sum_{j=1}^{n_{\pi}} \alpha_{j} \beta_{j, b s s}\right) z_{i, a s s}=z_{i, b s s}-\sum_{j=1}^{n_{\pi}} \alpha_{j} \beta_{j, b s s} z_{i, j, b s s} \\
z_{i, a s s}=\frac{z_{i, b s s}-\sum_{j=1}^{n_{\pi}} \alpha_{j} \beta_{j, b s s} z_{i, j, b s s}}{1-\sum_{j=1}^{n_{\pi}} \alpha_{j} \beta_{j, b s s}}
\end{gathered}
$$

To relate $\beta_{j, b s s}$ and $\beta_{j, a s s}$, the following relation can be derived: 


$$
\beta_{j, a s s}=\frac{\dot{n}_{j, a s s}}{\dot{n}_{a s s}}=\frac{\dot{n}_{j, b s s}\left(1-\alpha_{j}\right)}{\dot{n}_{b s s}-\sum_{j=1}^{n_{\pi}} \alpha_{j} \dot{n}_{j, b s s}}=\frac{\beta_{j, b s s}\left(1-\alpha_{j}\right)}{1-\sum_{j=1}^{n_{\pi}} \alpha_{j} \beta_{j, b s s}}
$$

\subsubsection{Shockwave location}

The occurrence and position of the shockwaves is a pivotal phenomenon in supersonic gas separation. After the flow turns supersonic beyond the throat, pressure and temperature drop significantly allowing the condensation of water, sour gases and heavy hydrocarbons. After separation of the condensed phase, the flow needs to return to the gaseous phase at high pressure to assure appropriate pipeline flow. Restoring the initial flow state of subsonic, high pressure and single phase is the function of the shockwave. The position of the shockwave significantly affects the performance of the nozzle [14]. Location of the shockwave in the diverging nozzle depends on boundary conditions, precisely pressure, and swirl strength [14,37,53].

Determination of the shockwave location is associated with six thermodynamic variables namely temperature, pressure, density, entropy, enthalpy and flow velocity [32]. All of these variables go through an abrupt, irreversible change in their values with the exception of the stagnation enthalpy which is conserved across the shockwave. 


\subsection{Equation of state}

Evaluation of fluid properties is carried out through an equation of state (EOS). Erroneous evaluation of PVT data leads to poor prediction of flow properties. Thus, a real gas EOS is necessary for the calculation of thermodynamic properties at a wide range of conditions including high pressures and low temperatures [27]. In addition to PVT data, the equation of state provides the values for residual enthalpy, residual entropy, fugacity coefficients, and thermodynamic sound speed.

Cubic equations of state are valuable in prediction vapor-pressure data, PVT data and vapor-liquid equilibrium data [32]. These equations can be expressed in the following general format [54]:

$$
P=\frac{R T}{v-b}-\frac{\xi}{(v+c)+(v+d)}
$$

with $b, c$ and $d$ as constants. Also, $\xi$ is a function of temperature. The Peng-Robinson [55] EOS is one of the most used equations of state in the studies of supersonic separation. In comparison to most of the preceding cubic equations of state, the PengRobinson EOS has a third parameter $\alpha$ to improve the accuracy of compressibility data [32]. The Peng-Robinson EOS can be expressed as follows:

$$
P=\frac{R T}{v-b_{m}}-\frac{a_{m} \alpha}{v\left(v+b_{m}\right)+b_{m}\left(v-b_{m}\right)}
$$

The parameters $a_{m}$ and $b_{m}$ depend only on pure components properties and are found from the following equations:

$$
\begin{gathered}
a_{i}=0.45724 \frac{R^{2} T_{c i}{ }^{2}}{P_{c i}} \\
b_{i}=0.0778 \frac{R T_{c i}}{P_{c i}} \\
\alpha_{i}=\left[1+\left(1-\sqrt{\frac{T}{T_{c i}}}\right)\left(0.37464+1.54226 \omega_{i}-0.26992 \omega_{i}{ }^{2}\right)\right]^{2}
\end{gathered}
$$


When dealing with multi-component mixtures, determination of parameters $a$ and $b$ of the equation of state can be extended by using the following van der Waals mixing rules [56].

Where,

$$
a_{m}=\sum_{i=1}^{N} \sum_{j=1}^{N} x_{i} x_{j} a_{i j}
$$

$$
a_{i j}=\sqrt{a_{i i} a_{j j}}\left(1-k_{i j}\right)
$$

and

$$
b_{m}=\sum_{i=1}^{N} x_{j} b_{i}
$$

This work employs the Peng-Robinson EOS. However, the model development and formulation is general and shall allow the use of higher-complexity equations of state in the future. 


\subsection{Governing equations}

Governing equations are derived from mass, energy, entropy and momentum balances. The specific essential balances are listed in Table 1 based on the different sections in the converging-diverging nozzle.

Table 1: List of governing equations.

\begin{tabular}{|c|c|c|c|}
\hline Description & Equations & Eq.\# & Section \\
\hline \multirow{5}{*}{ 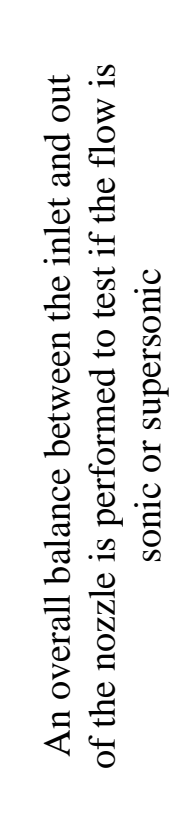 } & $\frac{A_{t} u_{t}}{v_{t}\left(T_{t}, P_{t}, \underline{z}_{\text {in }}\right)}=\frac{A_{\text {out }} u_{\text {out }}}{v_{\text {out }}\left(T_{\text {out }}, P_{b}, \underline{z}_{\text {in }}\right)}$ & (23) & \\
\hline & $h_{i n}+M_{i n} \frac{u_{i n}^{2}}{2}=h_{t}\left(T_{t}, P_{t}, \underline{z}_{i n}\right)+M_{i n} \frac{u_{t}^{2}}{2}$ & (24) & \\
\hline & $\begin{array}{c}h_{\text {in }}+M_{\text {in }} \frac{u_{\text {in }}^{2}}{2} \\
=h_{\text {out }}\left(T_{\text {out }}, P_{\text {out }}, \underline{z}_{\text {in }}\right)+M_{\text {in }} \frac{u_{\text {out }}{ }^{2}}{2}\end{array}$ & $(25)$ & \\
\hline & $s_{i n}=s_{t}\left(T_{t}, P_{t}, \underline{z}_{i n}\right)$ & (26) & \\
\hline & $s_{\text {in }}=s_{\text {out }}\left(T_{\text {out }}, P_{b}, \underline{z}_{\text {in }}\right)$ & $(27)$ & \\
\hline 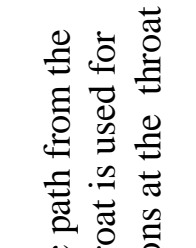 & $\begin{array}{c}h_{i n}+M_{i n} \frac{u_{i n}{ }^{2}}{2} \\
=h_{t}\left(T_{t}, P_{t}, \underline{z}_{i n}\right)+M_{i n} \frac{a\left(\left(T_{t}, P_{t}, \underline{z}_{i n}\right)\right)^{2}}{2}\end{array}$ & $(28)$ & \\
\hline 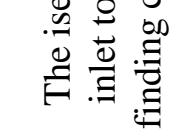 & $s_{i n}=s_{t}\left(T_{t}, P_{t}, \underline{z}_{i n}\right)$ & (29) & \\
\hline
\end{tabular}


Table 1 Continued

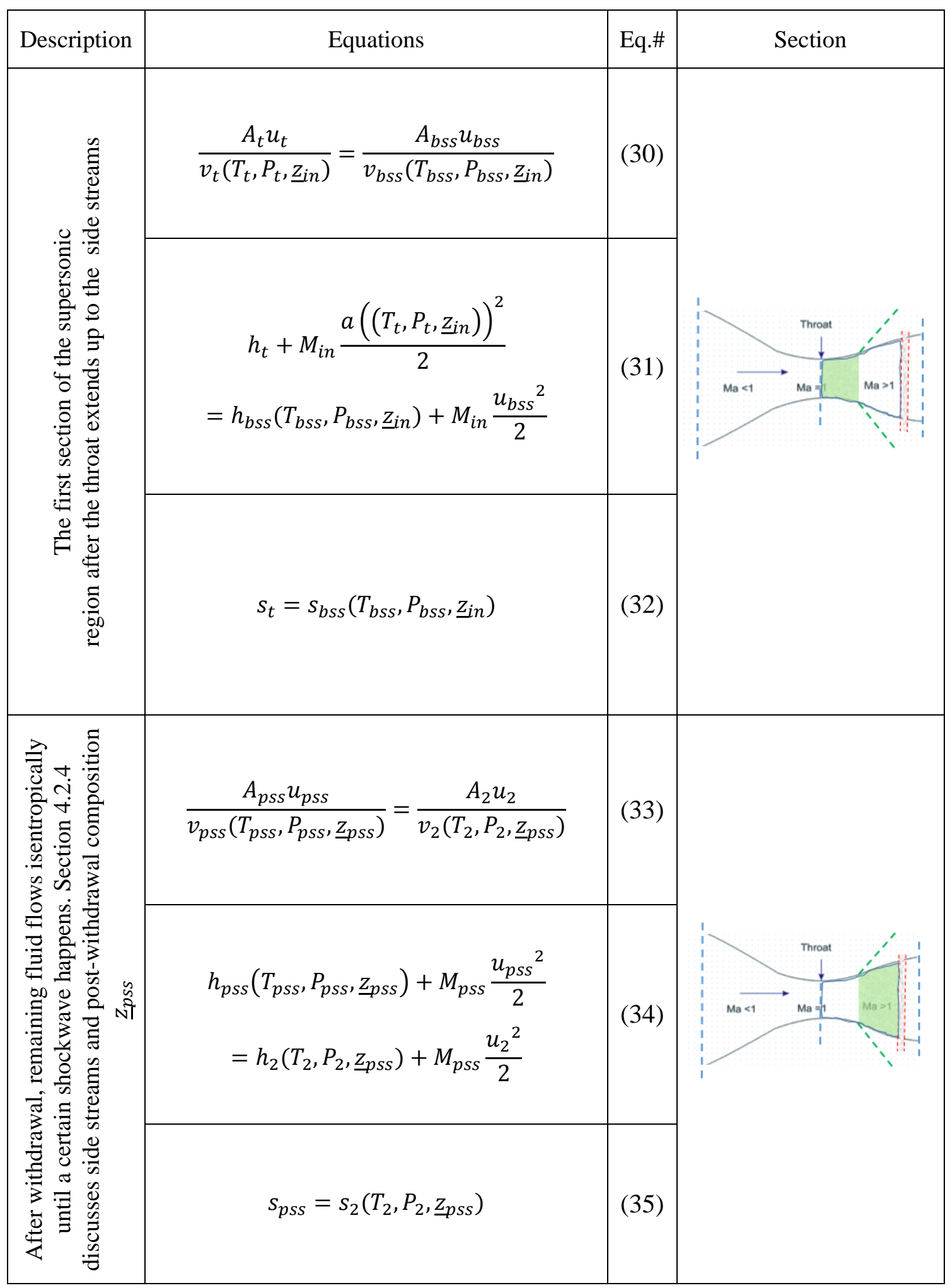


Table 1 Continued

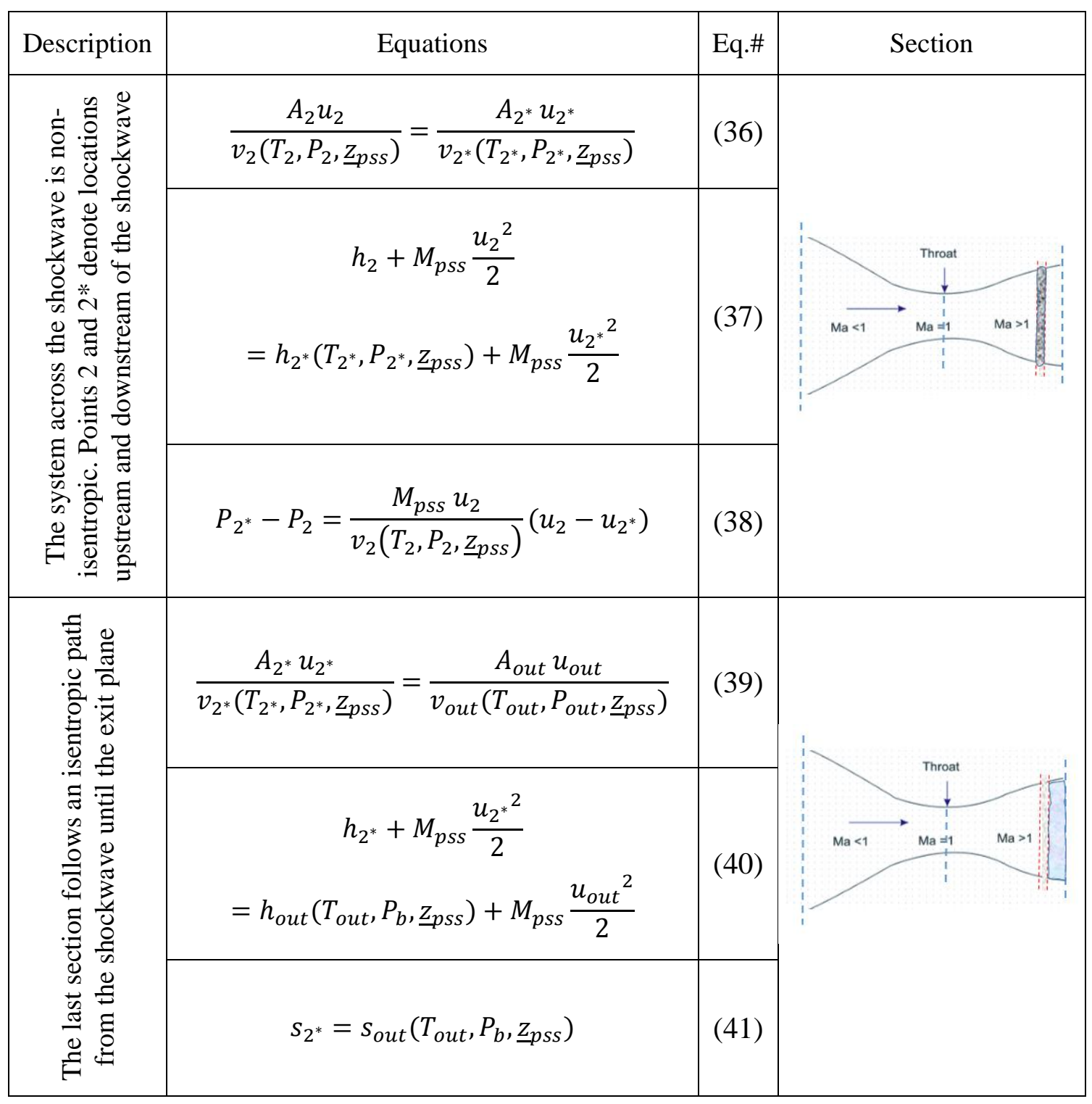




\section{MODEL SOLUTION}

\subsection{Nozzle configuration and boundary conditions}

Supersonic separators typically consist of a swirling device, a laval nozzle, a cyclonic separation and a diffuser extension. A schematic of the central convergingdiverging nozzle is shown in Figure 4 below. The swirling device transfers some axial velocity to angular velocity which helps increase centrifugal separation of condensed phase [27]. The swirling wings or vanes could exist upstream or downstream of the nozzle throat as depicted in the schematics in Figures 5 and 6. The Laval nozzle consists of three sections: the convergent subsonic section, throat (sonic) position and the divergent supersonic section.

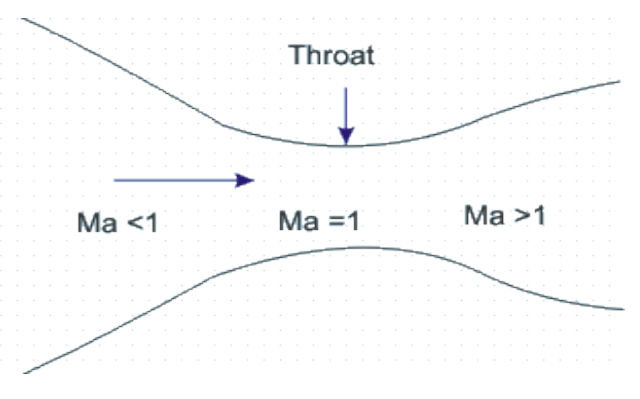

Figure 4: Converging-Diverging nozzle. Reprinted from [63]. 


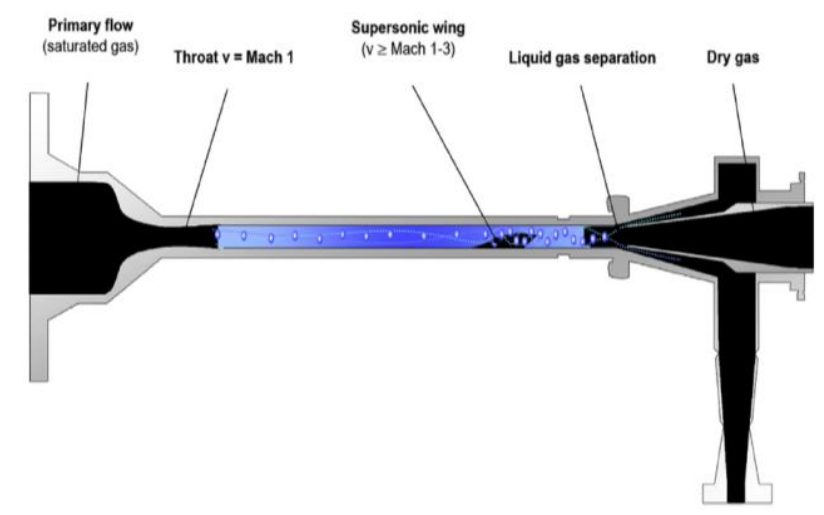

Figure 5: Schematic of Twister Mark I $[10,42] .^{2}$

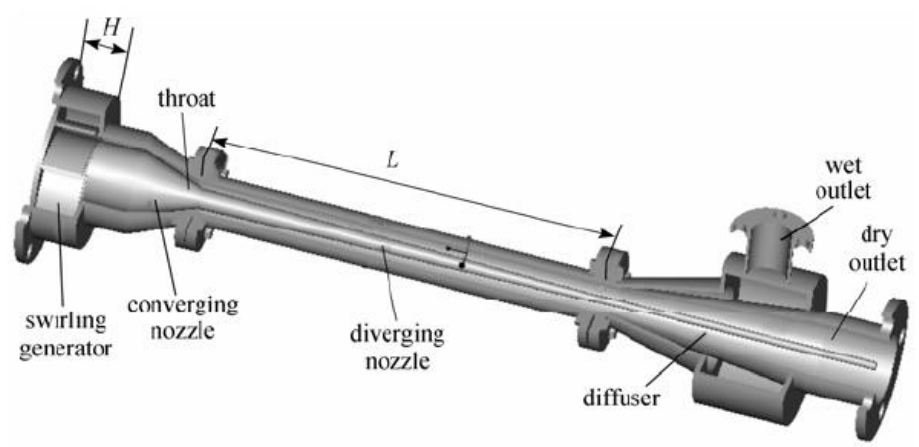

Figure 6: Schematic of constructed SGS device by Qingfen et al. [28]. ${ }^{3}$

In the supersonic separator, thermodynamic properties change along the axial length of the nozzle. Therefore, the position along the nozzle is a key parameter in modeling. Nozzle geometries, however, differ based on the design. Generally, geometrical configuration of the nozzle is defined by certain converging-diverging

\footnotetext{
${ }^{2}$ Reprinted from Journal of Natural Gas Science and Engineering, 27, M. Haghighi, K.A. Hawboldt, M.A. Abdi, Supersonic Gas Separators: Review of Latest Developments, 109-121, Copyright (2015), with permission from Elsevier

${ }^{3}$ Reprinted from Chinese Journal of Chemical Engineering, 17, M. Qingfen, H. Dapeng, H. Gaohong, H. Shijun, L. Wenwei, X. Qiaolian, W. Yuxin, Performance of Inner-core Supersonic Gas Separation Device with Droplet Enlargement Method, 925-933, Copyright (2009), with permission from Elsevier
} 
angles or equations. Many of these appear in the literature. For instance, In the work of Arina [57], the adopted geometry equations for the converging and diverging sections of the nozzle are expressed as follows:

$$
\frac{A(x)}{A_{t}}=2.5+3\left(\frac{x}{x_{t}}-1.5\right)\left(\frac{x}{x_{t}}\right)^{2} \quad x \leq x_{t}
$$

The equation provides the ratio of the cross-sectional area at a position $x$ in the converging nozzle relative to that at the throat. Similarly;

$$
\frac{A(x)}{A_{t}}=3.5-\frac{x}{x_{t}}\left(6-4.5 \frac{x}{x_{t}}+\left(\frac{x}{x_{t}}\right)^{2}\right) \quad x \geq x_{t}
$$

When $x$ denotes the longitudinal distance, the three essential positions at the nozzle are the entrance $\left(x_{i n}\right)$, the throat $\left(x_{t}\right)$ and the nozzle exit $\left(x_{o u t}\right)$. In his work, these arbitrarily followed a length scale equal to 0,5 and 10 for each position, respectively. Since nozzle geometries differ, the best approach to modeling is to make the relationship for the position general and applicable to any geometry. In this case, this is done through making the calculations dependent on a dimensionless parameter. In this shortcut model, all calculations depend only on area ratio $\left(A / A_{t}\right)$ as the key variable. Therefore, the development and procedures for the model are general due to the dependence on cross sectional area rather than longitudes length. Through this technique, any nozzle with any geometry can be simulated and once longitudal length is desired, the specific convergence-divergence equation can be used for conversion.

Boundary conditions of the separator are the conditions of the feed and the defined back pressure. Since the boundary conditions and compositions of Arina [57], Wen et al. [58] and Machado et al. [6] will be used, they are detailed in their respective sections in the results and discussion (Chapter 6) of this report. 


\subsection{Working fluid}

Supersonic separators are designed to condition natural gas and dehydrate it. Hence, it is apparent that when designing these separators, models should be able to deal with typical 13-14 component raw natural gas. However, due to difficulties in modeling complex mixtures specifically dealing with multi-phase flow, phase equilibrium calculations, stability of simulations and computational load, many studies develop models and test them with simplified working fluid. For instance, numerous CFD studies use pure methane, air, water or a mixture of them as their working fluid in supersonic nozzles [59-61]. Other studies use simplified natural gas working fluids with a 2-5 component mixture [17,19].

To make these simplified natural gas mixtures more realistic and mimicking to real behavior of raw natural gas, components and their composition are selected methodically. 
Table 2: Simulated working fluids in the works of Castier [19] and Secchi et al. [17].

\begin{tabular}{ccccc}
\hline & \multicolumn{2}{c}{ Castier [19] } & \multicolumn{2}{c}{ Secchi et al. [21] } \\
\cline { 2 - 5 } Component & Mole fraction & Mole fraction & Mole fraction & Mole fraction \\
\hline Carbon dioxide & $1.3926 \times 10^{-3}$ & - & - & $4.3000 \times 10^{-2}$ \\
\hline Nitrogen & $1.9831 \times 10^{-3}$ & - & - & - \\
\hline Methane & $9.6038 \times 10^{-1}$ & $9.6044 \times 10^{-1}$ & $8.2000 \times 10^{-1}$ & $8.2000 \times 10^{-1}$ \\
\hline Ethane & $2.3168 \times 10^{-2}$ & $2.9800 \times 10^{-2}$ & $1.1200 \times 10^{-1}$ & $6.9000 \times 10^{-2}$ \\
\hline Propane & $6.9151 \times 10^{-3}$ & $9.7600 \times 10^{-3}$ & $6.800 \times 10^{-2}$ & $3.5000 \times 10^{-2}$ \\
\hline iso-Butane & $2.0203 \times 10^{-3}$ & - & - & $3.3000 \times 10^{-2}$ \\
\hline n-Butane & $1.6700 \times 10^{-3}$ & - & - & - \\
\hline iso-Pentane & $8.7495 \times 10^{-4}$ & - & - & - \\
\hline n-Pentane & $4.4682 \times 10^{-4}$ & - & - & - \\
\hline n-Hexane & $4.5240 \times 10^{-4}$ & - & - & - \\
\hline n-Heptane & $4.9547 \times 10^{-4}$ & - & - & - \\
\hline n-Octane & $1.9027 \times 10^{-4}$ & - & - & - \\
\hline n-Nonane & $9.8702 \times 10^{-6}$ & - & - & - \\
\hline
\end{tabular}

In the work of Castier [19], two natural gas (NG) mixtures that were simulated. NG A is a simplified 3-component mixture with methane, ethane and propane. On the other hand, NG B is a 13-component natural gas mixture based on the work of Machado et al. [6] representing a gas feed to a Twister separator. The composition disregarded water and readjusted the mole fractions.

Similarly, in the work of Secchi et al. [17], two simplified mixtures were simulated. The first is the 3-component mixture with the same components as those in Castier's. The second mixture includes 5 components with the addition of carbon dioxide and butane. The simulated working fluids and their compositions at both studies are listed in Table 2. 
A proper way of leveling down to the 3-component mixture is to combine the mass fractions of Nitrogen with that of methane, the fraction of carbon dioxide with ethane and all other components into that of propane. This criterion of combining fluid species is based on similarities in the value of critical temperatures and allows for a simplified working fluid [17]. Figure 7 displays the T-s diagram from each natural gas component and the drawn red lines indicate the regions of similar components to be merged.

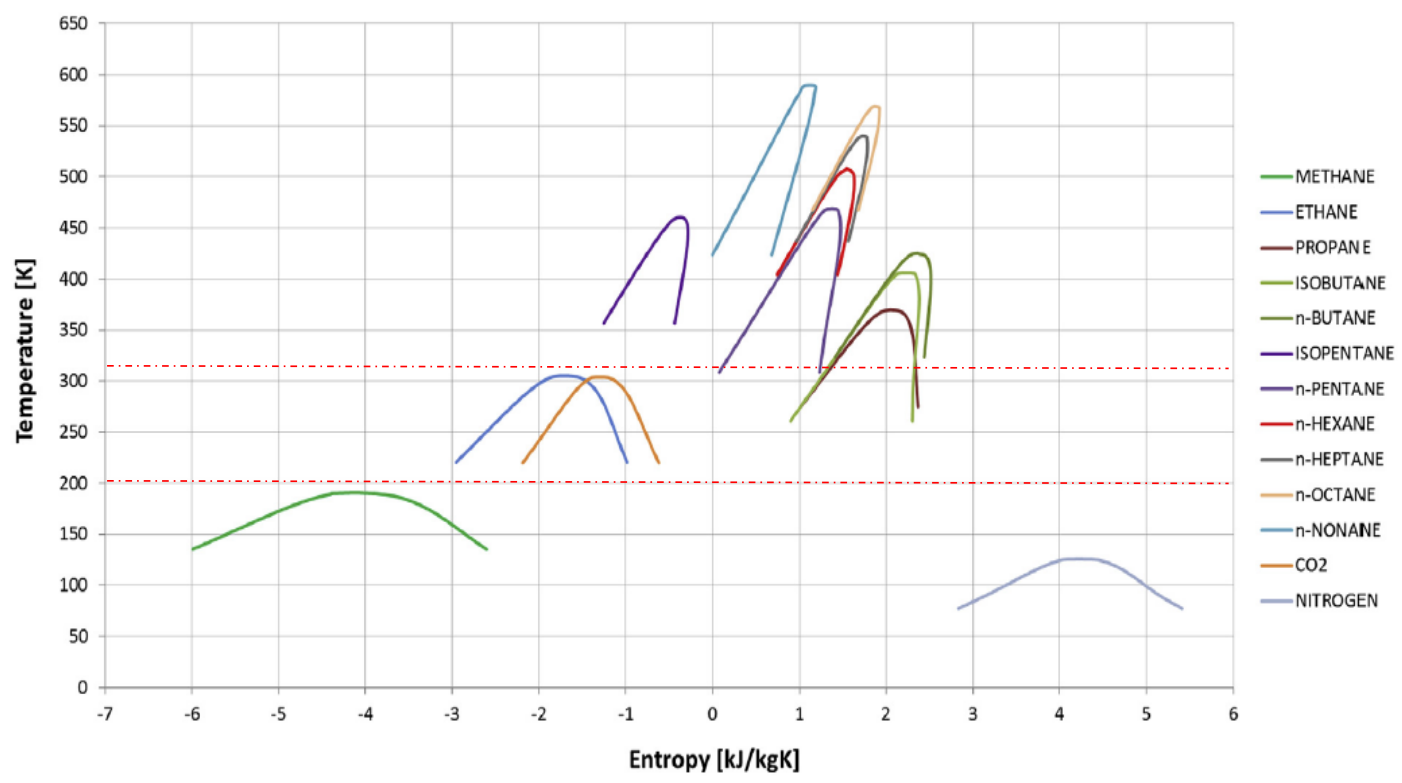

Figure 7: T-s diagram for raw natural gas components [17]. ${ }^{4}$

As an extension of the work by Castier [21] and for result comparison, this study will incorporate both 3-component and 13-component working fluids.

\footnotetext{
${ }^{4}$ Reprinted from Journal of Natural Gas Science and Engineering, 34, R. Secchi, G. Innocenti, D. Fiaschi, Supersonic Swirling Separator for Natural Gas Heavy Fractions Extraction: 1D Model with Real Gas EOS for Preliminary Design, 197-215, Copyright (2016), with permission from Elsevier
} 


\subsection{Fortran code}

To implement the shortcut model, the development and programming of the model simulator was carried out in Fortran. The model is structured in a manner that performs rigorous calculations for the fundamental points detailed in the introduction. Results for the side stream location, shockwave location and all other thermodynamic parameters are obtained. Since this is a shortcut model, it tries to make substantial contribution in the computational load part. This is achieved by eliminating the need for discretization of the flow and doing layer by layer calculations such as those in Castier's [21] work, which this study tries to improve and extend. The structure of the programming algorithms follows a sequential solving scheme for section by section as displayed in Table 3. The table shows a simplified algorithm flowchart of the program at each part of the diverging nozzle.

The first algorithm runs throughout the nozzle to check if the flow at the throat is sonic. If not, then, by default, the flow is not supersonic anywhere in the nozzle and no separation or condensation will occur. On the other hand, in the case of sonic flow at the throat, the program proceeds to identify the thermodynamic conditions at the throat. The next tasks beyond the throat is where most of the work for the shortcut model is introduced. The identification of the side stream location, which is defined by a specified temperature, and the shockwave location without the need for incremental discretization approach presents the most difficult challenge.

Due to the high nonlinearity of the system, especially when employing a multiphase thermodynamic sound speed method, the implementation necessitates creating structured nested loops. Isentropic and isenthalpic flash calculations and sound speed calculations occur through recalling pre-existing subroutines which are independent Fortran programs themselves. The secant method is utilized to converge the guessed parameters in loop iterations. The development is general in several aspects. The first is

the ability to adopt any EOS. Also, the program is developed in a manner that allows any number of components. Additionally, multiple side streams are possible, each to be specified to be located at a set temperature. 
Table 3: Fortran code algorithms.

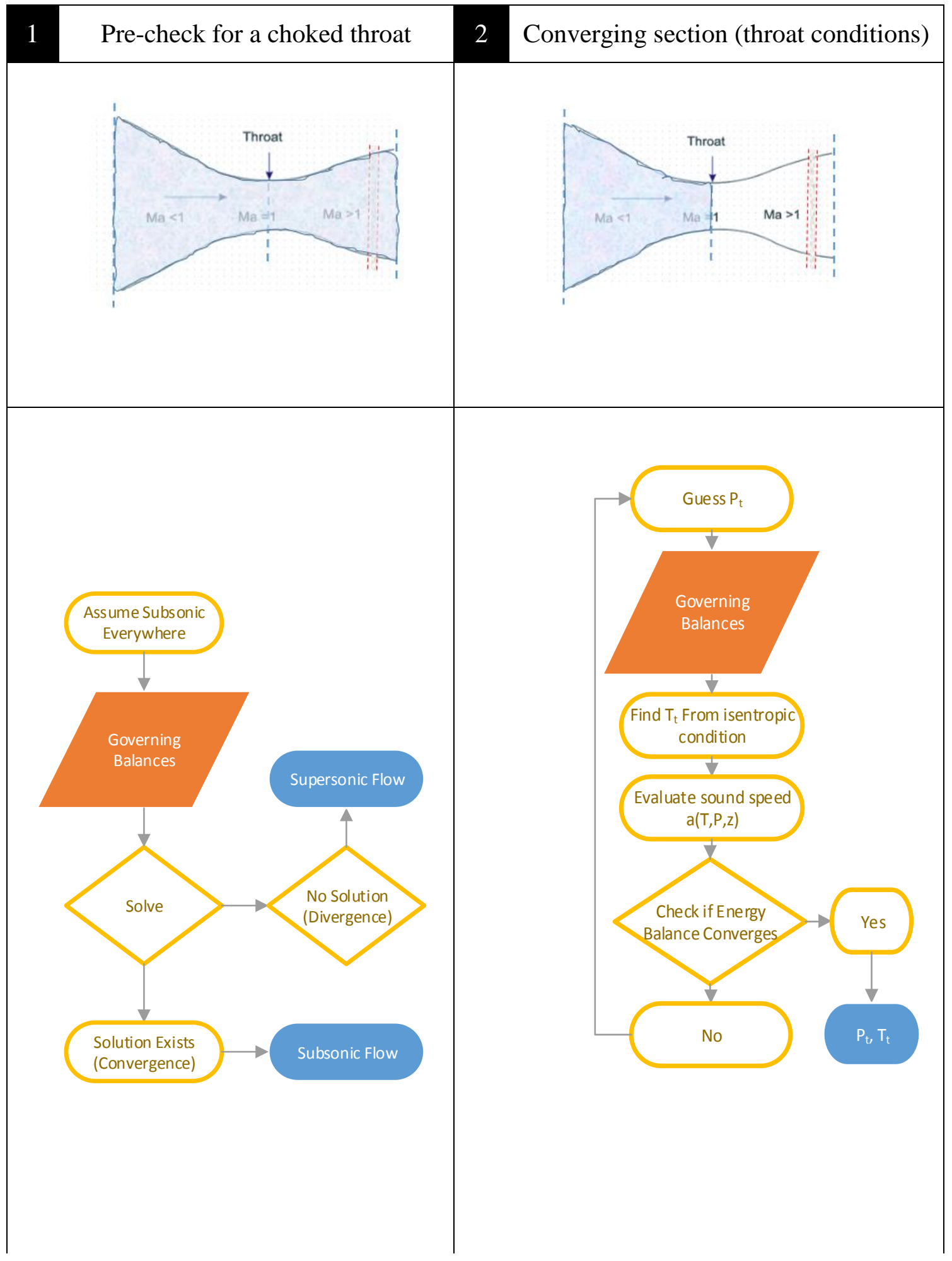


Table 3 Continued

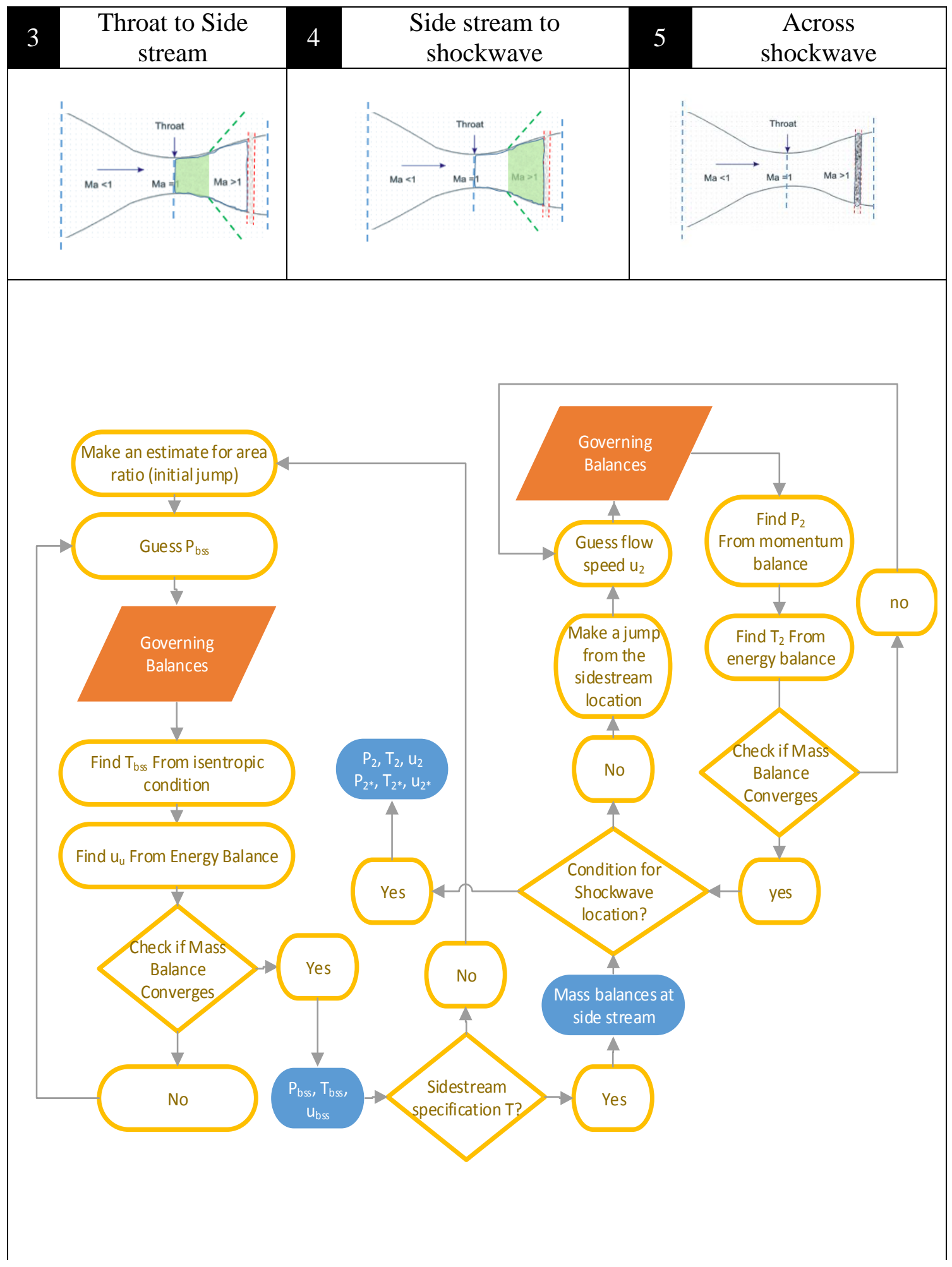


Table 3 Continued

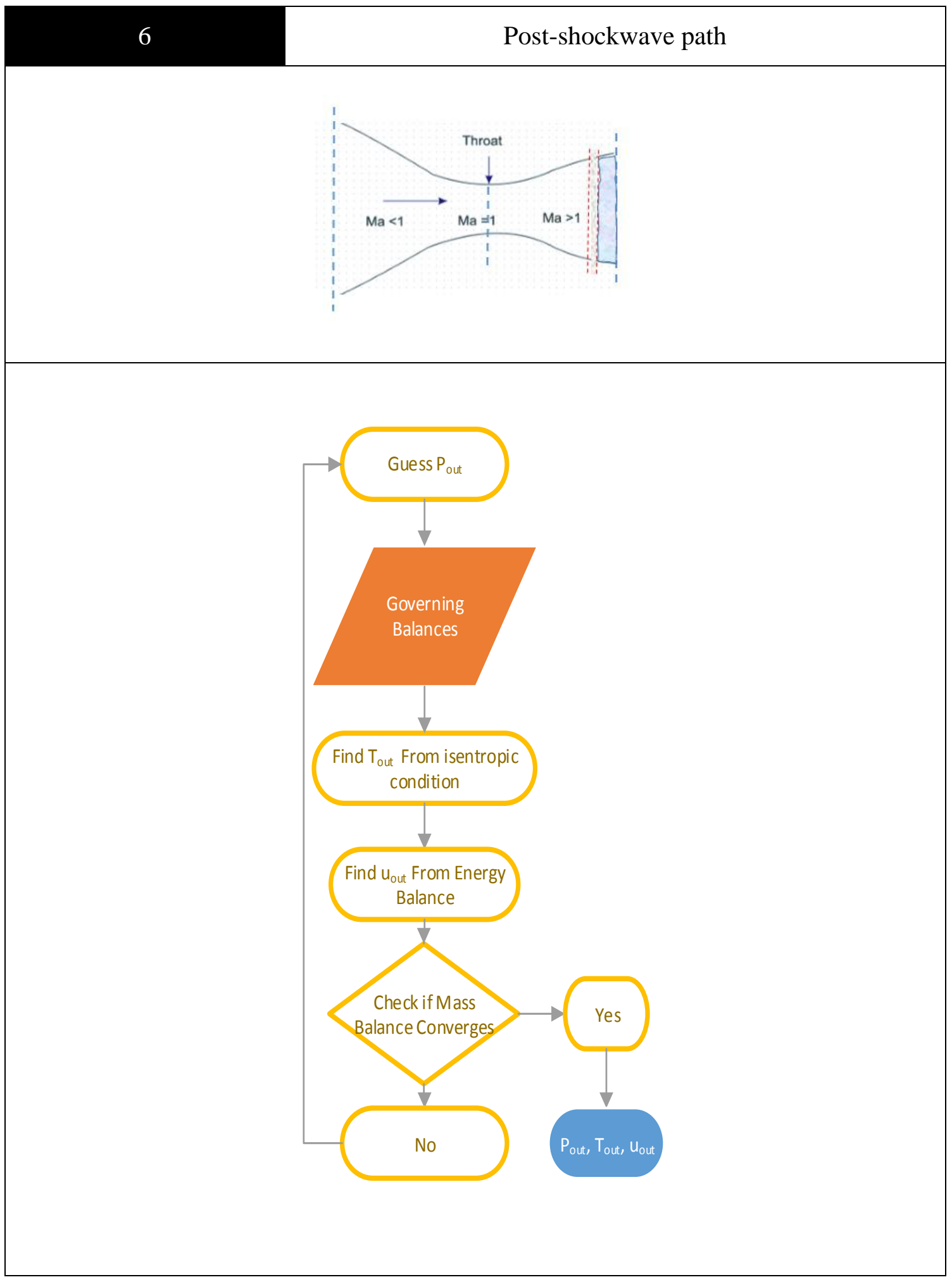




\section{RESULTS AND DISCUSSION}

The validation of any model occurs through cross-checking the results and comparing them with those of experimental work or previously validated models.

Validation steps taken here follow an ascending scheme in terms of simpler case testing to confirm reliability before expanding to more comprehensive cases. Tested nozzles varied in their specifications and conditions as demonstrated. Air, 3-component natural gas and 13- component natural gas mixtures were used as the working fluids for these cases.

All results of this model will be cross-checked with the discretization-based numerical model of Castier [21] since it is the basis for this work and shares most of the assumptions and model formulation fundamentals. It is important to reiterate that the shortcut model developed in this work does not produce property profiles along the diverging section. Rather, it only the produces the results at the five fundamental points clarified in chapter 1 . Hence, reported figures contain scattered points representing the results of this work along with profiles obtained from the model program of Castier [21] for comparison purposes only. After validation of the results, computational loads and simulation run times are discussed to prove the premise for the advantage of the shortcut model. Tabulated results for the cases in this section are attached in appendix A.

\subsection{Air expansion}

Several studies and models were used for benchmarking and validation of the shortcut model developed in this study. The first is taken from the work of Arina [57] in which a converging-diverging nozzle with no side streams was modeled. Air as binary mixture of Oxygen (21\%) and Nitrogen (79\%) enters as the nozzle feed at $288 \mathrm{~K}, 0.1$ $\mathrm{MPa}$ and 0.239543 Ma. The nozzle specifications include a back pressure of 0.083049 $\mathrm{MPa}$ and an area ratio $\left(\mathrm{A}_{\mathrm{out}} / \mathrm{A}_{\mathrm{t}}\right)$ of 1.5. The nozzle follows a dimensionless length scale equal to 0,5 and 10 for the inlet, throat, and exit, respectively. Figures 8 and 9 show the results for temperature and pressure profiles of the shortcut model and those by Arina. 
The shortcut model accurately predicts the conditions at the four fundamental points (since no side stream exits) represented in the throat, before the shockwave, after the shockwave and at the nozzle exit. Similar to Arina's results, the shockwave occurs at a dimensionless longitudal lenth of 7 . The results are also in excellent agreement with Castier [19] and Wen et al. [58] that modeled Arina's air expansion nozzle. Before the shockwave the simulation predict a temperature and pressure of $201.4 \mathrm{~K}$ and 0.0285 $\mathrm{MPa}$ respectively. Across the shockwave the temperature rises to $265.25 \mathrm{~K}$ whereas pressure rises to $0.0697 \mathrm{MPa}$.

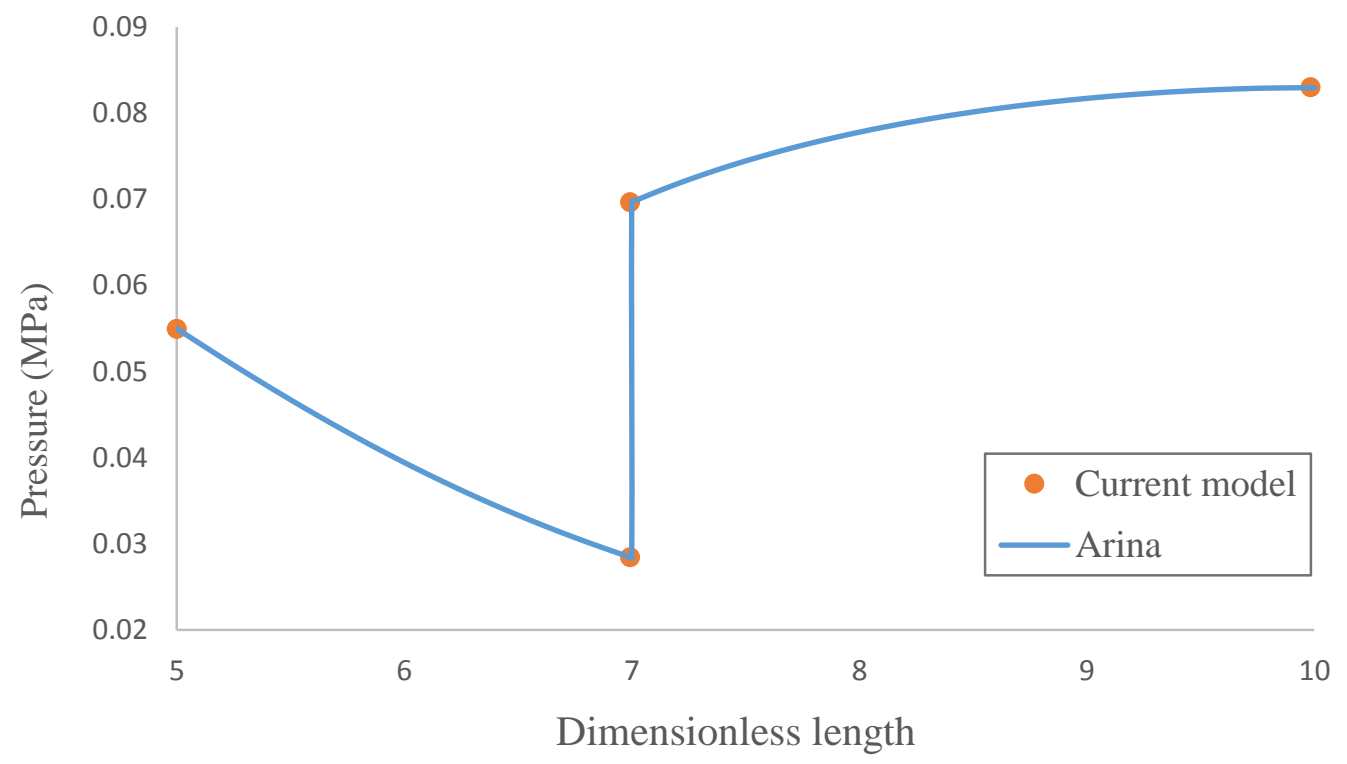

Figure 8: Pressure profile in the diverging section for air expansion. 


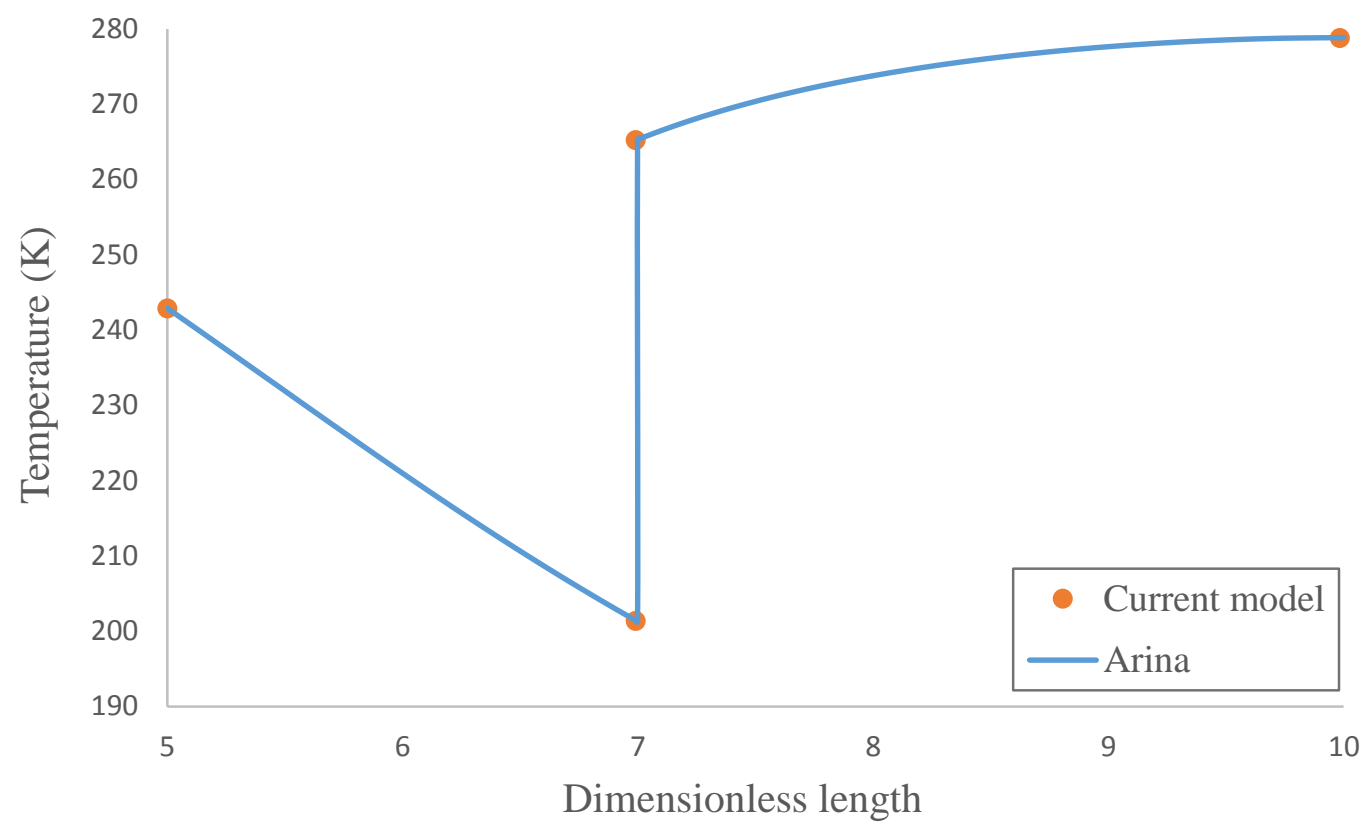

Figure 9: Temperature profile in the diverging section for air expansion.

\subsection{3-component natural gas}

This case stems from a study conducted by Wen et al. [58]. The supersonic conditioning of a ternary mixture of methane, ethane and propane with molar compositions of $96.044 \%, 2.98 \%$ and $0.976 \%$ respectively was modeled. The nozzle has no side streams with specifications for the back pressure at $7 \mathrm{MPa}$ and an area ratio $\left(A_{\text {out }} / A_{t}\right)$ of 4.9669 as converted by Castier [19]. The original work provides geometric parameters for the nozzle inlet, throat and outlet diameters to be $130 \mathrm{~mm}, 36.71 \mathrm{~mm}$ and $81.8 \mathrm{~mm}$ respectively. The diverging section of the nozzle has a length of $564.81 \mathrm{~mm}$. The following figure legends indicate (SC) and (AR) as abbreviations for the shortcut model and area ratio $\left(A_{\text {out }} / A_{t}\right)$, respectively. 
Figures 10 and 11 show results of the shortcut model against those reported in Castier's work. His discretized model agrees with the results of Wen in the following aspects:

(1) The occurrence of two phases between the throat and shockwave;

(2) Single phase existence beyond the shockwave;

(3) Property profiles between the throat and the shockwave as well as close to the nozzle exist.

The shortcut model provides information for the fundamental points across the diverging nozzle. It does not yield a profile but since the discussed models represent a CFD and a numerical model, their agreement is perceived to reflect accuracy.

However, the following notable discrepancies were reported:

(1) The abrupt jump in the Mach number right after the throat in Castier's work.

(2) Temperature, pressure and Mach number concave profiles right upstream of the shockwave in the original work of Wen et al. [58].

Similar to Castier's, the second point above is not observed in the similar works of Karimi and Abdi [2], Secchi et al. [17] and Arinelli et al. [15]. Meaningful and elaborate explanations for these discrepancies can be found in Castier [19]. Therefore, plots from the latter are used for analysis in this case. 


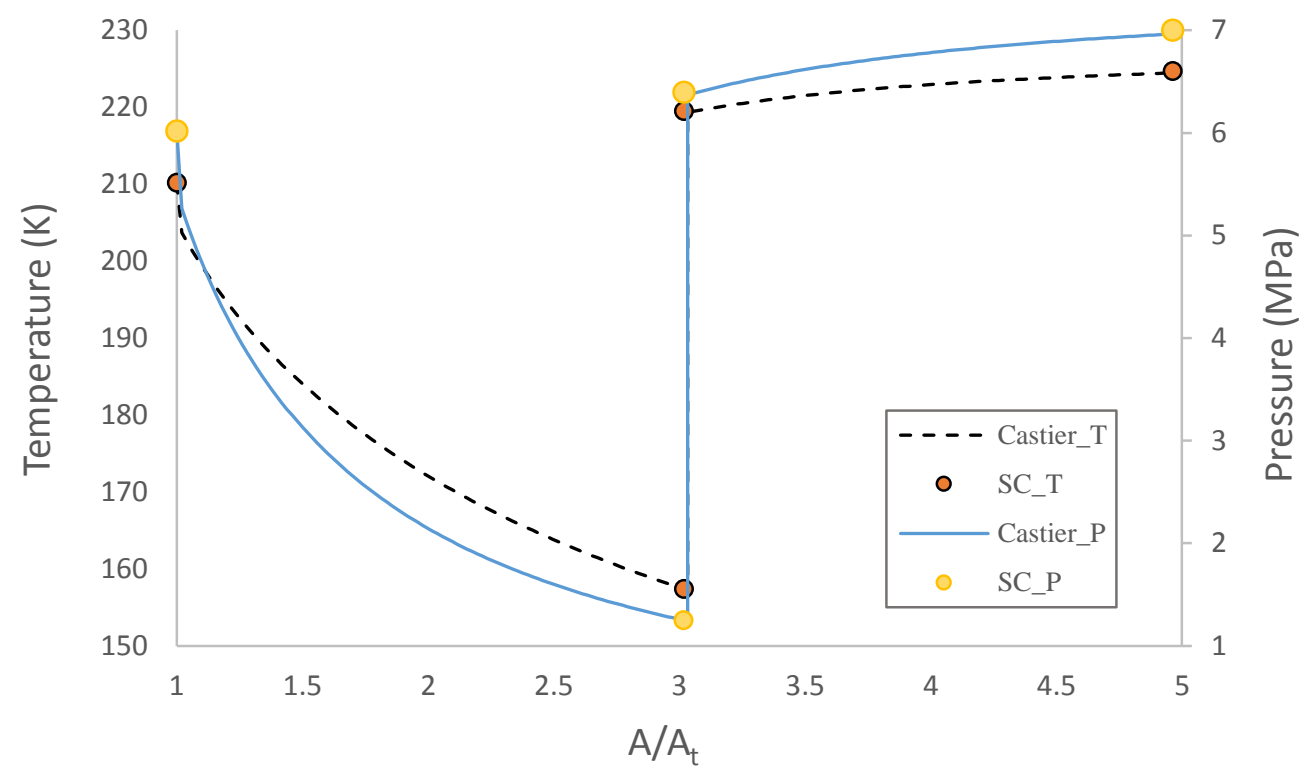

Figure 10: 3-component natural gas temperature and pressure profiles in the diverging section of a nozzle with $A_{\text {out }} / A_{t}=4.9669$ and no side streams.

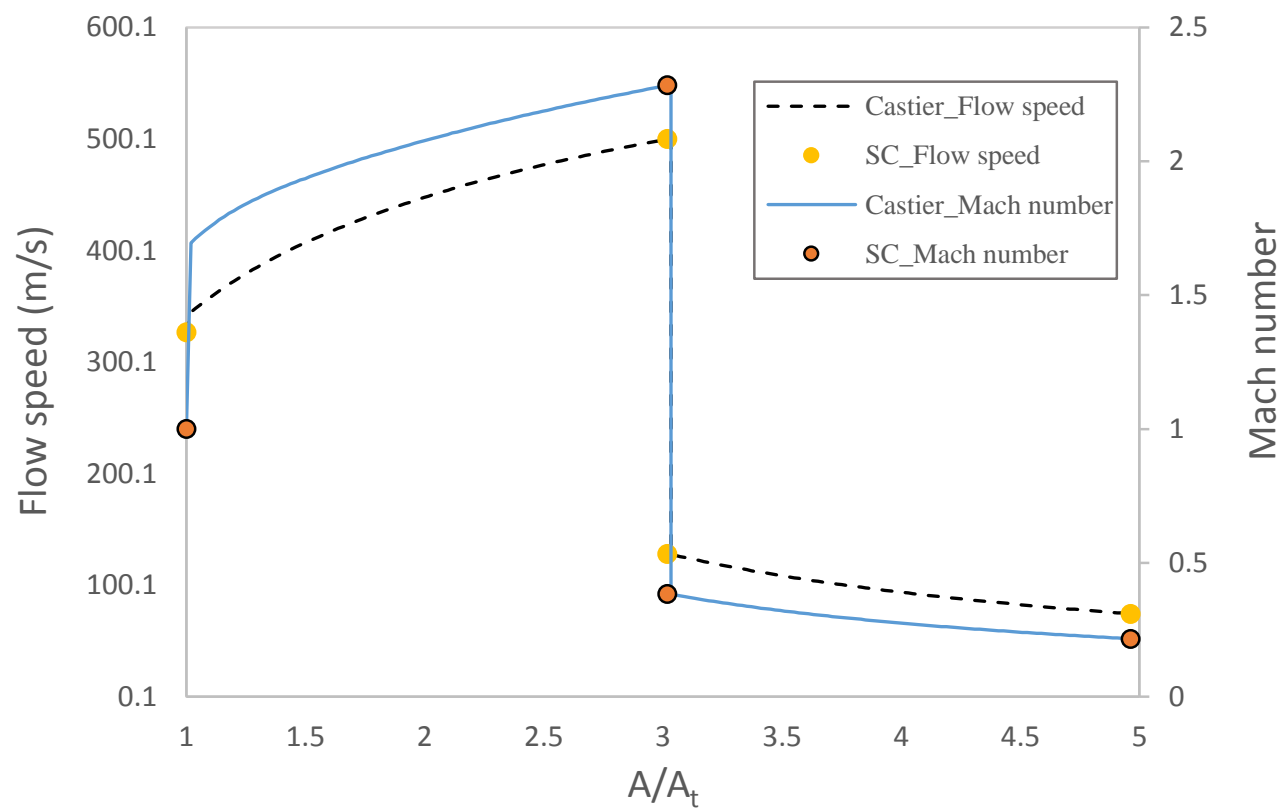

Figure 11: 3-component natural gas flow speed and Mach number profiles in the diverging section of a nozzle with $A_{\text {out }} / A_{t}=4.9669$ and no side streams. 
The scattered points of the shortcut model match the corresponding values from the discretization model for the fundamental points. An important observation is of the abrupt jump in Mach number slightly after the throat and that is due to the appearance of a second phase.

The same case with the 3-component mixture was tested by the one-dimensional numerical model by Secchi et al. [17]. Overall, their results were in good agreement with Castier's. A comparison is shown in Table 4 below.

Table 4: Temperature and pressure changes across the shockwave and shockwave position for 3-component natural gas in a nozzle with $A_{\text {out }} / A_{t}=4.9669$

\begin{tabular}{llll}
\hline & $\boldsymbol{\Delta T}(\mathbf{K})$ & $\Delta \mathbf{P}(\mathbf{M P a})$ & $\begin{array}{l}\text { Shockwave } \\
\text { location }\left(\boldsymbol{A} / \boldsymbol{A}_{\boldsymbol{t}}\right)\end{array}$ \\
\hline Shortcut model & 62.11 & 5.15 & 3.018 \\
\hline Castier [19] & 62.18 & 5.13 & 3.033 \\
\hline Secchi et al. [17] & 65.12 & 5.20 & 2.853 \\
\hline
\end{tabular}

Results show that results from Secchi et al. [17] have excellent agreement with the shortcut model and that of Castier's in the pressure change across the shockwave. The change in temperature, however, is different from both Castier's and the shortcut model by approximately $3 \mathrm{~K}$.

The shockwave position from the shortcut model excellently matches that of Castier with an error of $0.5 \%$. The minor difference in the shockwave location comes from the fact that Castier's model worked on discretization of the flow rather than locating the shockwave position exactly. The shortcut model, on the other hand, targets the exact location of the shockwave with a specified tolerance. However, Secchi et al. determine a different shockwave location at an area ratio $\left(A_{\text {out }} / A_{t}\right)$ of approximately 2.853. The use of Wood's law [49] model for multi-phase sound speed calculations 
might be responsible for the discrepancies in the temperature change across the shockwave as well as the position. The model is best applicable to two-phase systems when each phase has one component rather than a mixture of components. With the necessary modifications to avoid the aforementioned issue, Secchi et al. compared his modified sound speed calculations method with those published by Castier [50] and Nichita et al. [48] and found a difference of around 10\% in sound speed values with his being higher. The use of GERG equation of state might be another reason for the discrepancies, but the effect of sound speed calculations is probably more dominant. The nozzle is found to have an appearance of a second phase right after the throat. The shockwave, however, destroys the second phase and the nozzle has only one phase downstream of it. The ratio of the mole fraction in the liquid phase to the feed mole fraction for each of the 3 components was plotted along the diverging nozzle. Figure 12 illustrates the plot of the shortcut model and Castier's. Since the shortcut model of this study only provides data for the fundamental points, it could only result in points representing the values at the shockwave. The values are in excellent agreement with Castier's results. 


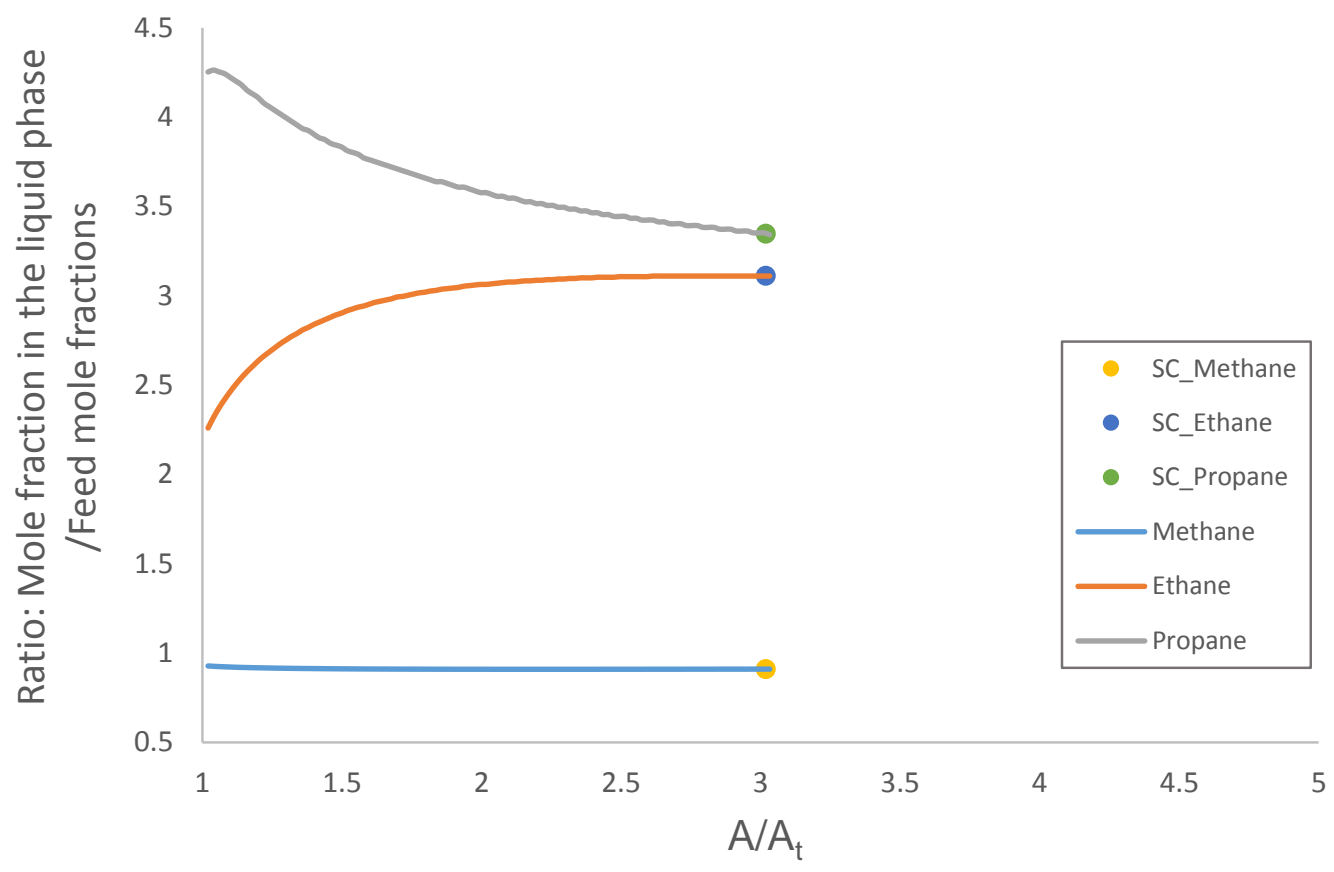

Figure 12: Profile of the ratio of mole fraction in liquid phase to the feed mole fraction along the diverging section of a nozzle with $A_{\text {out }} / A_{t}=4.9669$ for 3 -component natural gas mixture.

\subsection{3-component natural gas}

13-compnent natural gas mixtures were also tested for validation. The composition of the natural gas is shown in 
Table 5. The composition stems from a wet gas feed to a Twister separator in the work of Machado et al. [6] but recalculated after removing the water content. 
Table 5: 13-component natural gas molar composition.

\begin{tabular}{cccc}
\hline$\#$ & Component & Formula & Mole fraction \\
\hline 1 & Carbon dioxide & $\mathrm{CO}_{2}$ & $1.3926 \times 10^{-3}$ \\
\hline 2 & Nitrogen & $N_{2}$ & $19831 \times 10^{-3}$ \\
\hline 3 & Methane & $C_{4}$ & $9.6038 \times 10^{-1}$ \\
\hline 4 & Ethane & $C_{2} H_{6}$ & $2.3168 \times 10^{-2}$ \\
\hline 5 & Propane & $C_{3} H_{8}$ & $6.9151 \times 10^{-3}$ \\
\hline 6 & Iso-Butane & $C_{4} H_{10}$ & $2.0203 \times 10^{-3}$ \\
\hline 7 & $n-$ Butane & $C_{4} H_{10}$ & $1.6700 \times 10^{-3}$ \\
\hline 8 & Iso-Pentane & $C_{5} H_{12}$ & $8.7495 \times 10^{-4}$ \\
\hline 9 & $n-$ Pentane & $C_{5} H_{12}$ & $4.4682 \times 10^{-4}$ \\
\hline 10 & $n-$ Hexane & $C_{6} H_{14}$ & $4.5240 \times 10^{-4}$ \\
\hline 11 & $n-$ Heptane & $C_{7} H_{16}$ & $4.9547 \times 10^{-4}$ \\
\hline 12 & $n-$ Octane & $C_{8} H_{18}$ & $1.9027 \times 10^{-4}$ \\
\hline 13 & $n-$ Nonane & $C_{9} H_{20}$ & $9.8702 \times 10^{-6}$ \\
\hline
\end{tabular}

\subsubsection{Testing set $\mathrm{A}$}

Feed enters at a temperature and pressure of $251.97 \mathrm{~K}$ and $8.083 \mathrm{MPa}$ respectively. The backpressure is specified at 5.27 $\mathrm{MPa}$. The fluid enters at a speed of 80 $\mathrm{m} / \mathrm{s}$ as assumed by Caster [19].

Initially, tests were conducted to validate the results for the nozzle with area ratios $\left(A_{\text {out }} / A_{t}\right)$ of $1.5,3.0$ and 4.5 with no side streams. The following figure legends indicate (SC) and (AR) as abbreviations for the shortcut model and area ratio $\left(A_{\text {out }} / A_{t}\right)$, respectively.

Figures 13-15 show the pressure, temperature, and Mach number results of the shortcut model and of Castier's. Similar to Castier's, at the area ratio $A_{\text {out }} / A_{t}=1.5$, the shortcut model predicts a shockwave position beyond the nozzle exit plane. The 
fundamental points conditions from the shortcut model at the other area ratios are in excellent agreement.

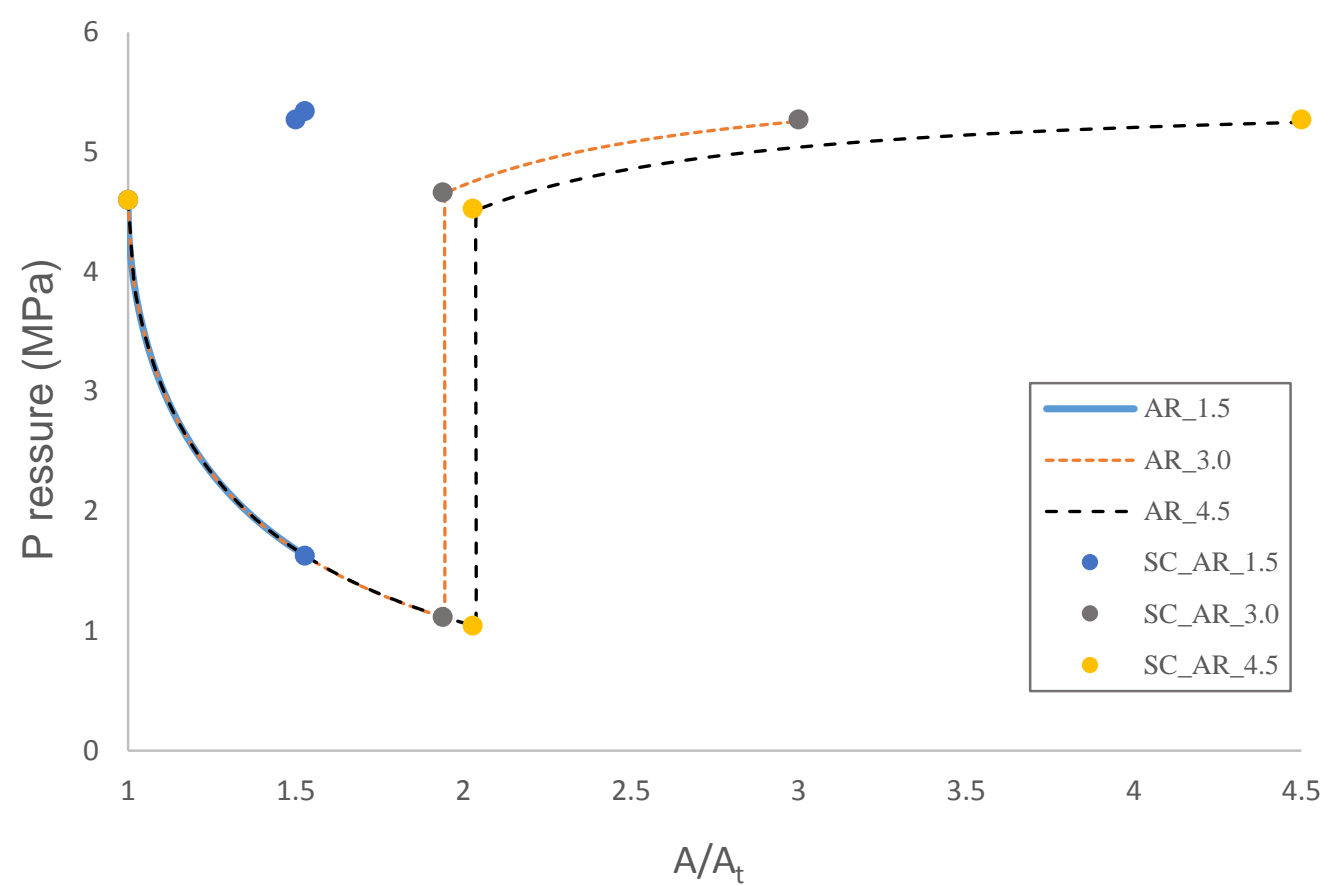

Figure 13: 13-component natural gas pressure profiles in the diverging sections of nozzles with $A_{\text {out }} / A_{t}$ ratios $(1.5,3.0$ and 4.5$)$ and no side streams. 


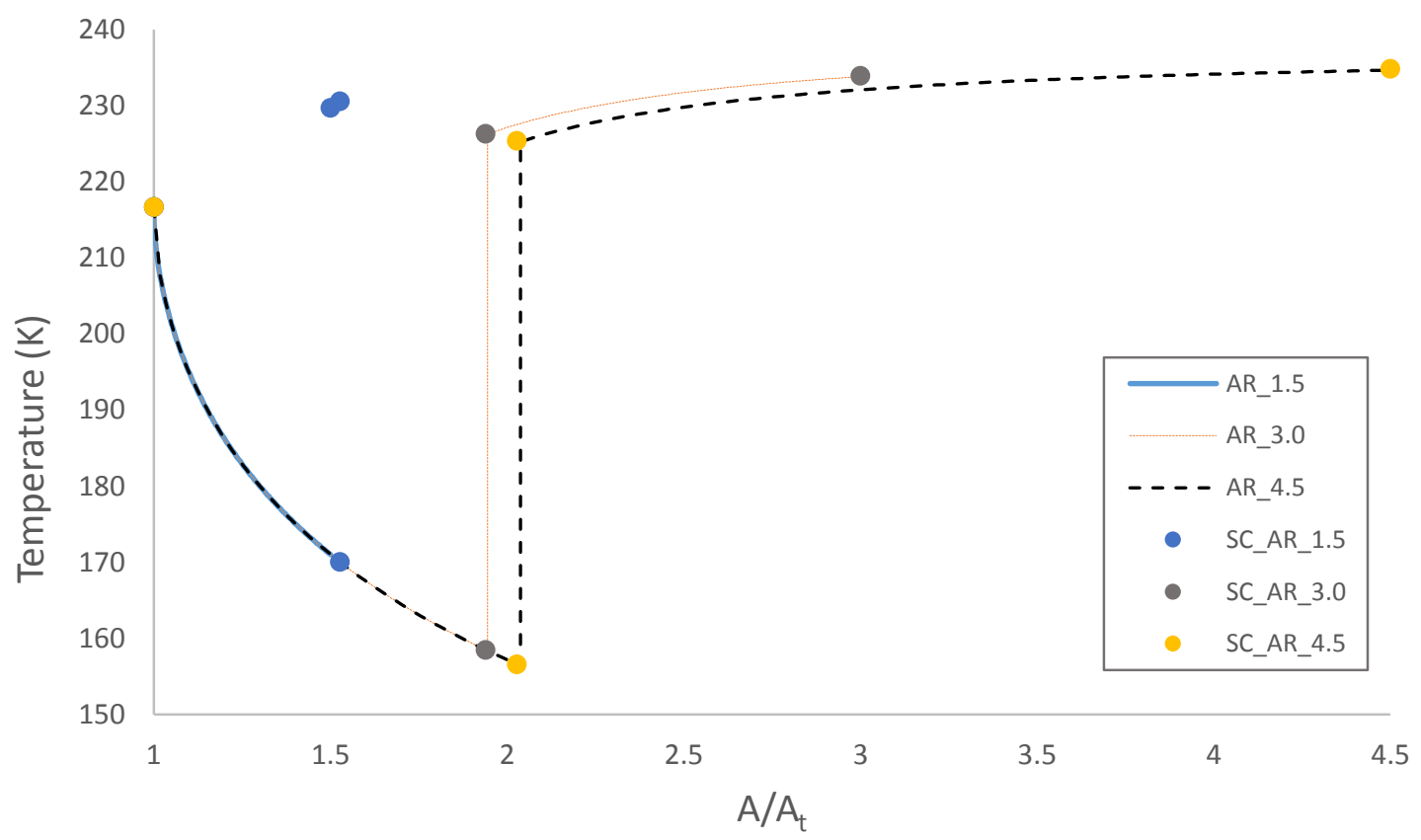

Figure 14: 13-component natural gas temperature profiles in the diverging sections of nozzles with $A_{\text {out }} / A_{t}$ ratios (1.5, 3.0 and 4.5$)$ and no side streams.

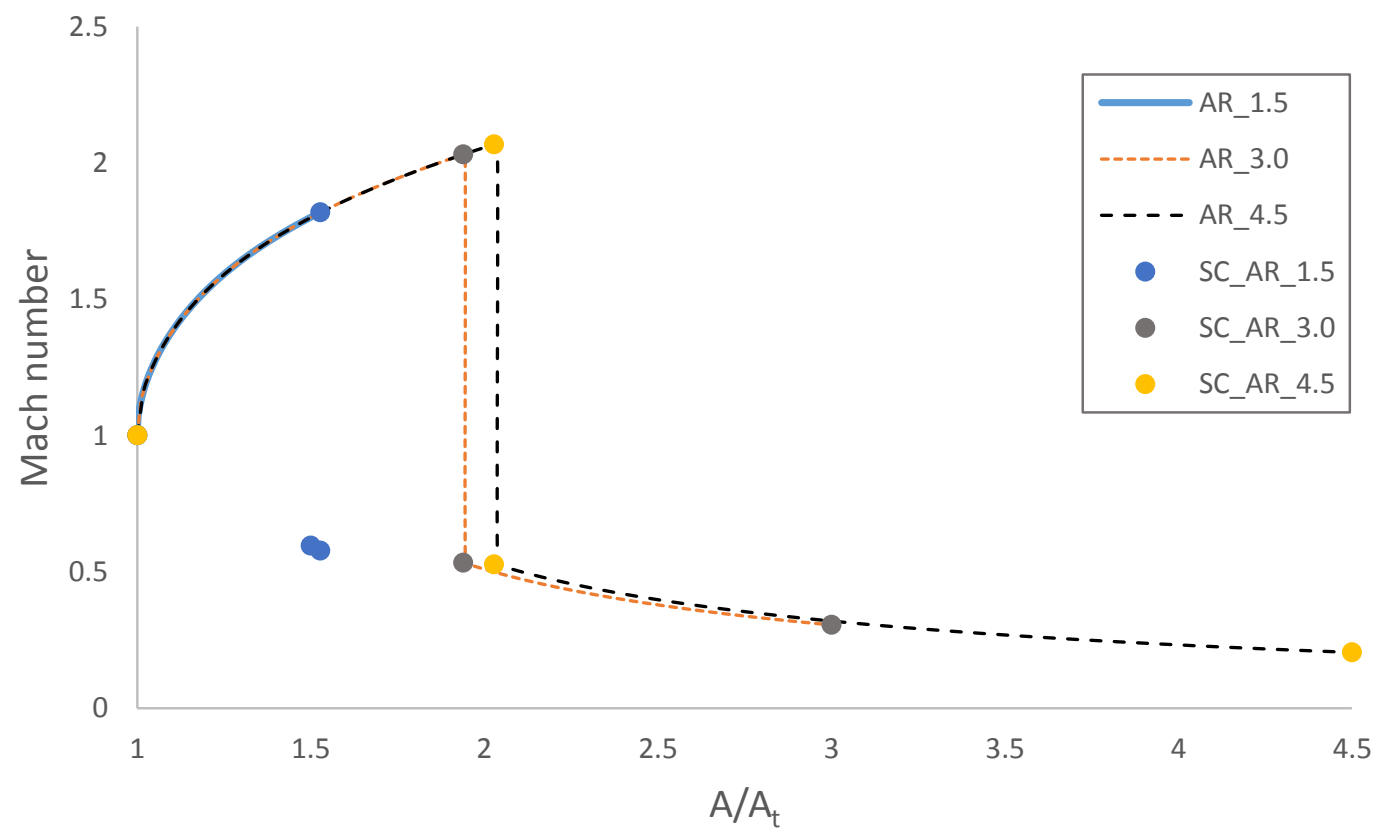

Figure 15: 13-component natural gas temperature profiles in the diverging sections of nozzles with $A_{\text {out }} / A_{t}$ ratios (1.5, 3.0 and 4.5) and no side streams. 
Another set of validation runs include the introduction of side streams for the nozzle with $A_{\text {out }} / A_{t}=3.0$ with, side stream location at $166.7 \mathrm{~K}$ and different specifications of liquid phase recoveries. Figures 16-18 display the results for specifying liquid phase recoveries at $50 \%, 70 \%$ and $90 \%$.

The shortcut model shows excellent agreement with the discretization model. Since these cases include side streams, the shortcut model should provide the conditions of the 5 fundamental points at the inlet, side stream, before shockwave, after shockwave and exit plane, respectively. At first glance, it might seem from the plots that only 4 are represented. However, that is because at this low temperature as specification of the side stream, the shockwaves moved upstream until the gap between the two points is minimal. The condition at the side stream and that upstream the shockwave essentially overlap.

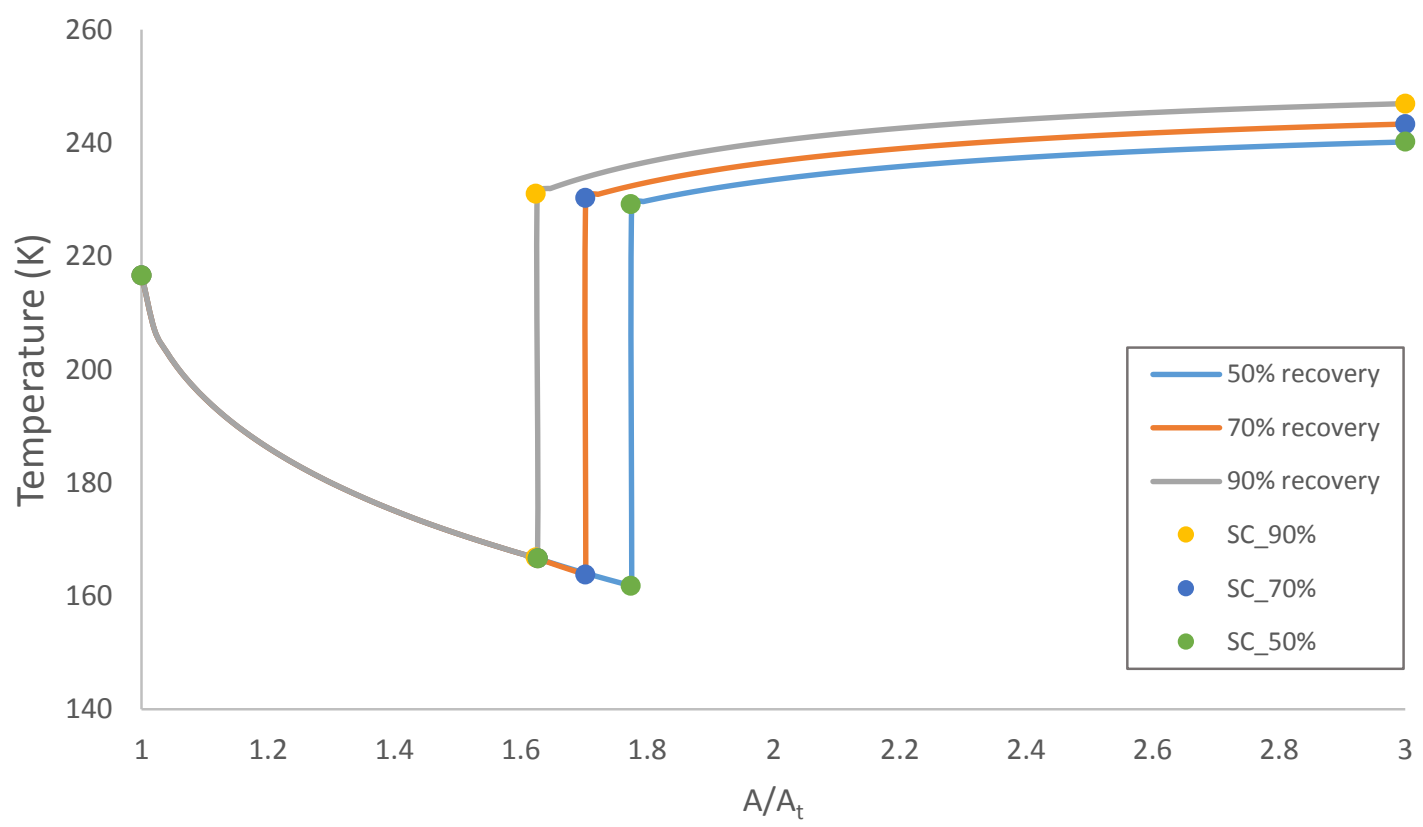

Figure 16: 13-component natural gas temperature profiles in the diverging sections of nozzles with $A_{\text {out }} / A_{t}=3.0$, side stream at $166.7 \mathrm{~K}$ and liquid phase recoveries of $50 \%$, $70 \%$ and $90 \%$. 


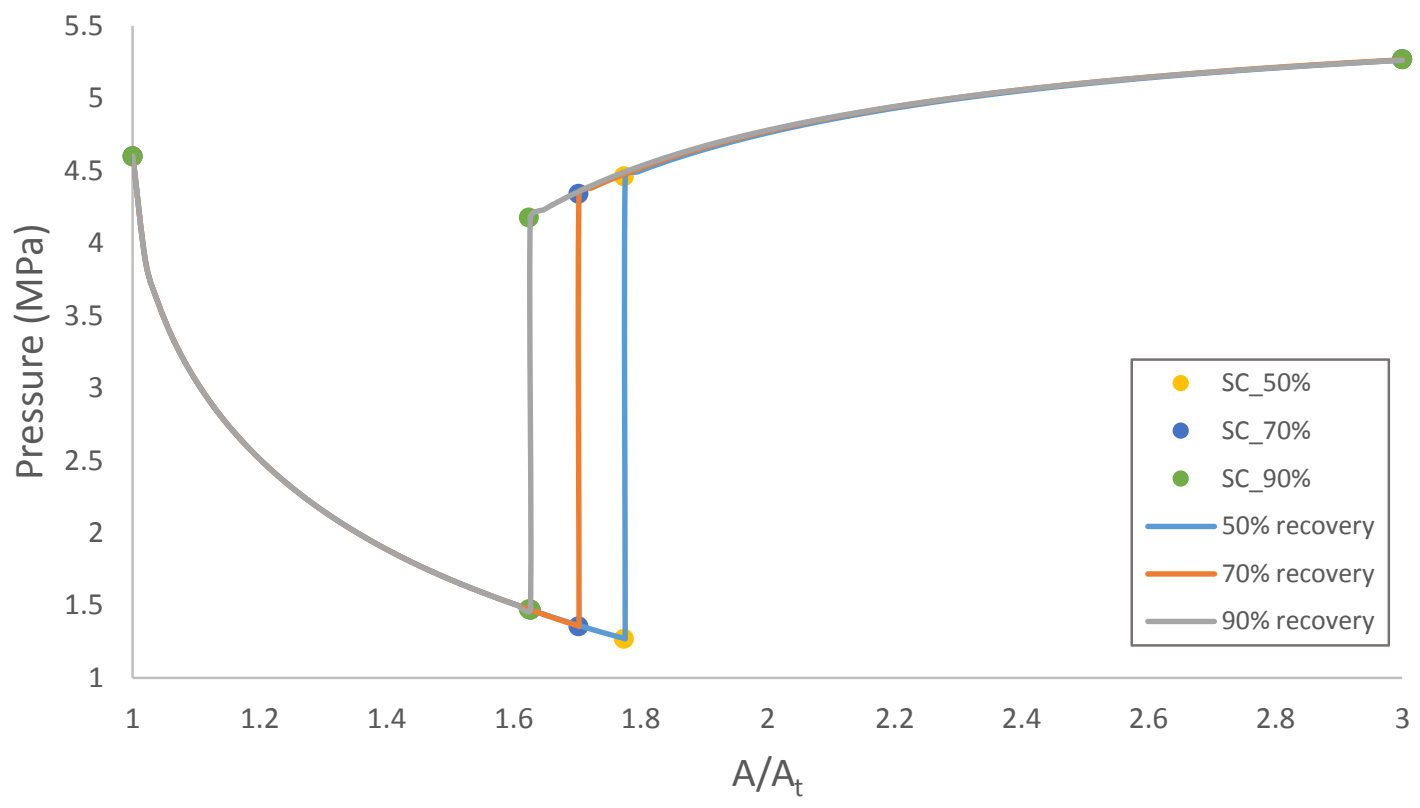

Figure 17: 13-component natural gas pressure profiles in the diverging sections of nozzles with $A_{\text {out }} / A_{t}=3.0$, side stream at $166.7 \mathrm{~K}$ and liquid phase recoveries of $50 \%$, $70 \%$ and $90 \%$.

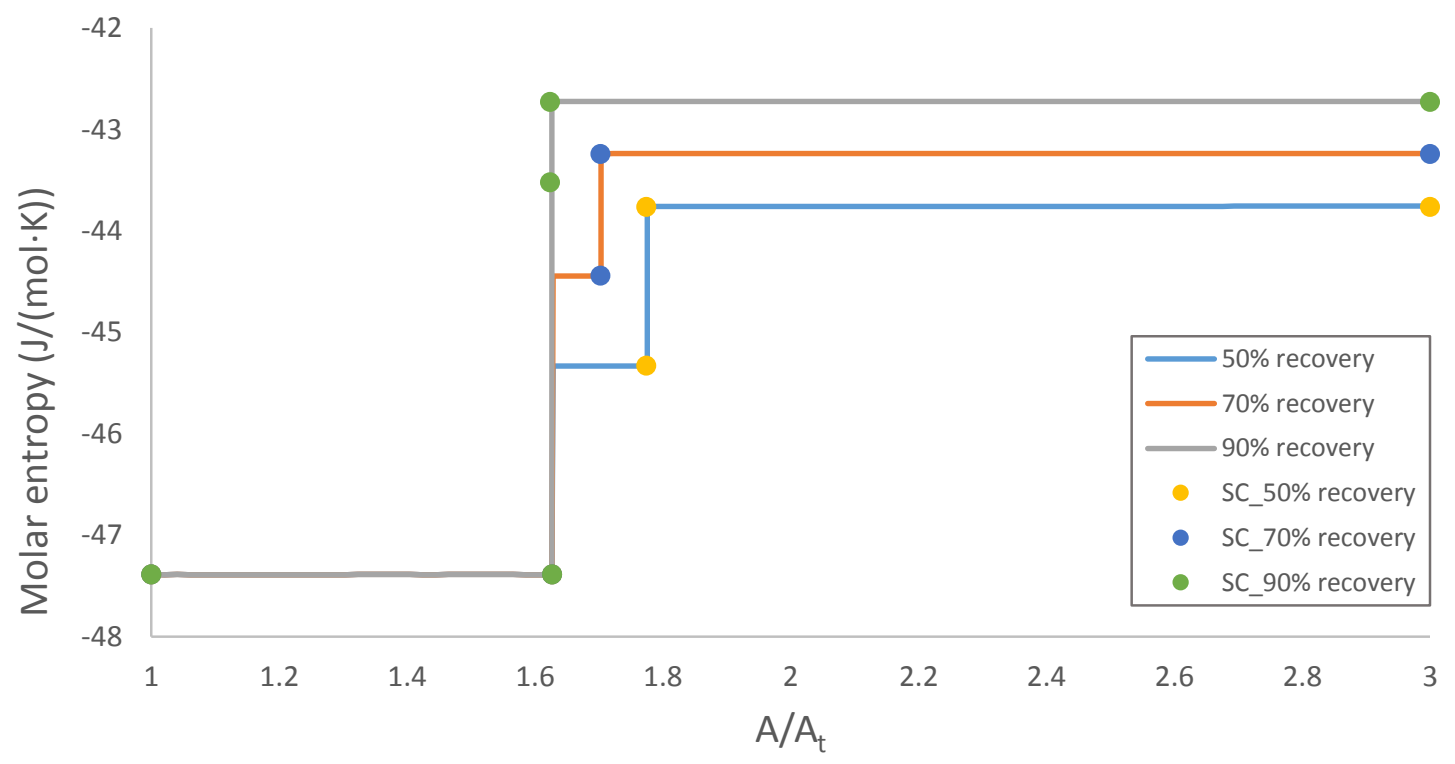

Figure 18: 13-component natural gas molar entropy profiles in the diverging sections of nozzles with $A_{\text {out }} / A_{t}=3.0$, side stream at $166.7 \mathrm{~K}$ and liquid phase recoveries of $50 \%$, $70 \%$ and $90 \%$. 
In Figure 18, the fluid shows three entropy levels. This is apparent due to the existence of 3 isentropic paths within the diverging section of the nozzle. The isentropic path is from the throat to the side stream location whereas, the second and third isentropic paths run from the side stream to upstream of the shockwave and downstream of the shockwave to the exit, respectively. Results show excellent match.

\subsubsection{Testing set $B$}

There is a notable deficiency in the wealth of experimental data available in literature for natural gas supersonic separators. Few experimental information has been reported with no details of the experimental conditions such as the case of Twister [10]. Janssen and Betting [62] reported some experimental data over four runs on a Twister supersonic separator with natural gas mixtures. However, there is no information provided regarding the natural gas composition and a few on operating conditions.

In the following set of tests, the same 13-component natural gas composition is adopted. Feed enters at $297 \mathrm{~K}, 3.2 \mathrm{MPa}$ and $120 \mathrm{~m} / \mathrm{s}$ respectively [21]. Backpressure is specified at 2.4 MPa. The nozzle was tested with no side stream and at side streams at 169.3 K, 174.8 K or 179.9 K. The following figure legends indicate (SC) and (AR) as abbreviations for the shortcut model and area ratio $\left(A_{\text {out }} / A_{t}\right)$, respectively. Figures 19-22 show the results of the shortcut model versus those reported by Castier [21]. The shortcut model shows excellent agreement for the determination of the conditions at the 5 fundamental points. 


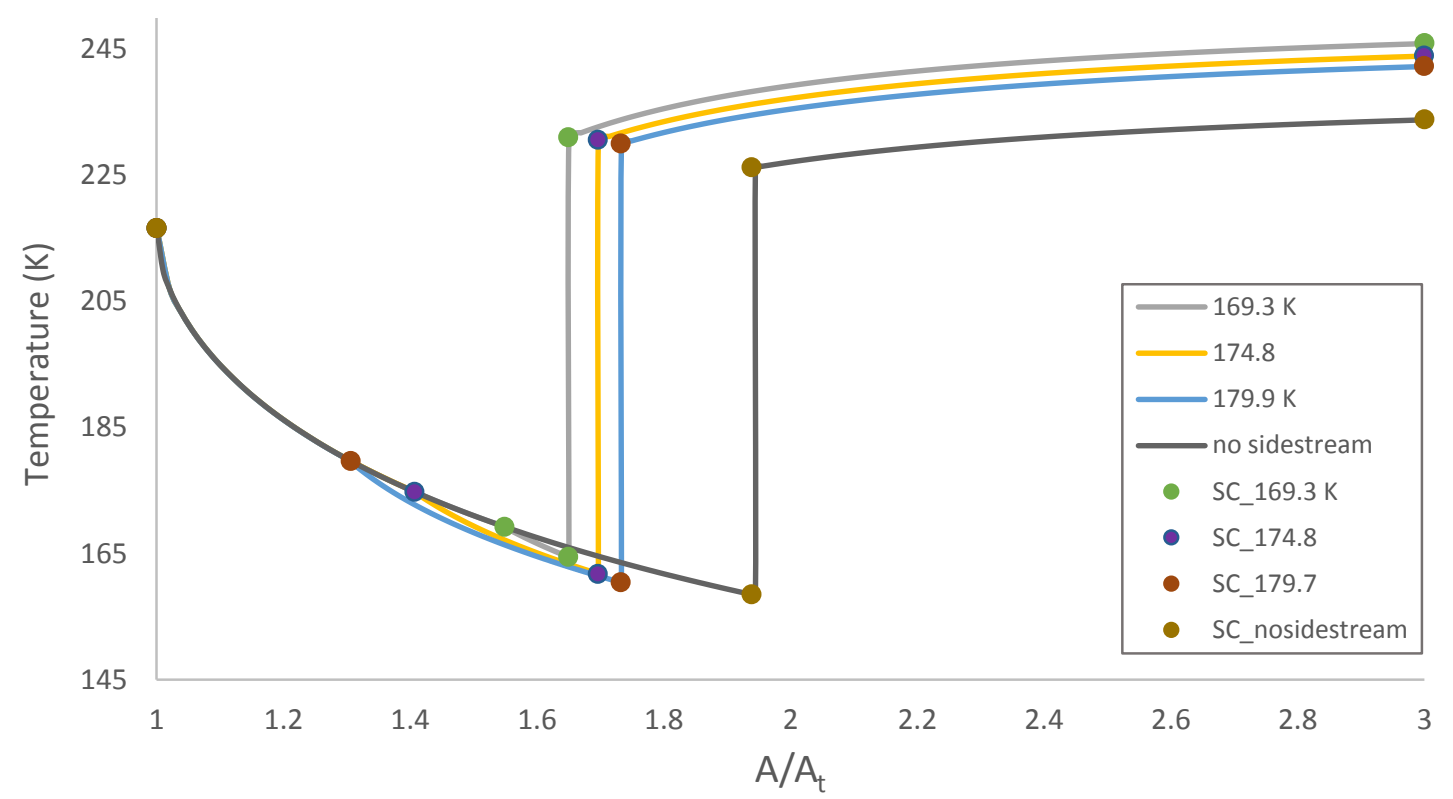

Figure 19: 13-component natural gas temperature profiles in the diverging sections of nozzles with $90 \%$ liquid phase recovery, $A_{\text {out }} / A_{t}=3.0$ and side streams at $169.3 \mathrm{~K}$, 174.8 K, $179.9 \mathrm{~K}$ and no side streams.

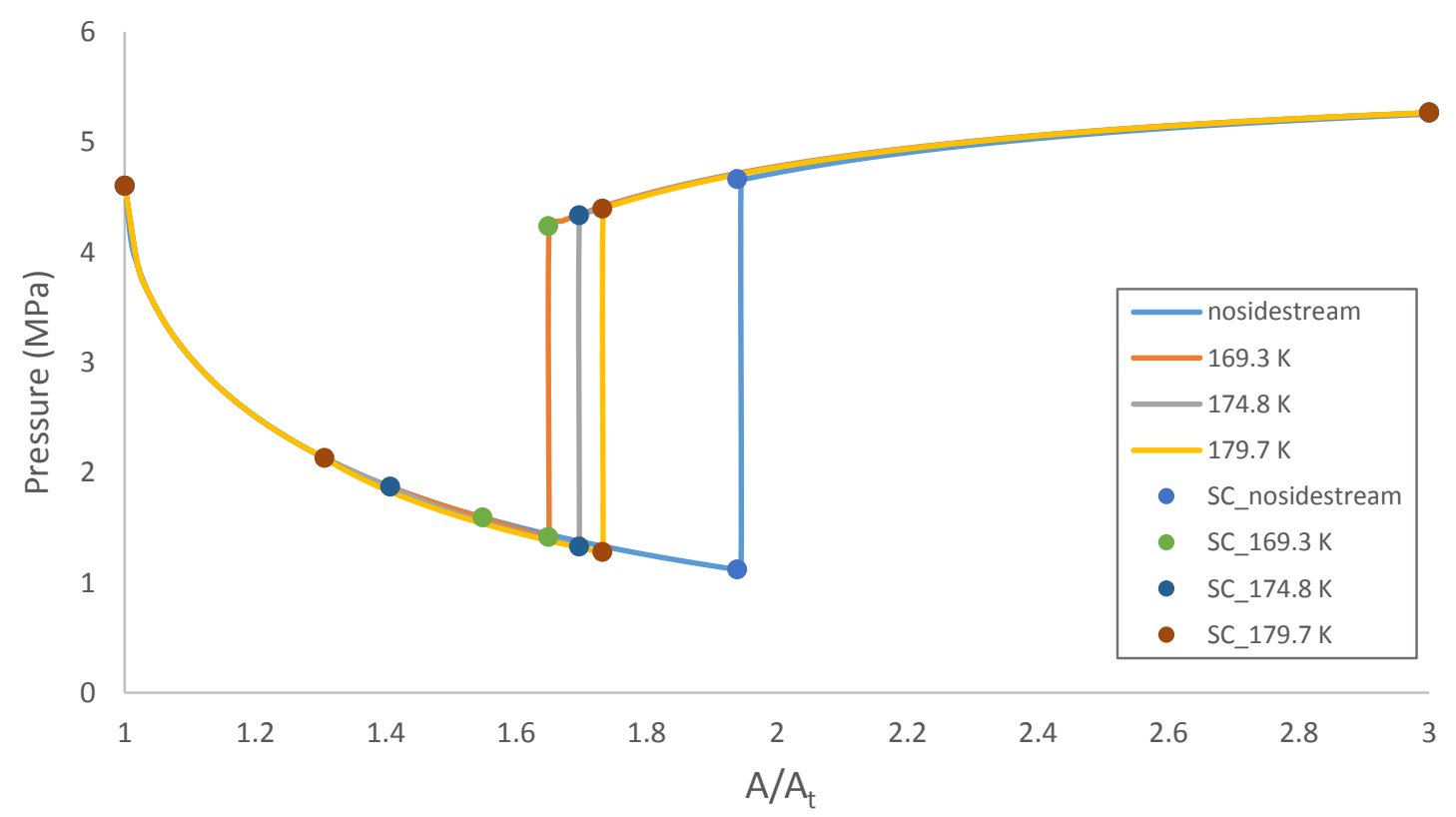

Figure 20: 13-component natural gas pressure profiles in the diverging sections of nozzles with $90 \%$ liquid phase recovery, $A_{\text {out }} / A_{t}=3.0$ and side streams at $169.3 \mathrm{~K}$, $174.8 \mathrm{~K}, 179.9 \mathrm{~K}$ and no side streams. 


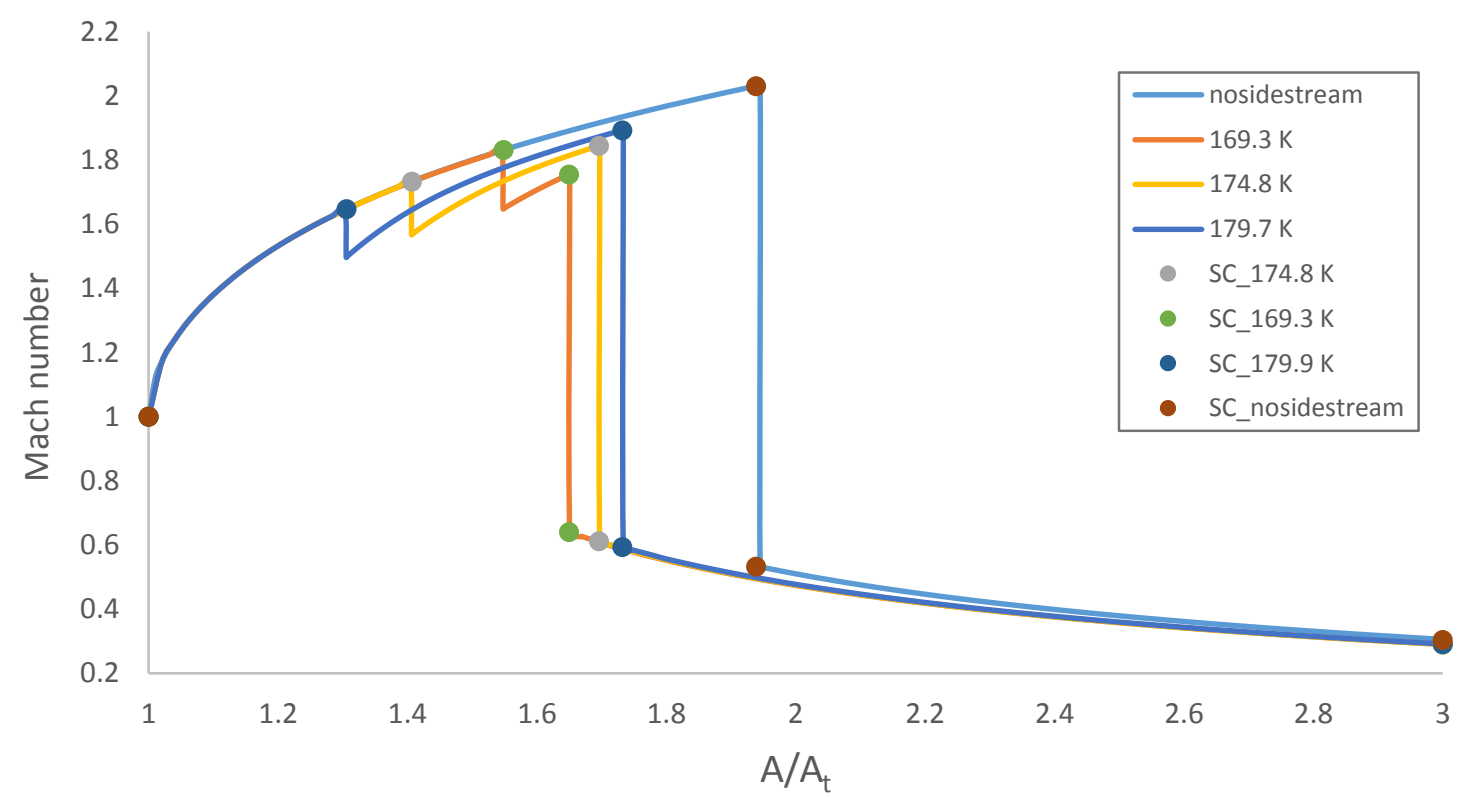

Figure 21: 13-component natural gas Mach number profiles in the diverging sections of nozzles with $90 \%$ liquid phase recovery, $A_{\text {out }} / A_{t}=3.0$ and side streams at $169.3 \mathrm{~K}$, $174.8 \mathrm{~K}, 179.9 \mathrm{~K}$ and no side streams.

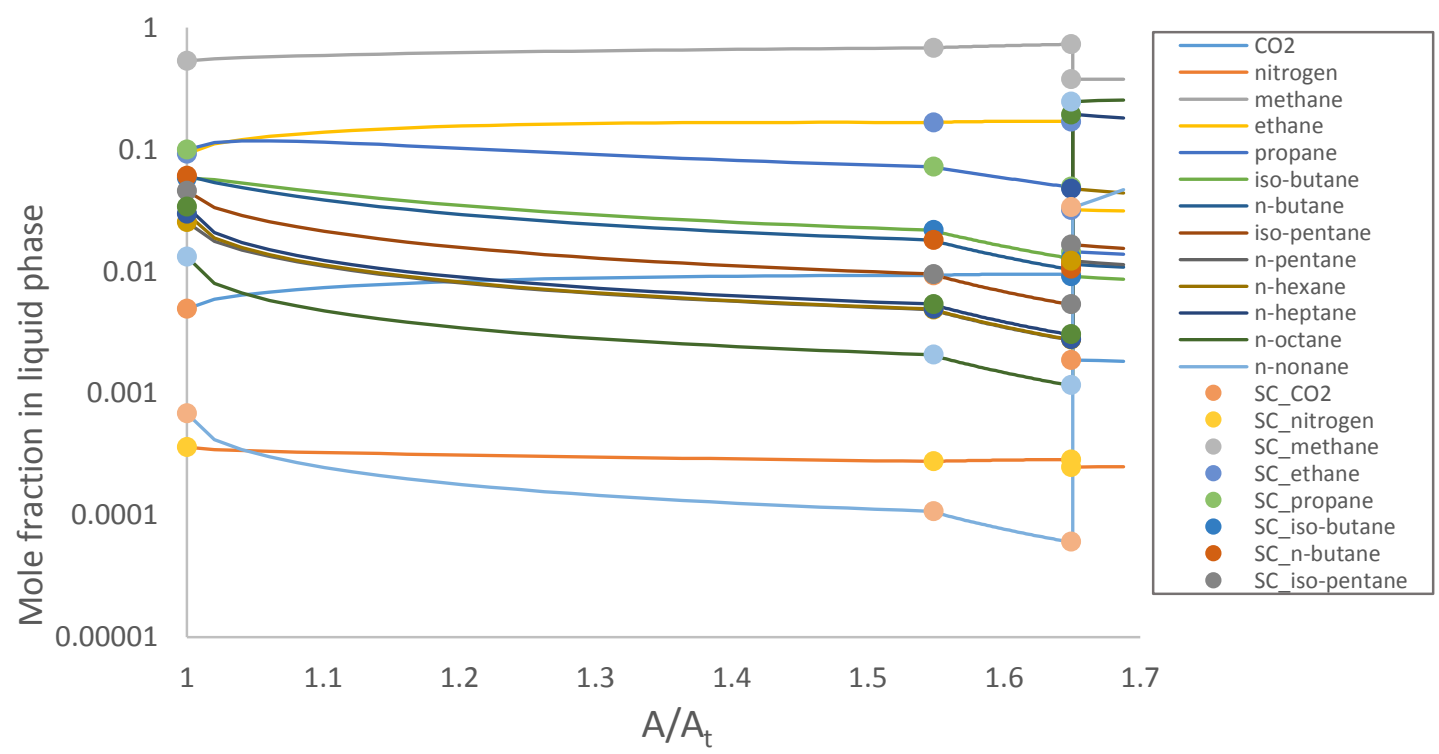

Figure 22: 13-component natural gas mole fraction in the liquid phase profile in the diverging sections of a nozzle with $90 \%$ liquid phase recovery, $A_{\text {out }} / A_{t}=3.0$ and a side stream at $169.3 \mathrm{~K}$. 
Finally, to confirm the adaptability to different specifications and conditions, the last test targeted higher temperature specifications in a shorter nozzle. The nozzle was specified to have an area ratio $\left(A_{\text {out }} / A_{t}\right)$ of 1.5 and side streams specified at $210 \mathrm{~K}, 220$ $\mathrm{K}$ and $230 \mathrm{~K}$. These runs were not reported in the work of Castier [21] but due to the accessibility to his discretization model, the plots were generated for comparison. Figures 23-27 show the profiles along the diverging section of the nozzle for temperature, pressure, sound speed, Mach number and molar entropy respectively.

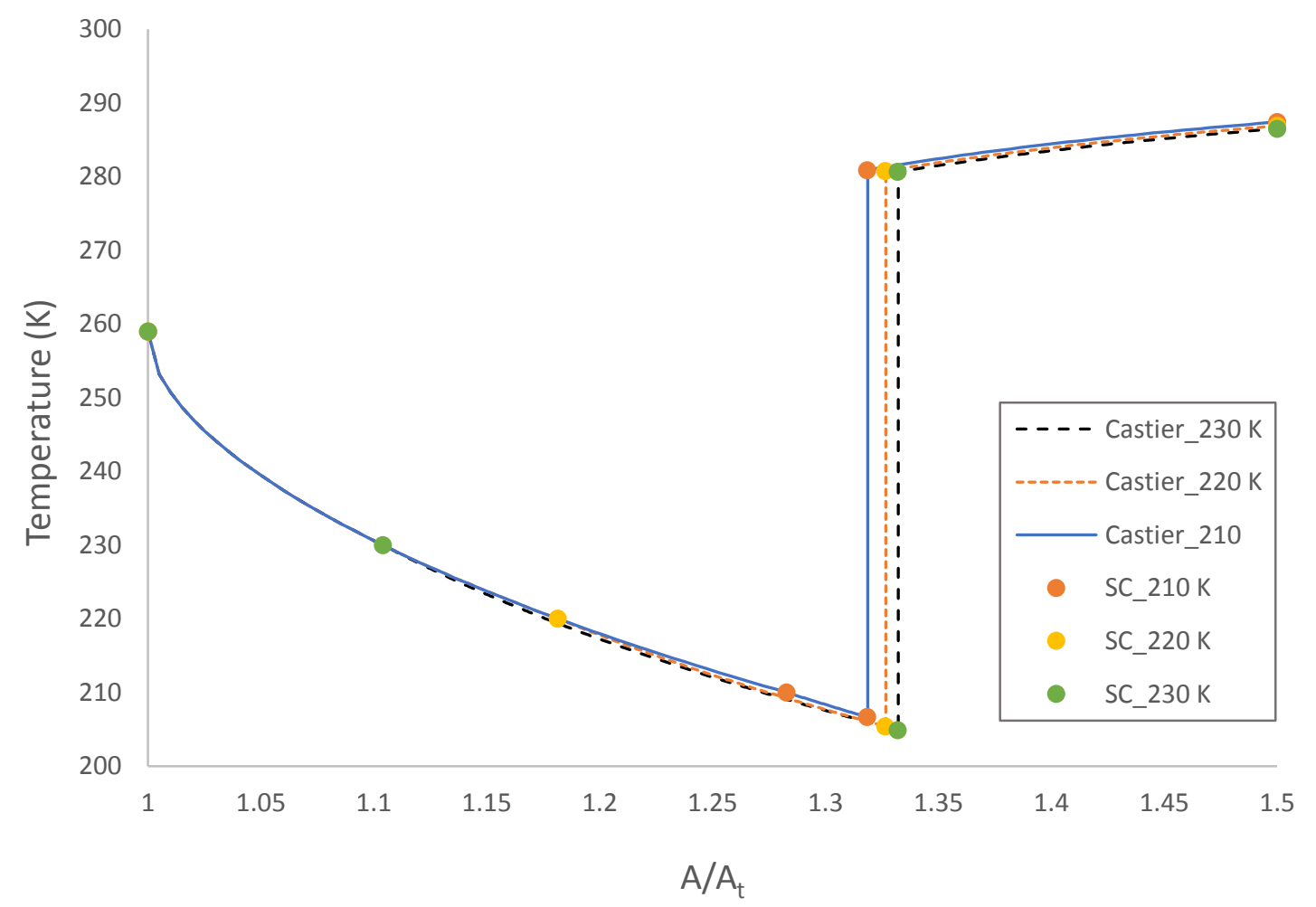

Figure 23: 13-component natural gas temperature profiles in the diverging sections of nozzles with $A_{\text {out }} / A_{t}=1.5$ and side streams at $210 \mathrm{~K}, 220 \mathrm{~K}$ and $230 \mathrm{~K}$. 


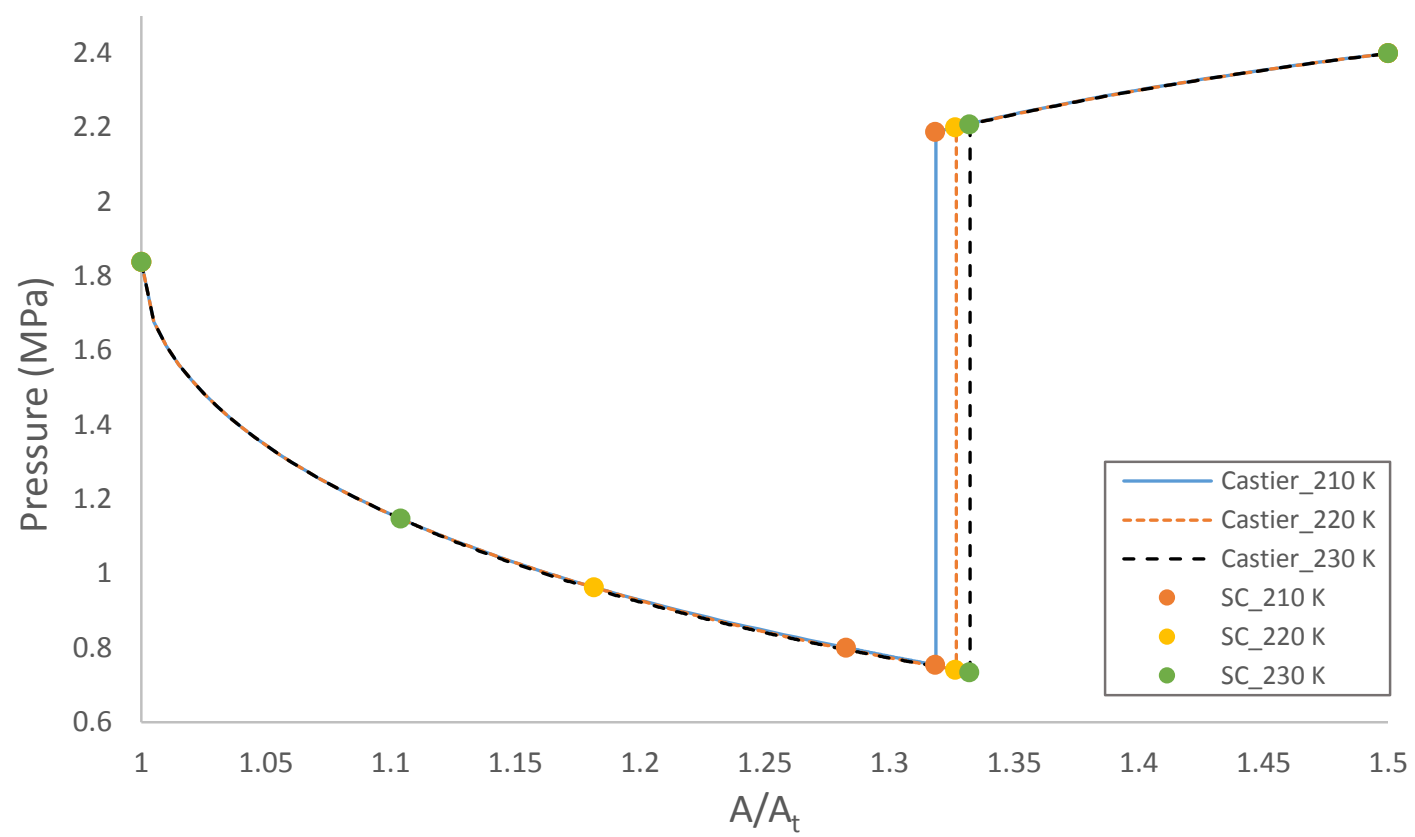

Figure 24: 13-component natural gas pressure profiles in the diverging sections of nozzles with $A_{\text {out }} / A_{t}=1.5$ and side streams at $210 \mathrm{~K}, 220 \mathrm{~K}$ and $230 \mathrm{~K}$.

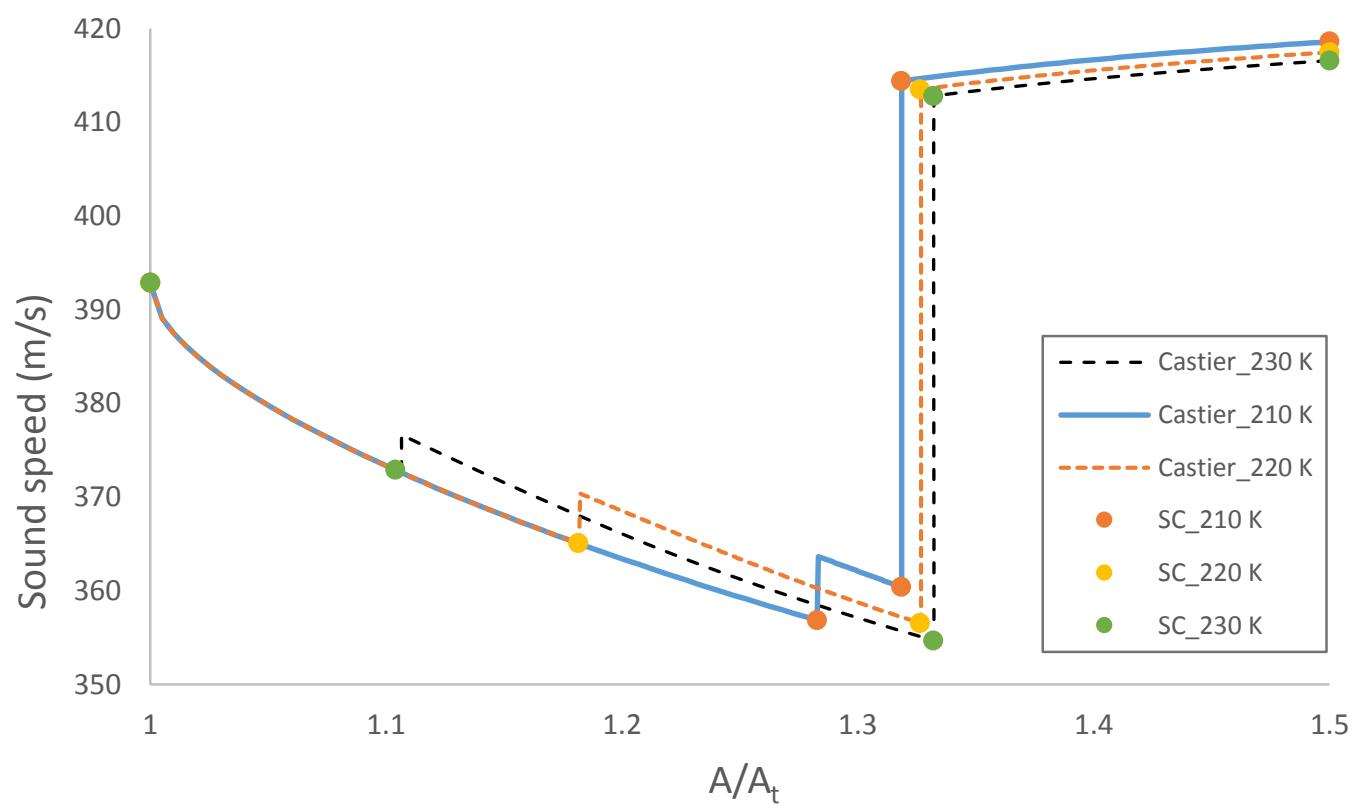

Figure 25: 13-component natural gas sound speed profiles in the diverging sections of nozzles with $A_{\text {out }} / A_{t}=1.5$ and side streams at $210 \mathrm{~K}, 220 \mathrm{~K}$ and $230 \mathrm{~K}$. 


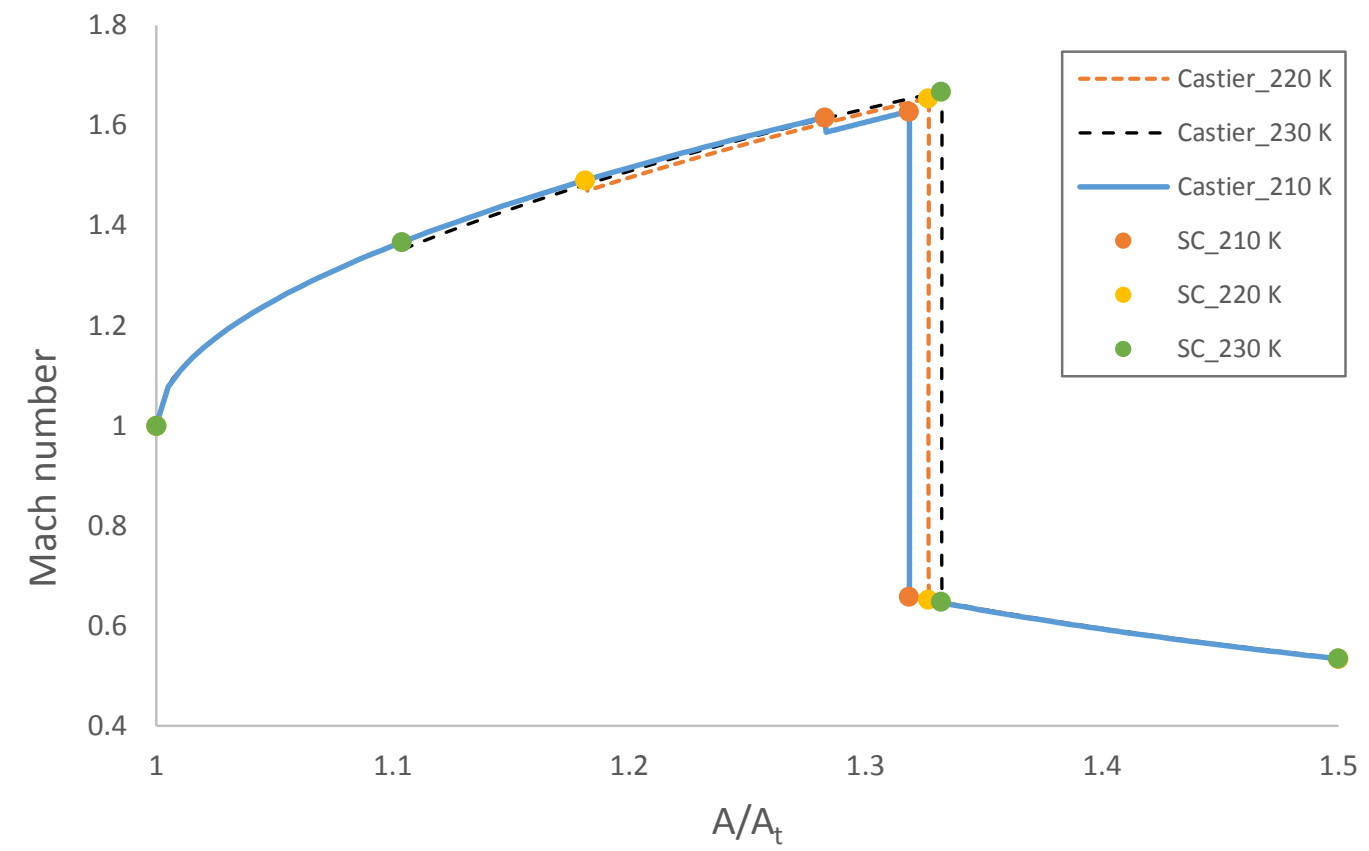

Figure 26: 13-component natural gas Mach number profiles in the diverging sections of nozzles with $A_{\text {out }} / A_{t}=1.5$ and side streams at $210 \mathrm{~K}, 220 \mathrm{~K}$ and $230 \mathrm{~K}$.

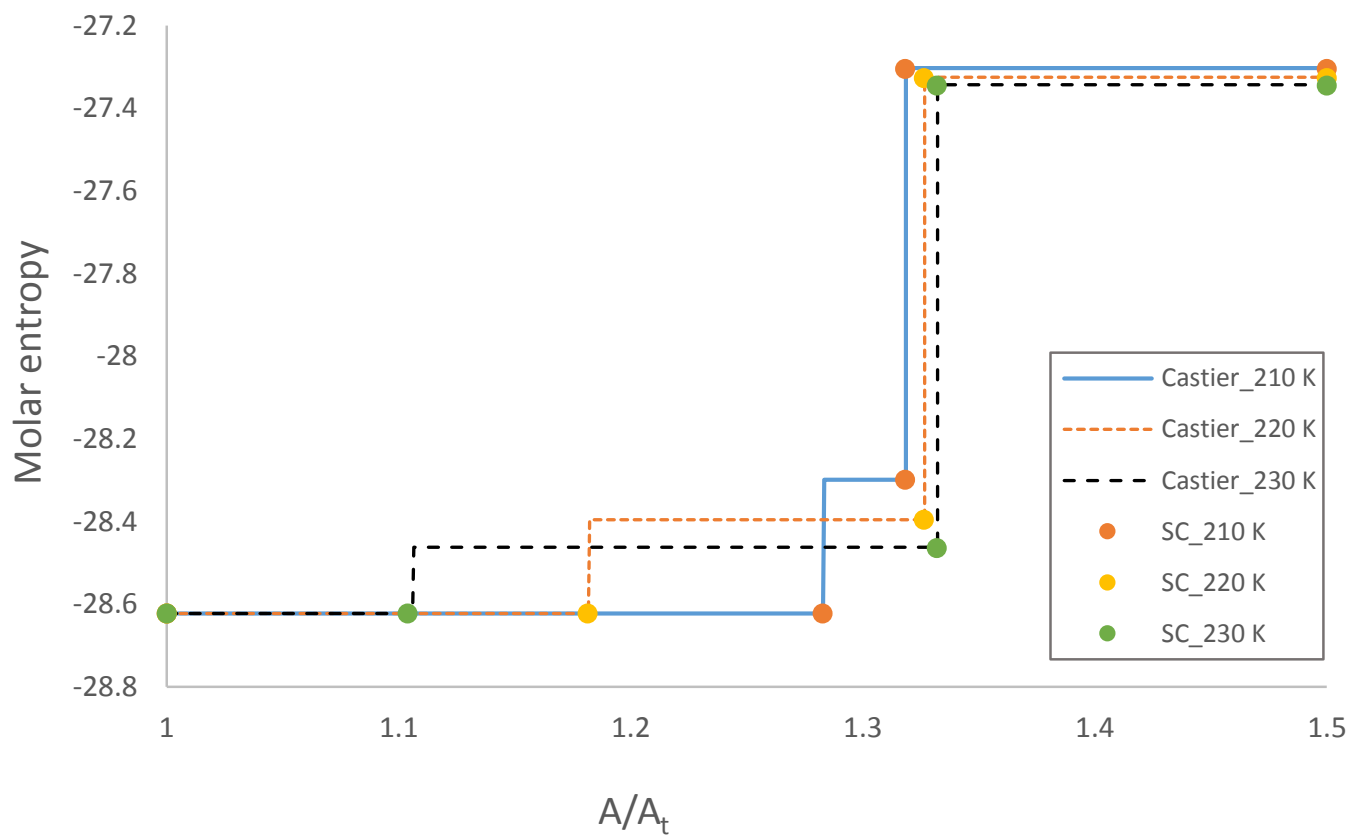

Figure 27: 13-component natural gas molar entropy profiles in the diverging sections of nozzles with $A_{\text {out }} / A_{t}=1.5$ and side streams at $210 \mathrm{~K}, 220 \mathrm{~K}$ and $230 \mathrm{~K}$. 
All results are in excellent match with the discretization method. It is important to note that the conditions at the side stream, as the second fundamental point, are the conditions just before withdrawal. This is illustrated in Figures 25 and 26 of this test as well as sound speed, flow speed or Mach number figures in the previous sets. Since the shortcut model does not produce property profiles, sound speed, flow speed and Mach number right after withdrawal cannot be obtained.

Similar to previous observations, the flow exhibits three entropy values as shown in Figure 27. However, the isentropic section between the side stream and the shockwave is longer in these tests due to the higher side stream specification temperatures. The gap between the side stream and the shockwave, therefore, is larger. Due to the nature of the stepwise-like nature of these graphs, the whole profile is graphically obtainable from the shortcut model by means of straight line data fitting. 


\subsection{Computational load}

The biggest advantage that the shortcut model has is the ability to significantly decrease computational time and computational load. This perfectly matches the purpose of the one-dimensional model as a preliminary design tool that provides essential results for the five fundamental points along the diverging nozzle starting from the throat and ending at the exit plane. CFD models are known for the demanding computational load and thus will not be a matter of discussion.

A sample of seven runs, based on numerical models, is illustrated in this section to prove the success of the shortcut model. Examples discussed here are taken from different specifications for feed conditions, nozzle area ratios liquid phase recoveries and side streams positions to demonstrate the generality and applicability of the developed model. All runs were performed on a Lenovo ThinkPad Yoga 14 with Intel CORE i7 processor.

The first set is for nozzles with area ratio $\left(A_{\text {out }} / A_{t}=1.5\right), 90 \%$ liquid phase recovery and side streams at $210 \mathrm{~K}, 220 \mathrm{~K}$ and $230 \mathrm{~K}$. Figures 28 and 29 display the simulation run times and percentage reduction achieved by the shortcut model respectively.

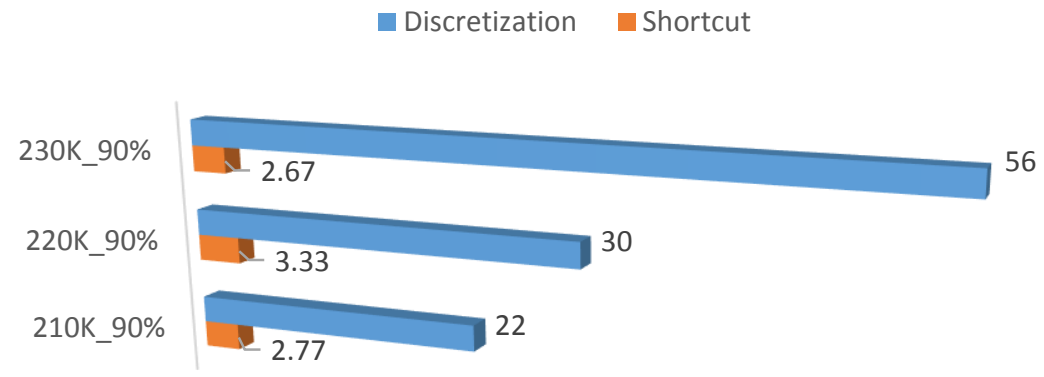

Run time (minutes)

Figure 28: Simulation run time comparison for nozzles at $A_{\text {out }} / A_{t}=1.5,90 \%$ liquid phase recovery and side streams at $210 \mathrm{~K}, 220 \mathrm{~K}$ and $230 \mathrm{~K}$. 


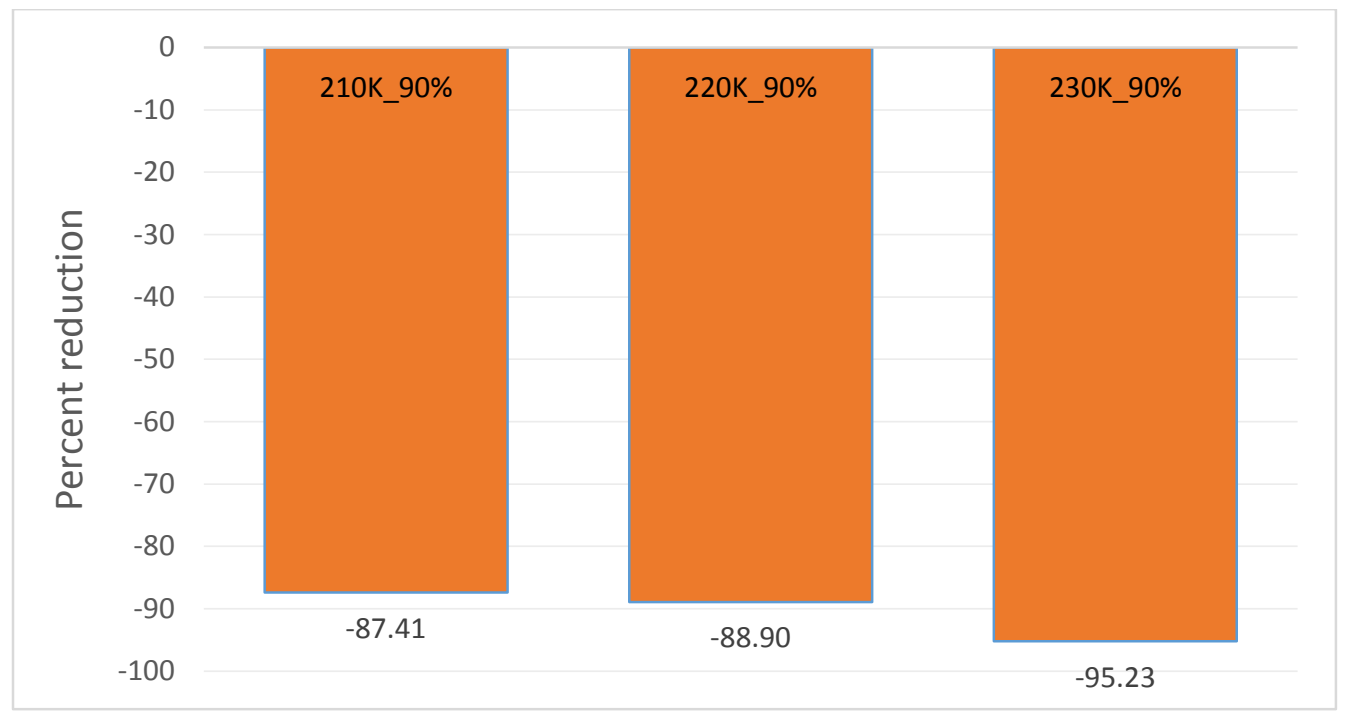

Figure 29: Percentage reduction in computational time for nozzles at $A_{\text {out }} / A_{t}=1.5$, $90 \%$ liquid phase recovery and side streams at $210 \mathrm{~K}, 220 \mathrm{~K}$ and $230 \mathrm{~K}$..

The model was able to reduce the simulation run time for all of the cases above by at least $87 \%$. The second set of tests is for nozzles with area ratio $A_{\text {out }} / A_{t}=3.0$, side stream specified at $166.7 \mathrm{~K} 90 \%$ liquid phase recoveries of $50 \%, 70 \%$ and $90 \%$. Figures 30 and 31 display the simulation run times and percentage reduction achieved by the shortcut model, respectively. 


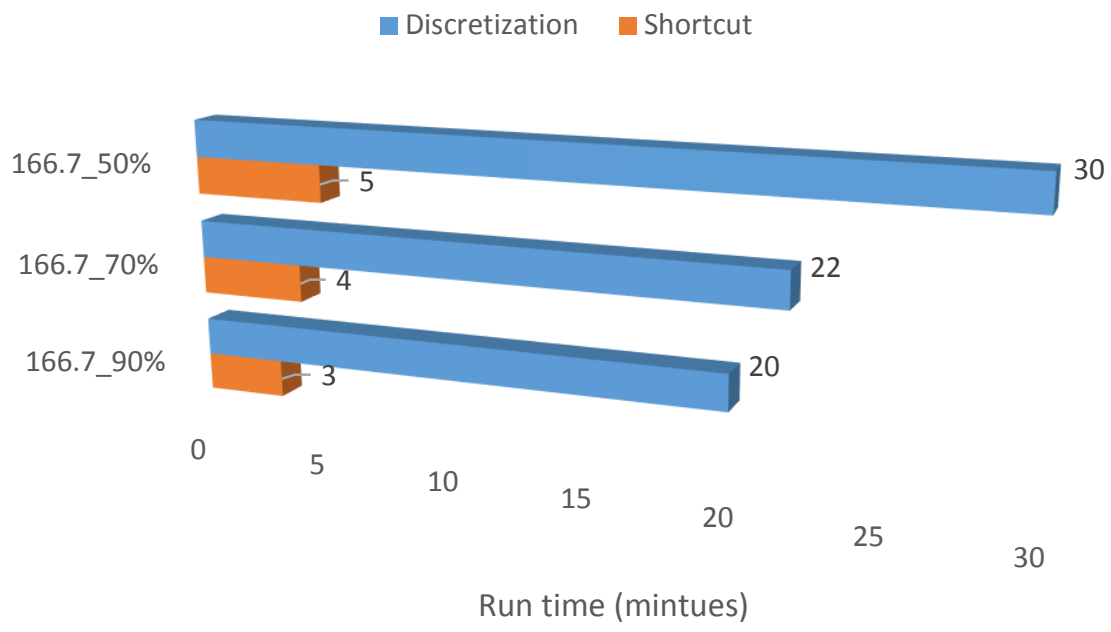

Figure 30: Simulation run time comparison for nozzles at $A_{\text {out }} / A_{t}=3.0$, side stream at $166.7 \mathrm{~K}$ and liquid phase recoveries of $50 \%, 70 \%$ and $90 \%$.

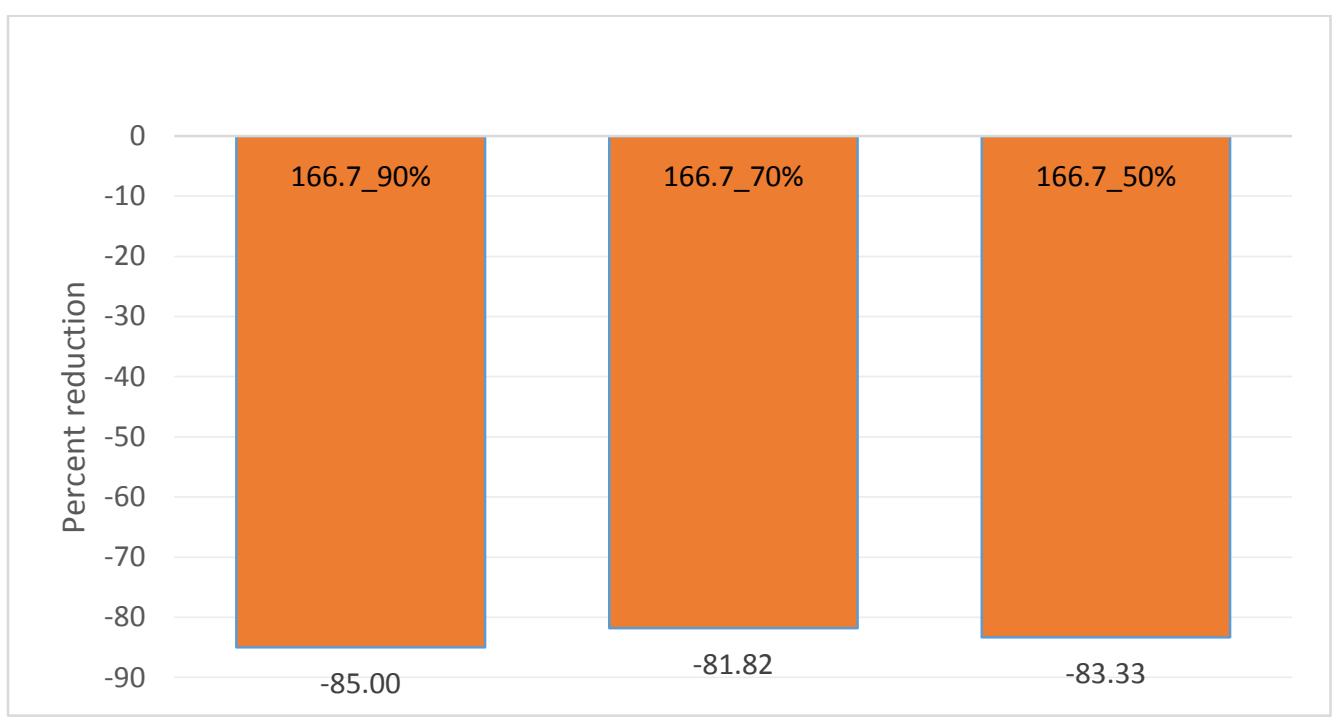

Figure 31: Percentage reduction in computational time for nozzles at $A_{\text {out }} / A_{t}=3.0$, side stream at $166.7 \mathrm{~K}$ and liquid phase recoveries of $50 \%, 70 \%$ and $90 \%$.

Similar to the first set, the simulation run time was reduced by at least $81 \%$. 
Another way of illustrating computational load reduction comes from the number of iterations and number of locations tested in the diverging section of the nozzle for the previous six runs. Table 6 lists the number of locations tested in the diverging nozzle for the discretization method versus the shortcut model in addition to percent reduction in computational load for the cases discussed above.

Table 6: Computational load comparisons.

\begin{tabular}{|c|c|c|c|c|c|}
\hline \multirow[b]{2}{*}{$\begin{array}{c}\text { Area } \\
\text { ratio } \\
\text { (Aout/At) }\end{array}$} & \multirow[b]{2}{*}{$\begin{array}{c}\text { Side stream } \\
\text { specification } \\
\text { (K) }\end{array}$} & \multicolumn{3}{|c|}{$\begin{array}{c}\text { Number of locations } \\
\text { tested in the diverging } \\
\text { nozzle }\end{array}$} & \multirow[b]{2}{*}{$\begin{array}{c}\text { Percent } \\
\text { reduction in } \\
\text { computationa } \\
\text { load }(\%)\end{array}$} \\
\hline & & $\begin{array}{l}\text { Liquid } \\
\text { phase } \\
\text { recovery }\end{array}$ & $\begin{array}{l}\text { Discretization } \\
\text { model }\end{array}$ & $\begin{array}{l}\text { Shortcut } \\
\text { model }\end{array}$ & \\
\hline \multirow{3}{*}{1.5} & 210.0 & $90 \%$ & 172 & 12 & 93.0 \\
\hline & 220.0 & $90 \%$ & 388 & 11 & 97.2 \\
\hline & 230.0 & $90 \%$ & 549 & 13 & 97.6 \\
\hline \multirow{3}{*}{3} & 166.7 & $90 \%$ & 101 & 15 & 85.1 \\
\hline & 166.7 & $70 \%$ & 139 & 16 & 88.5 \\
\hline & 166.7 & $50 \%$ & 175 & 12 & 93.1 \\
\hline
\end{tabular}

At least $85 \%$ percent less locations are tested in the diverging section. This illustrated the improvement the shortcut model provides as a preliminary design tool.

The last comparison comes from the work of Secchi et al. [17]. In this work, no side streams were modeled in nozzles. Additionally, a simplified sound speed model is 
used. The paper reports an average run time of 10 minutes for the runs but does not provide timing, computational load or number of iterations for each run.

The 10-minute average time is assumed to be the simulation time for the 3-component natural gas runs by Wen et al. [58] which were discussed earlier in section 7.2. Figure 32 shows the simulation run time comparison.

The shortcut model for the same case runs for 2.2 minutes whereas the run in the referenced work runs for 10 minutes. This shows a $78 \%$ reduction in simulation run time.

The shortcut model is able to produce results for similar run times that are relatively short even in cases with side streams which require more calculations. The shortcut model of this study also adopts a more complicated model for sound speed in multi-phase flow. Finally, 13-component natural gas mixtures were not studied by Secchi et al.

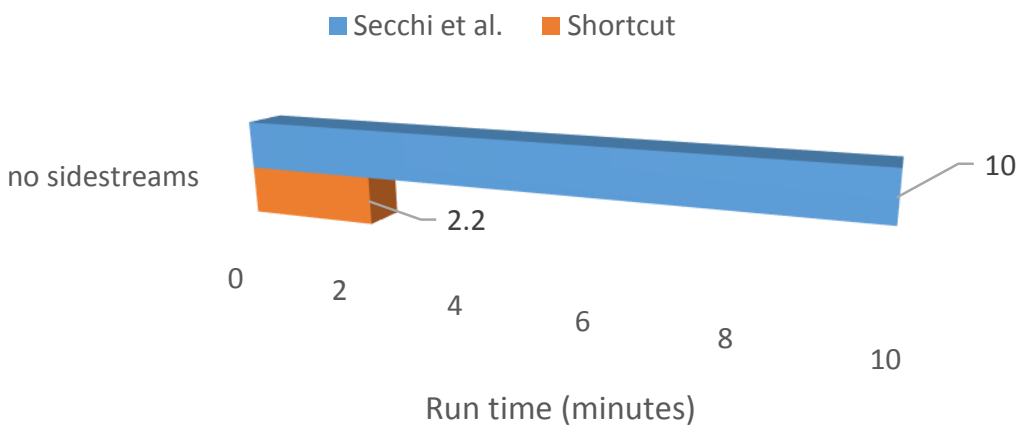

Figure 32: Simulation run time comparison for a nozzles at $A_{\text {out }} / A_{t}=4.9669,90 \%$ liquid phase recovery and no side streams. 


\section{CONCLUSIONS}

A one-dimensional thermodynamic shortcut model was developed for the conceptual preliminary design of supersonic separators. The model is comprised of rigorous thermodynamic and phase equilibrium calculations as well as multi-phase sound speed calculations. Although Peng-Robinson was used, the approach is general and compatible with other equations of state.

Significance associated with the shortcut model pertains to its the ability to simulate supersonic separators at a fraction of the time taken by other existing numerical models. Although, the results will not detail the profiles of the thermodynamic conditions along the nozzle but the six fundamental points are accurately predicted. Those points represent the inlet, nozzle throat, side stream location, upstream of the shockwave, downstream of the shockwave and the nozzle exit. These fundamental points serve as the necessary pivotal information in the design of supersonic separators.

The model was validated and cross-check with other existing models. Validation tests included different working fluids, feed conditions, nozzle geometries, specifications for side streams and liquid phase recovery specifications. Reduction in simulation run time and computational load represented by number of locations tested in the diverging section was demonstrated. A decrease of $75 \%-97 \%$, depending on the specific case, in either the simulation time, number of locations tested or both has been achieved.

In future studies, this model can be further developed by employing an equation of state of higher complexity such as the GERG-2008 EOS developed by the European Gas Research Group [18]. Furthermore, investigating the effect of having multiple side streams is also possible since the current program is developed to allow multiple withdrawal points in the nozzle. 


\section{REFERENCES}

[1] BP statistical review of world energy, 67th edition, BP p.1.c., London, United Kingdom, 2018.

[2] A. Karimi, M.A. Abdi, Selective dehydration of high-pressure natural gas using supersonic nozzles, Chem. Eng. Process. Process Intensif. 48 (2009) 560-568.

[3] C. Wen, X. Cao, Y. Yang, K. Zhang, Swirling effects on the performance of supersonic separators for natural gas separation, Chem. Eng. Technol. 34 (2011) $1575-1580$.

[4] W. Parrish, A. Kidnay, Fundamentals of Natural Gas Processing, CRC Press Taylor \& Francis Group, Florida, 2006.

[5] S.H.R. Shooshtari, A. Shahsavand, Reliable prediction of condensation rates for purification of natural gas via supersonic separators, Sep. Purif. Technol. 116 (2013) 458-470.

[6] P.B. Machado, J.G.M. Monteiro, J.L. Medeiros, H.D. Epsom, O.Q.F. Araujo, Supersonic separation in onshore natural gas dew point plant, J. Nat. Gas Sci. Eng. 6 (2012) 43-49.

[7] Eriqitai, H.A.N. Jing, D. Ran, W. Meng, Performance of dual-throat supersonic separation device with porous wall structure, Chinese J. Chem. Eng. 22 (2014) $370-382$.

[8] V.I. Alferov, Ll.A. Bagurov, V.I. Feygin, A.A. Arbatov, S.Z. Imaev, L.M. Dmitriev, V.I. Rezuneko, Method of and apparatus for the separation of components of gas mixtures and liquification of a gas, US6372019B1, 2002.

[9] M. Betting, T. van Holten, J.M.H. van Veen, Supersonic separation apparatus and method, US6524368B2, 2003.

[10] F. Okimoto, J.M. Brouwer, Supersonic gas conditioning, World Oil. 223 (2002) 89-92.

[11] M. Betting, H. Epsom, Supersonic separator gains market acceptance., World Oil. (2007) 197-200. 
[12] B. Lingling, L. Zhongliang, L. Hengwei, J. Wenming, Z. Ming, Z. Jian, Phase equilibrium calculation of multi-component gas separation of supersonic separator, Sci. China Technol. Sci. 53 (2010) 435-443.

[13] A. Borissov, G. Mirzoev, V. Shtern, Supersonic swirling separator 2 (SUSTOR 2), US8790455B2, 2014.

[14] P.H. Niknam, H.R. Mortaheb, B. Mokhtarani, Optimization of dehydration process to improve stability and efficiency of supersonic separation, J. Nat. Gas Sci. Eng. 43 (2017) 90-95.

[15] L. de O. Arinelli, T.A.F. Trotta, A.M. Teixeira, J.L. de Medeiros, O. de Q.F. Araujo, Offshore processing of $\mathrm{CO} 2$ rich natural gas with supersonic separator versus conventional routes, J. Nat. Gas Sci. Eng. 46 (2017) 199-221.

[16] J. Zhao, P. Liu, D. Hu, Flow and separation performance of supersonic gas separator, Appl. Mech. Mater. 552 (2014) 3-7.

[17] R. Secchi, G. Innocenti, D. Fiaschi, Supersonic swirling separator for natural gas heavy fractions extraction : 1D model with real gas EOS for preliminary design, J. Nat. Gas Sci. Eng. 34 (2016) 197-215.

[18] O. Kunz, W. Wagner, The GERG-2008 wide-range equation of state for natural gases and other mixtures: An expansion of GERG-2004, J. Chem. Eng. Data. 57 (2012) 3032-3091.

[19] M. Castier, Modeling and simulation of supersonic gas separations, J. Nat. Gas Sci. Eng. 18 (2014) 304-311.

[20] C. Wen, X. Cao, Y. Yang, J. Zhang, Evaluation of natural gas dehydration in supersonic swirling separators applying the Discrete Particle Method, Adv. Powder Technol. 23 (2012) 228-233.

[21] M. Castier, Effect of side streams on supersonic gas separations, J. Nat. Gas Sci. Eng. 35 (2016) 299-308.

[22] W. Chuang, C. Xuewen, Y. Yan, Z. Jing, Supersonic swirling characteristics of natural gas in convergent-divergent nozzles, Pet. Sci. 8 (2011) 114-119.

[23] W. Sun, X. Cao, W. Yang, X. Jin, Numerical simulation of CO2 condensation 
process from CH4-CO2 binary gas mixture in supersonic nozzles, Sep. Purif. Technol. 188 (2017) 238-249.

[24] J. Bian, W. Jiang, L. Teng, Y. Liu, S. Wang, Z. Deng, Structure improvements and numerical simulation of supersonic separators, Chem. Eng. Process. Process Intensif. 110 (2016) 214-219.

[25] D.A. Salikaev, O.A. Gumerov, Study of supersonic separation of associated petroleum gas using UNISIM DESIGN R400, Oil Gas Bus. 2 (2016) 151-189.

[26] F.M. Mohd Hashim, M.F.A. Ahmad, Numerical simulation of supersonic subsea compact wet gas separator for gas transmission pipeline, Appl. Mech. Mater. 607 (2014) 298-302.

[27] W. Chuang, C. Xuewen, Y. Yan, F. Yuqing, Prediction of mass flow rate in supersonic natural gas processing, Oil Gas Sci. Technol. 70 (2015) 1101-1109.

[28] M. Qingfen, H. Dapeng, H. Gaohong, H. Shijun, L. Wenwei, X. Qiaolian, W. Yuxin, Performance of inner-core supersonic gas separation device with Droplet Enlargement Method, Chinese J. Chem. Eng. 17 (2009) 925-933.

[29] S.H.R. Shooshtari, A. Shahsavand, Maximization of energy recovery inside supersonic separator in the presence of condensation and normal shock wave, Energy. 120 (2017) 153-163.

[30] Y. Yang, A. Li, C. Wen, Optimization of static vanes in a supersonic separator for gas purification, Fuel Process. Technol. 156 (2017) 265-270.

[31] Y. Yang, C. Wen, CFD modeling of particle behavior in supersonic flows with strong swirls for gas separation, Sep. Purif. Technol. 174 (2017) 22-28.

[32] E. Jassim, M.A. Abdi, Y. Muzychka, Computational fluid dynamics study for flow of natural gas through high-pressure supersonic nozzles: Part 1. real gas effects and shockwave, Pet. Sci. Technol. 26 (2008) 1757-1772.

[33] Y. Yang, C. Wen, S. Wang, Y. Feng, Numerical simulation of real gas flows in natural gas supersonic separation processing, J. Nat. Gas Sci. Eng. 21 (2014) 829836.

[34] L. Xingwei, L. Zhongliang, L. Yanxia, Investigation on separation efficiency in 
supersonic separator with gas-droplet flow based on DPM approach, Sep. Sci. Technol. 49 (2014) 2603-2612.

[35] Y. Yang, C. Wen, S. Wang, Y. Feng, Theoretical and numerical analysis on pressure recovery of supersonic separators for natural gas dehydration, Appl. Energy. 132 (2014) 248-253.

[36] Q. Xiao, H.M. Tsai, D. Papamoschou, Numerical investigation of supersonic nozzle flow separation, AIAA J. 45 (2007) 532-541.

[37] Y. Yang, C. Wen, S. Wang, Y. Feng, Effect of inlet and outlet flow conditions on natural gas parameters in supersonic separation process, PLoS One. 9 (2014).

[38] X. Cao, W. Yang, The dehydration performance evaluation of a new supersonic swirling separator, J. Nat. Gas Sci. Eng. 27 (2015) 1667-1676.

[39] C.J. Boerner, E.M. Sparrow, C.J. Scott, Compressible swirling flow through convergent-divergent nozzles, Heat Mass Transf. 5 (1972) 101-115.

[40] S. Risti, M. Kozi, M. Puhari, Experimental and numerical investigation of flow separation in supersonic nozzle, J. Russ. Laser Res. 29 (2008) 377-389.

[41] W.K. Anderson, J.L. Thomas, B. Van Leer, Comparison of finite volume flux vector splittings for the Euler equations, AIAA J. 24 (1986) 1453-1460.

[42] M. Haghighi, K.A. Hawboldt, M.A. Abdi, Supersonic gas separators: Review of latest developments, J. Nat. Gas Sci. Eng. 27 (2015) 109-121.

[43] P.H. Niknam, B. Mokhtarani, H.R. Mortaheb, Prediction of shockwave location in supersonic nozzle separation using self-organizing map classification and artificial neural network modeling, J. Nat. Gas Sci. Eng. 34 (2016) 917-924.

[44] N. Titchener, H. Babinsky, A review of the use of vortex generators for mitigating shock-induced separation, Shock Waves. 25 (2015) 473-494.

[45] Y.A. Cengel, M.A. Boles, Thermodynamics: An Engineering Approach, 5th ed., McGraw-Hill, New York, 2004.

[46] M.A. Saad, Compressible Fluid Flow, 2nd ed., Prentice- Hall., New Jersey, 1993.

[47] A. Firoozabadi, H. Pan, Two-phase isentropic compressibility and two-phase sonic velocity for multicomponent-hydrocarbon mixtures, SPE Reserv. Eval. Eng. 
3 (2000) 5-8.

[48] D.V. Nichita, P. Khalid, D. Broseta, Calculation of isentropic compressibility and sound velocity in two-phase fluids, Fluid Phase Equilib. 291 (2010) 95-102.

[49] A.B. Wood, A textbook of sound: being an account of the physics of vibrations with special reference to recent theoretical and technical developments, The Macmillan Company, New York, 1930.

[50] M. Castier, Thermodynamic speed of sound in multiphase systems, Fluid Phase Equilib. 306 (2011) 204-211.

[51] M.L. Michelsen, The isothermal flash problem. Part I. Stability, Fluid Phase Equilib. 9 (1982) 1-19.

[52] M.L. Michelsen, The isothermal flash problem. Part II. Phase-split calculation, Fluid Phase Equilib. 9 (1982) 21-40.

[53] C. Wen, A. Li, J. Honore, Y. Yang, Effect of swirling device on flow behavior in a supersonic separator for natural gas dehydration, Sep. Purif. Technol. 168 (2016) 68-73.

[54] K. Wark, Advanced Thermodynamics for Engineers, McGraw-Hill, New York, 1995.

[55] D.Y. Peng, D.B. Robinson, A new two-constant equation of state, Ind. Eng. Chem. Fundam. 15 (1976) 59-64.

[56] T.Y. Kwak, G.A. Mansoori, Rules for Cubic Equations, Chem. Eng. Sci. 41 (1986) 1303-1986.

[57] R. Arina, Numerical simulation of near-critical fluids, Appl. Numer. Math. 51 (2004) 409-426.

[58] C. Wen, X. Cao, Y. Yang, W. Li, An unconventional supersonic liquefied technology for natural gas, Energy Educ. Sci. Technol. Part A Energy Sci. Res. 30 (2012) 651-660.

[59] X. Cao, W. Yang, Numerical simulation of binary-gas condensation characteristics in supersonic nozzles, J. Nat. Gas Sci. Eng. 25 (2015) 197-206.

[60] J. Dengyu, Q. Eri, C. Wang, H. Liu, Y. Yuan, A fast and efficiency numerical 
simulation method for supersonic gas processing, SPE 131239. (2010).

[61] E. Jassim, M.A. Abdi, Y. Muzychka, Computational fluid dynamics study for flow of natural gas through high-pressure supersonic nozzles: Part 2. Nozzle geometry and vorticity, Pet. Sci. Technol. 26 (2008) 1773-1785.

[62] J.W.F. Janssen, M. Betting, Combined test with the improved performance TWISTER ${ }^{\mathrm{TM}}$ supersonic separator and the GASUNIE cyclone separator, in: 23rd World Gas Conf., Amesterdam, 2006.

[63] I. Kanpur, Convergent-Divergent Nozzle, (2009). https://nptel.ac.in/courses/112104118/lecture-40/40_4_nozzle.htm. 
APPENDIX A

TABULATED RESULTS 
Table A.1: Results for air expansion in a nozzle with $A_{\text {out }} / A_{t}=3.0$ and no side streams.

\begin{tabular}{lcccc}
\hline Dimensionless length & $\mathbf{5}$ & $\mathbf{6 . 9 9 1 2 8 5}$ & $\mathbf{6 . 9 9 1 2 8 5}$ & $\mathbf{9 . 9 8 3 8 2}$ \\
\hline Number of phases & 1 & 1 & 1 & 1 \\
\hline Area ratio & 1 & 1.174746 & 1.174746 & 1.499984 \\
\hline Temperature $(\boldsymbol{K})$ & 242.90 & 201.40 & 265.24 & 278.85 \\
\hline Pressure $(\boldsymbol{M P a})$ & $5.50 \mathrm{E}-02$ & $2.85 \mathrm{E}-02$ & $6.97 \mathrm{E}-02$ & $8.30 \mathrm{E}-02$ \\
\hline Molar entropy $(\boldsymbol{J} / \mathbf{m o l} \cdot \boldsymbol{K})$ & 3.2423 & 3.2423 & 3.8409 & 3.8409 \\
\hline Molar volume $\left(\boldsymbol{m}^{\mathbf{3}} / \mathbf{m o l}\right)$ & $3.67 \mathrm{E}-02$ & $5.88 \mathrm{E}-02$ & $3.16 \mathrm{E}-02$ & $2.79 \mathrm{E}-02$ \\
\hline Molar density $\left(\mathbf{m o l} / \mathbf{m}^{\mathbf{3}}\right)$ & 27.240 & 17.009 & 31.617 & 35.845 \\
\hline Mass density $\left(\boldsymbol{k g} / \mathbf{m}^{\mathbf{3}}\right)$ & 0.785771 & 0.490649 & 0.912006 & $-3.12 \mathrm{E}-64$ \\
\hline Flow speed $(\boldsymbol{m} / \boldsymbol{s})$ & 312.78 & 426.41 & 229.40 & 158.47 \\
\hline Sound speed $(\boldsymbol{m} / \boldsymbol{s})$ & 312.78 & 284.66 & 326.91 & 335.21 \\
\hline Mach number & 1 & 1.497964 & 0.701725 & 0.472737 \\
\hline
\end{tabular}

Table A.2: Results for 3-component natural gas in a nozzle with $A_{\text {out }} / A_{t}=4.9669$ and no side streams.

\begin{tabular}{|c|c|c|c|c|}
\hline Number of phases & 1 & 2 & 1 & 1 \\
\hline Area ratio & 1 & 3.017895 & 3.017895 & 4.962597 \\
\hline Temperature $(K)$ & 210.18 & 157.41 & 219.52 & 224.70 \\
\hline Pressure $(M P a)$ & 6.0183 & 1.2498 & 6.3971 & 7.0000 \\
\hline Molar entropy $(\mathrm{J} / \mathrm{mol} \cdot \mathrm{K})$ & -56.132 & -56.132 & -52.862 & -52.863 \\
\hline Molar volume $\left(\mathrm{m}^{3} / \mathrm{mol}\right)$ & $1.31 \mathrm{E}-04$ & $6.04 \mathrm{E}-04$ & $1.55 \mathrm{E}-04$ & $1.48 \mathrm{E}-04$ \\
\hline Molar density $\left(\mathrm{mol} / \mathrm{m}^{3}\right)$ & 7643.8 & 1655.3 & 6461.3 & 6774.5 \\
\hline Mass density $\left(\mathrm{kg} / \mathrm{m}^{3}\right)$ & 127.9134 & 27.69965 & 108.1253 & $-1.81 \mathrm{E}-64$ \\
\hline Flow speed $(m / s)$ & 326.64 & 499.82 & 128.05 & 74.269 \\
\hline Sound speed $(m / s)$ & 326.64 & 218.94 & 334.20 & 344.50 \\
\hline Mach number & 1 & 2.282959 & 0.383141 & 0.215584 \\
\hline \multicolumn{5}{|c|}{ Gas phase } \\
\hline Gas phase fraction & 1 & 0.703011 & 1 & 1 \\
\hline Methane & 0.96044 & 0.9967 & 0.96044 & 0.96044 \\
\hline Ethane & $2.98 \mathrm{E}-02$ & $3.22 \mathrm{E}-03$ & $2.98 \mathrm{E}-02$ & $2.98 \mathrm{E}-02$ \\
\hline Propane & $9.76 \mathrm{E}-03$ & 8.01E-05 & $9.76 \mathrm{E}-03$ & $9.76 \mathrm{E}-03$ \\
\hline \multicolumn{5}{|c|}{ Liquid phase } \\
\hline Liquid phase fraction & & 0.296989 & & \\
\hline Methane & & 0.874607 & & \\
\hline Ethane & & $9.27 \mathrm{E}-02$ & & \\
\hline Propane & & $3.27 \mathrm{E}-02$ & & \\
\hline
\end{tabular}


Table A.3: Results for 13-component natural gas in a nozzle with $A_{\text {out }} / A_{t}=1.5$ and no side streams.

\begin{tabular}{|c|c|c|c|c|}
\hline Number of phases & 2 & 2 & 2 & 2 \\
\hline Area ratio & 1 & 1.526822 & 1.526822 & 1.499998 \\
\hline Temperature $(K)$ & 216.69 & 170.04 & 230.58 & 229.74 \\
\hline Pressure $(\mathrm{MPa})$ & 4.6017 & 1.6293 & 5.3427 & 5.2700 \\
\hline Molar entropy $(\mathrm{J} / \mathrm{mol} \cdot \mathrm{K})$ & -47.387 & -47.390 & -46.073 & -46.070 \\
\hline Molar volume $\left(\mathrm{m}^{3} / \mathrm{mol}\right)$ & $2.62 \mathrm{E}-04$ & $6.26 \mathrm{E}-04$ & $2.50 \mathrm{E}-04$ & $2.53 \mathrm{E}-04$ \\
\hline Molar density $\left(\mathrm{mol} / \mathrm{m}^{3}\right)$ & 3811.7 & 1596.5 & 4000.3 & 3960.4 \\
\hline Mass density $\left(\mathrm{kg} / \mathrm{m}^{3}\right)$ & 64.58662 & 27.05163 & 67.78332 & $-1.83 \mathrm{E}-64$ \\
\hline Flow speed $(m / s)$ & 305.64 & 477.94 & 190.75 & 196.12 \\
\hline Sound speed $(m / s)$ & 305.64 & 262.92 & 330.50 & 329.22 \\
\hline Mach number & 1 & 1.817818 & 0.57715 & 0.595702 \\
\hline \multicolumn{5}{|c|}{ Gas phase } \\
\hline Gas phase fraction & 0.985633 & 0.909887 & 0.994009 & 0.993677 \\
\hline Carbon dioxide & $1.34 \mathrm{E}-03$ & $6.11 \mathrm{E}-04$ & $1.38 \mathrm{E}-03$ & $1.38 \mathrm{E}-03$ \\
\hline Nitrogen & 2.01E-03 & $2.15 \mathrm{E}-03$ & $1.99 \mathrm{E}-03$ & $1.99 \mathrm{E}-03$ \\
\hline Methane & 0.966587 & 0.987958 & 0.963284 & 0.963441 \\
\hline Ethane & 2.22E-02 & 8.91E-03 & 2.29E-02 & $2.28 \mathrm{E}-02$ \\
\hline Propane & $5.56 \mathrm{E}-03$ & 3.38E-04 & $6.49 \mathrm{E}-03$ & $6.46 \mathrm{E}-03$ \\
\hline iso-butane & $1.20 \mathrm{E}-03$ & $1.79 \mathrm{E}-05$ & $1.73 \mathrm{E}-03$ & $1.70 \mathrm{E}-03$ \\
\hline n-butane & 8.09E-04 & 7.59E-06 & $1.33 \mathrm{E}-03$ & $1.30 \mathrm{E}-03$ \\
\hline iso-pentane & $2.20 \mathrm{E}-04$ & $6.80 \mathrm{E}-07$ & 5.29E-04 & $5.08 \mathrm{E}-04$ \\
\hline n-pentane & $8.43 \mathrm{E}-05$ & $1.87 \mathrm{E}-07$ & 2.34E-04 & 2.22E-04 \\
\hline n-hexane & $2.60 \mathrm{E}-05$ & $1.85 \mathrm{E}-08$ & $1.12 \mathrm{E}-04$ & $1.02 \mathrm{E}-04$ \\
\hline n-heptane & $7.88 \mathrm{E}-06$ & 1.99E-09 & 4.49E-05 & $4.00 \mathrm{E}-05$ \\
\hline n-octane & 8.33E-07 & $7.62 \mathrm{E}-11$ & 5.73E-06 & $5.02 \mathrm{E}-06$ \\
\hline n-nonane & $1.20 \mathrm{E}-08$ & $4.03 \mathrm{E}-13$ & $9.62 \mathrm{E}-08$ & 8.31E-08 \\
\hline \multicolumn{5}{|c|}{ Liquid phase } \\
\hline Liquid phase fraction & $1.44 \mathrm{E}-02$ & 9.01E-02 & 5.99E-03 & $6.32 \mathrm{E}-03$ \\
\hline Carbon dioxide & 4.95E-03 & $9.28 \mathrm{E}-03$ & $3.88 \mathrm{E}-03$ & $3.94 \mathrm{E}-03$ \\
\hline Nitrogen & $3.60 \mathrm{E}-04$ & $2.78 \mathrm{E}-04$ & $3.44 \mathrm{E}-04$ & $3.42 \mathrm{E}-04$ \\
\hline Methane & 0.53468 & 0.681932 & 0.478736 & 0.479573 \\
\hline Ethane & 9.27E-02 & 0.167091 & 7.26E-02 & 7.37E-02 \\
\hline Propane & 9.95E-02 & 7.33E-02 & 7.71E-02 & 7.89E-02 \\
\hline iso-butane & 5.84E-02 & $2.22 \mathrm{E}-02$ & 5.07E-02 & $5.18 \mathrm{E}-02$ \\
\hline n-butane & 6.07E-02 & $1.85 \mathrm{E}-02$ & $5.81 \mathrm{E}-02$ & $5.92 \mathrm{E}-02$ \\
\hline iso-pentane & 4.58E-02 & $9.70 \mathrm{E}-03$ & 5.82E-02 & $5.85 \mathrm{E}-02$ \\
\hline n-pentane & $2.53 \mathrm{E}-02$ & 4.96E-03 & $3.58 \mathrm{E}-02$ & $3.57 \mathrm{E}-02$ \\
\hline n-hexane & $2.97 \mathrm{E}-02$ & $5.02 \mathrm{E}-03$ & 5.69E-02 & $5.54 \mathrm{E}-02$ \\
\hline n-heptane & 3.39E-02 & $5.50 \mathrm{E}-03$ & 7.53E-02 & $7.21 \mathrm{E}-02$ \\
\hline n-octane & 1.32E-02 & $2.11 \mathrm{E}-03$ & $3.08 \mathrm{E}-02$ & $2.93 \mathrm{E}-02$ \\
\hline n-nonane & $6.86 \mathrm{E}-04$ & $1.10 \mathrm{E}-04$ & $1.63 \mathrm{E}-03$ & $1.55 \mathrm{E}-03$ \\
\hline
\end{tabular}


Table A.4: Results for 13-component natural gas in a nozzle with $A_{\text {out }} / A_{t}=3.0$ and no side streams.

\begin{tabular}{|c|c|c|c|c|}
\hline Number of phases & 2 & 2 & $\mathbf{2}$ & 2 \\
\hline Area ratio & 1 & 1.938573 & 1.938573 & 3 \\
\hline Temperature $(K)$ & 216.69 & 158.52 & 226.32 & 233.94 \\
\hline Pressure (MPa) & 4.6017 & 1.1185 & 4.6628 & 5.2700 \\
\hline Molar entropy $(\mathrm{J} / \mathrm{mol} \cdot \mathrm{K})$ & -47.387 & -47.388 & -45.047 & -45.051 \\
\hline Molar volume $\left(\mathrm{m}^{3} / \mathrm{mol}\right)$ & $2.62 \mathrm{E}-04$ & 8.69E-04 & $2.90 \mathrm{E}-04$ & $2.65 \mathrm{E}-04$ \\
\hline Molar density $\left(\mathrm{mol} / \mathrm{m}^{3}\right)$ & 3811.7 & 1151.0 & 3452.5 & 3778.2 \\
\hline Mass density $\left(\mathrm{kg} / \mathrm{m}^{3}\right)$ & 64.58662 & 19.50285 & 58.50129 & $-1.83 \mathrm{E}-64$ \\
\hline Flow speed $(m / s)$ & 305.64 & 522.13 & 174.06 & 102.78 \\
\hline Sound speed $(\mathrm{m} / \mathrm{s})$ & 305.64 & 257.16 & 326.80 & 337.25 \\
\hline Mach number & 1 & 2.030348 & 0.532634 & 0.304755 \\
\hline \multicolumn{5}{|c|}{ Gas phase } \\
\hline Gas phase fraction & 0.985633 & 0.881964 & 0.992366 & 0.995134 \\
\hline Carbon dioxide & $1.34 \mathrm{E}-03$ & $3.62 \mathrm{E}-04$ & $1.37 \mathrm{E}-03$ & $1.38 \mathrm{E}-03$ \\
\hline Nitrogen & $2.01 \mathrm{E}-03$ & $2.22 \mathrm{E}-03$ & $2.00 \mathrm{E}-03$ & 1.99E-03 \\
\hline Methane & 0.966587 & 0.992235 & 0.964249 & 0.962871 \\
\hline Ethane & $2.22 \mathrm{E}-02$ & $5.07 \mathrm{E}-03$ & $2.27 \mathrm{E}-02$ & $2.29 \mathrm{E}-02$ \\
\hline Propane & $5.56 \mathrm{E}-03$ & $1.12 \mathrm{E}-04$ & $6.27 \mathrm{E}-03$ & $6.59 \mathrm{E}-03$ \\
\hline iso-butane & $1.20 \mathrm{E}-03$ & 4.49E-06 & $1.57 \mathrm{E}-03$ & $1.79 \mathrm{E}-03$ \\
\hline n-butane & 8.09E-04 & $1.74 \mathrm{E}-06$ & $1.16 \mathrm{E}-03$ & $1.40 \mathrm{E}-03$ \\
\hline iso-pentane & $2.20 \mathrm{E}-04$ & $1.20 \mathrm{E}-07$ & $3.96 \mathrm{E}-04$ & $5.82 \mathrm{E}-04$ \\
\hline n-pentane & $8.43 \mathrm{E}-05$ & $3.00 \mathrm{E}-08$ & $1.64 \mathrm{E}-04$ & $2.62 \mathrm{E}-04$ \\
\hline n-hexane & $2.60 \mathrm{E}-05$ & 2.09E-09 & $6.11 \mathrm{E}-05$ & $1.35 \mathrm{E}-04$ \\
\hline n-heptane & $7.88 \mathrm{E}-06$ & $1.59 \mathrm{E}-10$ & $2.04 \mathrm{E}-05$ & $5.65 \mathrm{E}-05$ \\
\hline n-octane & 8.33E-07 & 4.29E-12 & 2.27E-06 & 7.34E-06 \\
\hline n-nonane & $1.20 \mathrm{E}-08$ & $1.60 \mathrm{E}-14$ & $3.41 \mathrm{E}-08$ & $1.24 \mathrm{E}-07$ \\
\hline \multicolumn{5}{|c|}{ Liquid phase } \\
\hline Liquid phase fraction & $1.44 \mathrm{E}-02$ & 0.118037 & 7.63E-03 & 4.87E-03 \\
\hline Carbon dioxide & $4.95 \mathrm{E}-03$ & 9.09E-03 & 4.17E-03 & $3.66 \mathrm{E}-03$ \\
\hline Nitrogen & $3.60 \mathrm{E}-04$ & $2.48 \mathrm{E}-04$ & $3.08 \mathrm{E}-04$ & $3.22 \mathrm{E}-04$ \\
\hline Methane & 0.53468 & 0.722367 & 0.457571 & 0.45117 \\
\hline Ethane & $9.27 \mathrm{E}-02$ & 0.158408 & 7.90E-02 & $6.88 \mathrm{E}-02$ \\
\hline Propane & $9.95 \mathrm{E}-02$ & $5.77 \mathrm{E}-02$ & $9.05 \mathrm{E}-02$ & 7.41E-02 \\
\hline iso-butane & $5.84 \mathrm{E}-02$ & $1.71 \mathrm{E}-02$ & $6.04 \mathrm{E}-02$ & 4.97E-02 \\
\hline n-butane & $6.07 \mathrm{E}-02$ & $1.41 \mathrm{E}-02$ & $6.81 \mathrm{E}-02$ & $5.79 \mathrm{E}-02$ \\
\hline iso-pentane & $4.58 \mathrm{E}-02$ & 7.41E-03 & $6.32 \mathrm{E}-02$ & $6.08 \mathrm{E}-02$ \\
\hline n-pentane & $2.53 \mathrm{E}-02$ & $3.79 \mathrm{E}-03$ & $3.73 \mathrm{E}-02$ & $3.81 \mathrm{E}-02$ \\
\hline n-hexane & $2.97 \mathrm{E}-02$ & 3.83E-03 & $5.13 \mathrm{E}-02$ & $6.54 \mathrm{E}-02$ \\
\hline n-heptane & 3.39E-02 & $4.20 \mathrm{E}-03$ & $6.23 \mathrm{E}-02$ & $9.03 \mathrm{E}-02$ \\
\hline n-octane & $1.32 \mathrm{E}-02$ & $1.61 \mathrm{E}-03$ & $2.46 \mathrm{E}-02$ & $3.76 \mathrm{E}-02$ \\
\hline n-nonane & $6.86 \mathrm{E}-04$ & $8.36 \mathrm{E}-05$ & $1.29 \mathrm{E}-03$ & $2.00 \mathrm{E}-03$ \\
\hline
\end{tabular}


Table A.5: Results for 13-component natural gas in a nozzle with $A_{\text {out }} / A_{t}=4.5$ and no side streams.

\begin{tabular}{|c|c|c|c|c|}
\hline Number of phases & 2 & 2 & 2 & 2 \\
\hline Area ratio & 1 & 2.027606 & 2.027606 & 4.5 \\
\hline Temperature $(K)$ & 216.69 & 156.64 & 225.39 & 234.84 \\
\hline Pressure $(\mathrm{MPa})$ & 4.6017 & 1.0450 & 4.5287 & 5.2700 \\
\hline Molar entropy $(\mathrm{J} / \mathrm{mol} \cdot \mathrm{K})$ & -47.387 & -47.388 & -44.842 & -44.842 \\
\hline Molar volume $\left(\mathrm{m}^{3} / \mathrm{mol}\right)$ & $2.62 \mathrm{E}-04$ & 9.22E-04 & $2.99 \mathrm{E}-04$ & $2.67 \mathrm{E}-04$ \\
\hline Molar density $\left(\mathrm{mol} / \mathrm{m}^{3}\right)$ & 3811.7 & 1085.1 & 3346.8 & 3742.5 \\
\hline Mass density $\left(\mathrm{kg} / \mathrm{m}^{3}\right)$ & 64.58662 & 18.38634 & 56.70968 & $-1.83 \mathrm{E}-64$ \\
\hline Flow speed $(\mathrm{m} / \mathrm{s})$ & 305.64 & 529.52 & 171.68 & 69.170 \\
\hline Sound speed $(\mathrm{m} / \mathrm{s})$ & 305.64 & 256.15 & 326.17 & 338.86 \\
\hline Mach number & 1 & 2.067219 & 0.526346 & 0.204127 \\
\hline \multicolumn{5}{|c|}{ Gas phase } \\
\hline Gas phase fraction & 0.985633 & 0.877221 & 0.992013 & 0.995394 \\
\hline Carbon dioxide & $1.34 \mathrm{E}-03$ & $3.28 \mathrm{E}-04$ & $1.37 \mathrm{E}-03$ & $1.38 \mathrm{E}-03$ \\
\hline Nitrogen & $2.01 \mathrm{E}-03$ & $2.23 \mathrm{E}-03$ & $2.00 \mathrm{E}-03$ & $1.99 \mathrm{E}-03$ \\
\hline Methane & 0.966587 & 0.992782 & 0.964464 & 0.962763 \\
\hline Ethane & $2.22 \mathrm{E}-02$ & $4.57 \mathrm{E}-03$ & $2.27 \mathrm{E}-02$ & $2.30 \mathrm{E}-02$ \\
\hline Propane & $5.56 \mathrm{E}-03$ & $9.31 \mathrm{E}-05$ & $6.22 \mathrm{E}-03$ & $6.61 \mathrm{E}-03$ \\
\hline iso-butane & $1.20 \mathrm{E}-03$ & $3.55 \mathrm{E}-06$ & $1.53 \mathrm{E}-03$ & $1.80 \mathrm{E}-03$ \\
\hline n-butane & 8.09E-04 & $1.35 \mathrm{E}-06$ & $1.12 \mathrm{E}-03$ & $1.41 \mathrm{E}-03$ \\
\hline iso-pentane & $2.20 \mathrm{E}-04$ & 8.91E-08 & $3.69 \mathrm{E}-04$ & $5.97 \mathrm{E}-04$ \\
\hline n-pentane & $8.43 \mathrm{E}-05$ & 2.19E-08 & $1.50 \mathrm{E}-04$ & $2.71 \mathrm{E}-04$ \\
\hline n-hexane & $2.60 \mathrm{E}-05$ & $1.44 \mathrm{E}-09$ & $5.35 \mathrm{E}-05$ & $1.43 \mathrm{E}-04$ \\
\hline n-heptane & $7.88 \mathrm{E}-06$ & $1.03 \mathrm{E}-10$ & $1.72 \mathrm{E}-05$ & $6.08 \mathrm{E}-05$ \\
\hline n-octane & 8.33E-07 & $2.61 \mathrm{E}-12$ & $1.88 \mathrm{E}-06$ & 7.97E-06 \\
\hline n-nonane & $1.20 \mathrm{E}-08$ & $9.17 \mathrm{E}-15$ & $2.75 \mathrm{E}-08$ & $1.35 \mathrm{E}-07$ \\
\hline \multicolumn{5}{|c|}{ Liquid phase } \\
\hline Liquid phase fraction & $1.44 \mathrm{E}-02$ & 0.122779 & 7.99E-03 & $4.61 \mathrm{E}-03$ \\
\hline Carbon dioxide & $4.95 \mathrm{E}-03$ & $9.00 \mathrm{E}-03$ & $4.24 \mathrm{E}-03$ & $3.60 \mathrm{E}-03$ \\
\hline Nitrogen & $3.60 \mathrm{E}-04$ & $2.43 \mathrm{E}-04$ & $3.00 \mathrm{E}-04$ & $3.18 \mathrm{E}-04$ \\
\hline Methane & 0.53468 & 0.728888 & 0.453226 & 0.445588 \\
\hline Ethane & $9.27 \mathrm{E}-02$ & 0.156076 & $8.04 \mathrm{E}-02$ & $6.78 \mathrm{E}-02$ \\
\hline Propane & $9.95 \mathrm{E}-02$ & $5.57 \mathrm{E}-02$ & $9.35 \mathrm{E}-02$ & 7.31E-02 \\
\hline iso-butane & $5.84 \mathrm{E}-02$ & $1.64 \mathrm{E}-02$ & $6.24 \mathrm{E}-02$ & 4.92E-02 \\
\hline n-butane & $6.07 \mathrm{E}-02$ & $1.36 \mathrm{E}-02$ & 7.01E-02 & $5.74 \mathrm{E}-02$ \\
\hline iso-pentane & $4.58 \mathrm{E}-02$ & 7.13E-03 & $6.38 \mathrm{E}-02$ & $6.10 \mathrm{E}-02$ \\
\hline n-pentane & $2.53 \mathrm{E}-02$ & $3.64 \mathrm{E}-03$ & $3.73 \mathrm{E}-02$ & $3.85 \mathrm{E}-02$ \\
\hline n-hexane & 2.97E-02 & $3.68 \mathrm{E}-03$ & $5.00 \mathrm{E}-02$ & $6.74 \mathrm{E}-02$ \\
\hline n-heptane & 3.39E-02 & $4.04 \mathrm{E}-03$ & $5.99 \mathrm{E}-02$ & 0.09443 \\
\hline n-octane & $1.32 \mathrm{E}-02$ & $1.55 \mathrm{E}-03$ & $2.36 \mathrm{E}-02$ & $3.96 \mathrm{E}-02$ \\
\hline n-nonane & $6.86 \mathrm{E}-04$ & $8.04 \mathrm{E}-05$ & $1.23 \mathrm{E}-03$ & $2.11 \mathrm{E}-03$ \\
\hline
\end{tabular}


Table A.6: Results for 13-component natural gas in a nozzle with $A_{\text {out }} / A_{t}=3.0$ and side stream at 166.7 $K$ and $50 \%$ liquid recovery.

\begin{tabular}{|c|c|c|c|c|c|}
\hline Number of phases & 2 & 2 & 2 & 2 & 2 \\
\hline Area ratio & 1 & 1.62674 & 1.773842 & 1.773842 & 3 \\
\hline Temperature $(K)$ & 216.69 & 166.70 & 161.91 & 229.26 & 240.27 \\
\hline Pressure $(M P a)$ & 4.6017 & 1.4704 & 1.2718 & 4.4630 & 5.2700 \\
\hline Molar entropy $(\mathrm{J} / \mathrm{mol} \cdot \mathrm{K})$ & -47.387 & -47.388 & -45.329 & -43.764 & -43.764 \\
\hline Molar volume $\left(\mathrm{m}^{3} / \mathrm{mol}\right)$ & $2.62 \mathrm{E}-04$ & $6.85 \mathrm{E}-04$ & 8.12E-04 & $3.22 \mathrm{E}-04$ & $2.86 \mathrm{E}-04$ \\
\hline Molar density $\left(\mathrm{mol} / \mathrm{m}^{3}\right)$ & 3811.7 & 1459.8 & 1231.5 & 3103.7 & 3492.3 \\
\hline Mass density $\left(\mathrm{kg} / \mathrm{m}^{3}\right)$ & 64.58662 & 24.73615 & 20.42956 & 51.48927 & $-1.79 \mathrm{E}-64$ \\
\hline Flow speed $(m / s)$ & 305.64 & 490.58 & 508.88 & 201.91 & 106.09 \\
\hline Sound speed $(\mathrm{m} / \mathrm{s})$ & 305.64 & 261.28 & 270.44 & 347.95 & 359.41 \\
\hline Mach number & 1 & 1.877569 & 1.881671 & 0.580277 & 0.295189 \\
\hline \multicolumn{6}{|c|}{ Gas phase } \\
\hline Gas phase fraction & 0.985633 & 0.901998 & 0.937007 & 0.998424 & 0.999306 \\
\hline Carbon dioxide & $1.34 \mathrm{E}-03$ & $5.33 \mathrm{E}-04$ & $4.33 \mathrm{E}-04$ & $9.82 \mathrm{E}-04$ & $9.84 \mathrm{E}-04$ \\
\hline Nitrogen & $2.01 \mathrm{E}-03$ & $2.17 \mathrm{E}-03$ & 2.19E-03 & $2.07 \mathrm{E}-03$ & $2.07 \mathrm{E}-03$ \\
\hline Methane & 0.966587 & 0.989359 & 0.99116 & 0.975009 & 0.974516 \\
\hline Ethane & $2.22 \mathrm{E}-02$ & 7.67E-03 & $6.06 \mathrm{E}-03$ & $1.58 \mathrm{E}-02$ & $1.58 \mathrm{E}-02$ \\
\hline Propane & $5.56 \mathrm{E}-03$ & $2.48 \mathrm{E}-04$ & $1.48 \mathrm{E}-04$ & $3.68 \mathrm{E}-03$ & $3.73 \mathrm{E}-03$ \\
\hline iso-butane & $1.20 \mathrm{E}-03$ & $1.21 \mathrm{E}-05$ & 6.37E-06 & $1.01 \mathrm{E}-03$ & $1.05 \mathrm{E}-03$ \\
\hline n-butane & 8.09E-04 & $5.00 \mathrm{E}-06$ & $2.55 \mathrm{E}-06$ & $8.06 \mathrm{E}-04$ & 8.59E-04 \\
\hline iso-pentane & $2.20 \mathrm{E}-04$ & 4.17E-07 & $1.91 \mathrm{E}-07$ & $3.65 \mathrm{E}-04$ & 4.32E-04 \\
\hline n-pentane & $8.43 \mathrm{E}-05$ & $1.12 \mathrm{E}-07$ & 4.94E-08 & $1.71 \mathrm{E}-04$ & $2.16 \mathrm{E}-04$ \\
\hline n-hexane & $2.60 \mathrm{E}-05$ & $1.00 \mathrm{E}-08$ & 3.87E-09 & $9.80 \mathrm{E}-05$ & $1.83 \mathrm{E}-04$ \\
\hline n-heptane & $7.88 \mathrm{E}-06$ & 9.79E-10 & $3.31 \mathrm{E}-10$ & $4.10 \mathrm{E}-05$ & $1.31 \mathrm{E}-04$ \\
\hline n-octane & 8.33E-07 & $3.40 \mathrm{E}-11$ & $1.00 \mathrm{E}-11$ & $4.90 \mathrm{E}-06$ & $2.42 \mathrm{E}-05$ \\
\hline n-nonane & $1.20 \mathrm{E}-08$ & $1.63 \mathrm{E}-13$ & 4.18E-14 & 7.37E-08 & $4.80 \mathrm{E}-07$ \\
\hline \multicolumn{6}{|c|}{ Liquid phase } \\
\hline Liquid phase fraction & $1.44 \mathrm{E}-02$ & $9.80 \mathrm{E}-02$ & $6.30 \mathrm{E}-02$ & $1.58 \mathrm{E}-03$ & $6.94 \mathrm{E}-04$ \\
\hline Carbon dioxide & $4.95 \mathrm{E}-03$ & $9.30 \mathrm{E}-03$ & $9.20 \mathrm{E}-03$ & $2.83 \mathrm{E}-03$ & 2.34E-03 \\
\hline Nitrogen & $3.60 \mathrm{E}-04$ & 2.69E-04 & 2.63E-04 & 2.74E-04 & $2.95 \mathrm{E}-04$ \\
\hline Methane & 0.53468 & 0.693675 & 0.720707 & 0.412735 & 0.408183 \\
\hline Ethane & $9.27 \mathrm{E}-02$ & 0.16578 & 0.16104 & $5.18 \mathrm{E}-02$ & 4.27E-02 \\
\hline Propane & $9.95 \mathrm{E}-02$ & $6.83 \mathrm{E}-02$ & 5.74E-02 & $5.21 \mathrm{E}-02$ & $3.78 \mathrm{E}-02$ \\
\hline iso-butane & $5.84 \mathrm{E}-02$ & $2.05 \mathrm{E}-02$ & $1.69 \mathrm{E}-02$ & $3.88 \mathrm{E}-02$ & $2.62 \mathrm{E}-02$ \\
\hline n-butane & $6.07 \mathrm{E}-02$ & $1.70 \mathrm{E}-02$ & $1.39 \mathrm{E}-02$ & 4.82E-02 & $3.21 \mathrm{E}-02$ \\
\hline iso-pentane & 4.58E-02 & 8.92E-03 & $7.30 \mathrm{E}-03$ & 6.06E-02 & $4.06 \mathrm{E}-02$ \\
\hline n-pentane & $2.53 \mathrm{E}-02$ & $4.56 \mathrm{E}-03$ & $3.73 \mathrm{E}-03$ & 4.09E-02 & $2.81 \mathrm{E}-02$ \\
\hline n-hexane & $2.97 \mathrm{E}-02$ & 4.62E-03 & $3.78 \mathrm{E}-03$ & 8.88E-02 & 7.92E-02 \\
\hline n-heptane & 3.39E-02 & $5.06 \mathrm{E}-03$ & 4.14E-03 & 0.139324 & 0.186373 \\
\hline n-octane & $1.32 \mathrm{E}-02$ & $1.94 \mathrm{E}-03$ & $1.59 \mathrm{E}-03$ & 6.04E-02 & 0.109315 \\
\hline n-nonane & $6.86 \mathrm{E}-04$ & $1.01 \mathrm{E}-04$ & $8.24 \mathrm{E}-05$ & $3.25 \mathrm{E}-03$ & $6.79 \mathrm{E}-03$ \\
\hline
\end{tabular}


Table A.7: Results for 13-component natural gas in a nozzle with $A_{\text {out }} / A_{t}=3.0$, side stream at $166.7 \mathrm{~K}$ and $70 \%$ liquid recovery.

\begin{tabular}{|c|c|c|c|c|c|}
\hline Number of phases & 2 & 2 & 2 & 2 & 2 \\
\hline Area ratio & 1 & 1.62674 & 1.702016 & 1.702016 & 3 \\
\hline Temperature $(K)$ & 216.69 & 166.70 & 163.88 & 230.38 & 243.41 \\
\hline Pressure $(M P a)$ & 4.6017 & 1.4703 & 1.3580 & 4.3425 & 5.2700 \\
\hline Molar entropy $(\mathrm{J} / \mathrm{mol} \cdot \mathrm{K})$ & -47.388 & -47.388 & -44.444 & -43.242 & -43.242 \\
\hline Molar volume $\left(\mathrm{m}^{3} / \mathrm{mol}\right)$ & $2.62 \mathrm{E}-04$ & $6.85 \mathrm{E}-04$ & 7.82E-04 & $3.40 \mathrm{E}-04$ & $2.96 \mathrm{E}-04$ \\
\hline Molar density $\left(\mathrm{mol} / \mathrm{m}^{3}\right)$ & 3811.7 & 1459.8 & 1278.4 & 2944.2 & 3375.7 \\
\hline Mass density $\left(\mathrm{kg} / \mathrm{m}^{3}\right)$ & 64.58662 & 24.73615 & 21.01294 & 48.39527 & $-1.78 \mathrm{E}-64$ \\
\hline Flow speed $(m / s)$ & 305.64 & 490.58 & 501.03 & 217.54 & 107.64 \\
\hline Sound speed $(\mathrm{m} / \mathrm{s})$ & 305.64 & 261.28 & 277.80 & 355.28 & 367.93 \\
\hline Mach number & 1 & 1.877569 & 1.80355 & 0.612304 & 0.292556 \\
\hline \multicolumn{6}{|c|}{ Gas phase } \\
\hline Gas phase fraction & 0.985633 & 0.901998 & 0.962416 & 0.999476 & 0.999939 \\
\hline Carbon dioxide & $1.34 \mathrm{E}-03$ & $5.33 \mathrm{E}-04$ & $4.79 \mathrm{E}-04$ & 8.09E-04 & $8.10 \mathrm{E}-04$ \\
\hline Nitrogen & 2.01E-03 & $2.17 \mathrm{E}-03$ & $2.18 \mathrm{E}-03$ & $2.11 \mathrm{E}-03$ & $2.11 \mathrm{E}-03$ \\
\hline Methane & 0.966587 & 0.989359 & 0.990402 & 0.980333 & 0.980061 \\
\hline Ethane & $2.22 \mathrm{E}-02$ & $7.67 \mathrm{E}-03$ & $6.75 \mathrm{E}-03$ & $1.26 \mathrm{E}-02$ & $1.27 \mathrm{E}-02$ \\
\hline Propane & $5.56 \mathrm{E}-03$ & $2.48 \mathrm{E}-04$ & $1.77 \mathrm{E}-04$ & $2.38 \mathrm{E}-03$ & $2.39 \mathrm{E}-03$ \\
\hline iso-butane & $1.20 \mathrm{E}-03$ & $1.21 \mathrm{E}-05$ & 7.97E-06 & $6.46 \mathrm{E}-04$ & $6.58 \mathrm{E}-04$ \\
\hline n-butane & $8.09 \mathrm{E}-04$ & $5.00 \mathrm{E}-06$ & $3.23 \mathrm{E}-06$ & $5.25 \mathrm{E}-04$ & $5.40 \mathrm{E}-04$ \\
\hline iso-pentane & $2.20 \mathrm{E}-04$ & $4.17 \mathrm{E}-07$ & $2.54 \mathrm{E}-07$ & $2.59 \mathrm{E}-04$ & $2.81 \mathrm{E}-04$ \\
\hline n-pentane & $8.43 \mathrm{E}-05$ & $1.12 \mathrm{E}-07$ & $6.68 \mathrm{E}-08$ & $1.28 \mathrm{E}-04$ & $1.43 \mathrm{E}-04$ \\
\hline n-hexane & $2.60 \mathrm{E}-05$ & $1.00 \mathrm{E}-08$ & $5.56 \mathrm{E}-09$ & $9.76 \mathrm{E}-05$ & $1.42 \mathrm{E}-04$ \\
\hline n-heptane & $7.88 \mathrm{E}-06$ & $9.79 \mathrm{E}-10$ & $5.04 \mathrm{E}-10$ & $5.55 \mathrm{E}-05$ & $1.48 \mathrm{E}-04$ \\
\hline n-octane & $8.33 \mathrm{E}-07$ & $3.40 \mathrm{E}-11$ & $1.62 \mathrm{E}-11$ & $7.75 \mathrm{E}-06$ & $4.90 \mathrm{E}-05$ \\
\hline n-nonane & $1.20 \mathrm{E}-08$ & $1.63 \mathrm{E}-13$ & $7.21 \mathrm{E}-14$ & $1.22 \mathrm{E}-07$ & $1.78 \mathrm{E}-06$ \\
\hline \multicolumn{6}{|c|}{ Liquid phase } \\
\hline Liquid phase fraction & $1.44 \mathrm{E}-02$ & $9.80 \mathrm{E}-02$ & $3.76 \mathrm{E}-02$ & $5.25 \mathrm{E}-04$ & $6.11 \mathrm{E}-05$ \\
\hline Carbon dioxide & $4.95 \mathrm{E}-03$ & $9.30 \mathrm{E}-03$ & $9.30 \mathrm{E}-03$ & $2.27 \mathrm{E}-03$ & $1.81 \mathrm{E}-03$ \\
\hline Nitrogen & $3.60 \mathrm{E}-04$ & $2.69 \mathrm{E}-04$ & $2.69 \mathrm{E}-04$ & $2.59 \mathrm{E}-04$ & $2.86 \mathrm{E}-04$ \\
\hline Methane & 0.53468 & 0.693675 & 0.714307 & 0.393545 & 0.391492 \\
\hline Ethane & $9.27 \mathrm{E}-02$ & 0.16578 & 0.164117 & $4.05 \mathrm{E}-02$ & $3.24 \mathrm{E}-02$ \\
\hline Propane & $9.95 \mathrm{E}-02$ & $6.83 \mathrm{E}-02$ & 5.92E-02 & $3.34 \mathrm{E}-02$ & $2.29 \mathrm{E}-02$ \\
\hline iso-butane & $5.84 \mathrm{E}-02$ & $2.05 \mathrm{E}-02$ & $1.73 \mathrm{E}-02$ & $2.49 \mathrm{E}-02$ & $1.54 \mathrm{E}-02$ \\
\hline n-butane & $6.07 \mathrm{E}-02$ & $1.70 \mathrm{E}-02$ & $1.43 \mathrm{E}-02$ & $3.16 \mathrm{E}-02$ & $1.89 \mathrm{E}-02$ \\
\hline iso-pentane & $4.58 \mathrm{E}-02$ & 8.92E-03 & $7.50 \mathrm{E}-03$ & 4.39E-02 & $2.46 \mathrm{E}-02$ \\
\hline n-pentane & $2.53 \mathrm{E}-02$ & $4.56 \mathrm{E}-03$ & $3.83 \mathrm{E}-03$ & 3.13E-02 & $1.74 \mathrm{E}-02$ \\
\hline n-hexane & $2.97 \mathrm{E}-02$ & $4.62 \mathrm{E}-03$ & $3.88 \mathrm{E}-03$ & $9.19 \mathrm{E}-02$ & $5.70 \mathrm{E}-02$ \\
\hline n-heptane & $3.39 \mathrm{E}-02$ & $5.06 \mathrm{E}-03$ & $4.25 \mathrm{E}-03$ & 0.198534 & 0.19302 \\
\hline n-octane & $1.32 \mathrm{E}-02$ & $1.94 \mathrm{E}-03$ & $1.63 \mathrm{E}-03$ & 0.102068 & 0.201957 \\
\hline n-nonane & $6.86 \mathrm{E}-04$ & $1.01 \mathrm{E}-04$ & $8.46 \mathrm{E}-05$ & $5.83 \mathrm{E}-03$ & $2.29 \mathrm{E}-02$ \\
\hline
\end{tabular}


Table A.8: Results for 13-component natural gas in a nozzle with $A_{\text {out }} / A_{t}=3.0$, side stream at $166.7 \mathrm{~K}$ and $90 \%$ liquid recovery.

\begin{tabular}{|c|c|c|c|c|c|}
\hline Number of phases & 2 & 2 & 2 & 2 & 1 \\
\hline Area ratio & 1 & 1.62674 & 1.623759 & 1.623759 & 3 \\
\hline Temperature $(K)$ & 216.69 & 166.70 & 166.85 & 231.09 & 246.98 \\
\hline Pressure $(\mathrm{MPa})$ & 4.6017 & 1.4703 & 1.4756 & 4.1771 & 5.2700 \\
\hline Molar entropy $(\mathrm{J} / \mathrm{mol} \cdot \mathrm{K})$ & -47.387 & -47.388 & -43.521 & -42.730 & -42.730 \\
\hline Molar volume $\left(\mathrm{m}^{3} / \mathrm{mol}\right)$ & $2.62 \mathrm{E}-04$ & $6.85 \mathrm{E}-04$ & $7.45 \mathrm{E}-04$ & $3.62 \mathrm{E}-04$ & 3.07E-04 \\
\hline Molar density $\left(\mathrm{mol} / \mathrm{m}^{3}\right)$ & 3811.7 & 1459.8 & 1342.8 & 2766.2 & 3256.6 \\
\hline Mass density $\left(\mathrm{kg} / \mathrm{m}^{3}\right)$ & 64.58662 & 24.73615 & 21.85915 & 45.02878 & $-1.76 \mathrm{E}-64$ \\
\hline Flow speed $(m / s)$ & 305.64 & 490.58 & 490.10 & 237.91 & 109.37 \\
\hline Sound speed $(m / s)$ & 305.64 & 261.28 & 291.32 & 361.81 & 377.55 \\
\hline Mach number & 1 & 1.877569 & 1.68235 & 0.657562 & 0.289682 \\
\hline \multicolumn{6}{|c|}{ Gas phase } \\
\hline Gas phase fraction & 0.985633 & 0.901998 & 0.989442 & 0.999985 & 1 \\
\hline Carbon dioxide & $1.34 \mathrm{E}-03$ & 5.33E-04 & $5.35 \mathrm{E}-04$ & $6.28 \mathrm{E}-04$ & $6.28 \mathrm{E}-04$ \\
\hline Nitrogen & $2.01 \mathrm{E}-03$ & $2.17 \mathrm{E}-03$ & $2.17 \mathrm{E}-03$ & $2.15 \mathrm{E}-03$ & $2.15 \mathrm{E}-03$ \\
\hline Methane & 0.966587 & 0.989359 & 0.989319 & 0.98619 & 0.986181 \\
\hline Ethane & $2.22 \mathrm{E}-02$ & $7.67 \mathrm{E}-03$ & $7.71 \mathrm{E}-03$ & $9.37 \mathrm{E}-03$ & 9.37E-03 \\
\hline Propane & $5.56 \mathrm{E}-03$ & $2.48 \mathrm{E}-04$ & $2.53 \mathrm{E}-04$ & 9.79E-04 & 9.79E-04 \\
\hline iso-butane & $1.20 \mathrm{E}-03$ & $1.21 \mathrm{E}-05$ & $1.24 \mathrm{E}-05$ & 2.32E-04 & $2.32 \mathrm{E}-04$ \\
\hline n-butane & 8.09E-04 & $5.00 \mathrm{E}-06$ & $5.14 \mathrm{E}-06$ & $1.87 \mathrm{E}-04$ & $1.88 \mathrm{E}-04$ \\
\hline iso-pentane & 2.20E-04 & 4.17E-07 & 4.30E-07 & $9.61 \mathrm{E}-05$ & $9.63 \mathrm{E}-05$ \\
\hline n-pentane & $8.43 \mathrm{E}-05$ & $1.12 \mathrm{E}-07$ & $1.15 \mathrm{E}-07$ & 4.89E-05 & 4.91E-05 \\
\hline n-hexane & $2.60 \mathrm{E}-05$ & $1.00 \mathrm{E}-08$ & $1.04 \mathrm{E}-08$ & $4.89 \mathrm{E}-05$ & $4.96 \mathrm{E}-05$ \\
\hline n-heptane & $7.88 \mathrm{E}-06$ & $9.79 \mathrm{E}-10$ & $1.02 \mathrm{E}-09$ & 5.13E-05 & $5.43 \mathrm{E}-05$ \\
\hline n-octane & 8.33E-07 & $3.40 \mathrm{E}-11$ & $3.55 \mathrm{E}-11$ & $1.71 \mathrm{E}-05$ & $2.09 \mathrm{E}-05$ \\
\hline n-nonane & $1.20 \mathrm{E}-08$ & $1.63 \mathrm{E}-13$ & $1.71 \mathrm{E}-13$ & $5.96 \mathrm{E}-07$ & $1.08 \mathrm{E}-06$ \\
\hline \multicolumn{6}{|c|}{ Liquid phase } \\
\hline Liquid phase fraction & $1.44 \mathrm{E}-02$ & $9.80 \mathrm{E}-02$ & $1.06 \mathrm{E}-02$ & $1.51 \mathrm{E}-05$ & \\
\hline Carbon dioxide & $4.95 \mathrm{E}-03$ & $9.30 \mathrm{E}-03$ & $9.29 \mathrm{E}-03$ & $1.72 \mathrm{E}-03$ & \\
\hline Nitrogen & 3.60E-04 & 2.69E-04 & 2.69E-04 & $2.45 \mathrm{E}-04$ & \\
\hline Methane & 0.53468 & 0.693675 & 0.692074 & 0.374456 & \\
\hline Ethane & 9.27E-02 & 0.16578 & 0.165553 & 2.93E-02 & \\
\hline Propane & $9.95 \mathrm{E}-02$ & $6.83 \mathrm{E}-02$ & $6.90 \mathrm{E}-02$ & $1.37 \mathrm{E}-02$ & \\
\hline iso-butane & $5.84 \mathrm{E}-02$ & $2.05 \mathrm{E}-02$ & $2.08 \mathrm{E}-02$ & $9.09 \mathrm{E}-03$ & \\
\hline n-butane & $6.07 \mathrm{E}-02$ & $1.70 \mathrm{E}-02$ & $1.73 \mathrm{E}-02$ & $1.16 \mathrm{E}-02$ & \\
\hline iso-pentane & $4.58 \mathrm{E}-02$ & 8.92E-03 & $9.08 \mathrm{E}-03$ & 1.69E-02 & \\
\hline n-pentane & $2.53 \mathrm{E}-02$ & $4.56 \mathrm{E}-03$ & $4.64 \mathrm{E}-03$ & $1.25 \mathrm{E}-02$ & \\
\hline n-hexane & $2.97 \mathrm{E}-02$ & 4.62E-03 & 4.70E-03 & 4.91E-02 & \\
\hline n-heptane & 3.39E-02 & $5.06 \mathrm{E}-03$ & $5.15 \mathrm{E}-03$ & 0.199731 & \\
\hline n-octane & $1.32 \mathrm{E}-02$ & $1.94 \mathrm{E}-03$ & $1.98 \mathrm{E}-03$ & 0.24955 & \\
\hline n-nonane & $6.86 \mathrm{E}-04$ & $1.01 \mathrm{E}-04$ & $1.03 \mathrm{E}-04$ & $3.21 \mathrm{E}-02$ & \\
\hline
\end{tabular}


Table A.9: Results for 13-component natural gas in a nozzle with $A_{\text {out }} / A_{t}=3.0$, side stream at $163.7 \mathrm{~K}$ and $90 \%$ liquid recovery.

\begin{tabular}{|c|c|c|c|c|c|}
\hline Number of phases & 2 & 2 & 2 & 2 & 1 \\
\hline Area ratio & 1 & 1.590461 & 1.728699 & 1.728699 & 2.999938 \\
\hline Temperature $(K)$ & 216.69 & 171.26 & 163.69 & 230.79 & 248.17 \\
\hline Pressure $(\mathrm{MPa})$ & 4.6017 & 1.5818 & 1.3348 & 4.0886 & 5.2700 \\
\hline Molar entropy $(\mathrm{J} / \mathrm{mol} \cdot \mathrm{K})$ & -47.387 & -43.128 & -47.390 & -42.541 & -42.541 \\
\hline Molar volume $\left(\mathrm{m}^{3} / \mathrm{mol}\right)$ & $2.62 \mathrm{E}-04$ & 7.17E-04 & $7.45 \mathrm{E}-04$ & $3.71 \mathrm{E}-04$ & $3.10 \mathrm{E}-04$ \\
\hline Molar density $\left(\mathrm{mol} / \mathrm{m}^{3}\right)$ & 3811.7 & 1394.0 & 1342.1 & 2696.6 & 3224.2 \\
\hline Mass density $\left(\mathrm{kg} / \mathrm{m}^{3}\right)$ & 64.58662 & 22.66991 & 22.74148 & 43.8542 & $-1.76 \mathrm{E}-64$ \\
\hline Flow speed $(m / s)$ & 305.64 & 478.45 & 502.13 & 247.33 & 109.67 \\
\hline Sound speed $(\mathrm{m} / \mathrm{s})$ & 305.64 & 303.87 & 259.79 & 362.28 & 379.26 \\
\hline Mach number & 1 & 1.574529 & 1.932855 & 0.682712 & 0.289174 \\
\hline \multicolumn{6}{|c|}{ Gas phase } \\
\hline Gas phase fraction & 0.985633 & 0.894693 & 0.995135 & 0.999979 & 1 \\
\hline Carbon dioxide & $1.34 \mathrm{E}-03$ & $4.66 \mathrm{E}-04$ & $5.31 \mathrm{E}-04$ & 5.69E-04 & $5.69 \mathrm{E}-04$ \\
\hline Nitrogen & $2.01 \mathrm{E}-03$ & 2.19E-03 & $2.17 \mathrm{E}-03$ & $2.16 \mathrm{E}-03$ & $2.16 \mathrm{E}-03$ \\
\hline Methane & 0.966587 & 0.990514 & 0.988991 & 0.987198 & 0.987185 \\
\hline Ethane & 2.22E-02 & $6.64 \mathrm{E}-03$ & $7.81 \mathrm{E}-03$ & $8.46 \mathrm{E}-03$ & $8.46 \mathrm{E}-03$ \\
\hline Propane & $5.56 \mathrm{E}-03$ & $1.86 \mathrm{E}-04$ & $4.51 \mathrm{E}-04$ & $9.29 \mathrm{E}-04$ & $9.29 \mathrm{E}-04$ \\
\hline iso-butane & $1.20 \mathrm{E}-03$ & $8.43 \mathrm{E}-06$ & $3.23 \mathrm{E}-05$ & 2.30E-04 & 2.31E-04 \\
\hline n-butane & 8.09E-04 & $3.41 \mathrm{E}-06$ & $1.41 \mathrm{E}-05$ & $1.87 \mathrm{E}-04$ & $1.88 \mathrm{E}-04$ \\
\hline iso-pentane & 2.20E-04 & $2.65 \mathrm{E}-07$ & $1.31 \mathrm{E}-06$ & $9.65 \mathrm{E}-05$ & $9.69 \mathrm{E}-05$ \\
\hline n-pentane & $8.43 \mathrm{E}-05$ & $6.93 \mathrm{E}-08$ & $3.57 \mathrm{E}-07$ & $4.92 \mathrm{E}-05$ & 4.94E-05 \\
\hline n-hexane & $2.60 \mathrm{E}-05$ & 5.69E-09 & 3.49E-08 & 4.89E-05 & $5.00 \mathrm{E}-05$ \\
\hline n-heptane & $7.88 \mathrm{E}-06$ & $5.09 \mathrm{E}-10$ & 3.69E-09 & 5.04E-05 & $5.47 \mathrm{E}-05$ \\
\hline n-octane & 8.33E-07 & $1.61 \mathrm{E}-11$ & $1.40 \mathrm{E}-10$ & $1.58 \mathrm{E}-05$ & $2.10 \mathrm{E}-05$ \\
\hline n-nonane & $1.20 \mathrm{E}-08$ & 7.09E-14 & $7.34 \mathrm{E}-13$ & 4.91E-07 & $1.09 \mathrm{E}-06$ \\
\hline \multicolumn{6}{|c|}{ Liquid phase } \\
\hline Liquid phase fraction & $1.44 \mathrm{E}-02$ & 0.105307 & $4.87 \mathrm{E}-03$ & 2.09E-05 & \\
\hline Carbon dioxide & $4.95 \mathrm{E}-03$ & $9.26 \mathrm{E}-03$ & 8.20E-03 & $1.56 \mathrm{E}-03$ & \\
\hline Nitrogen & $3.60 \mathrm{E}-04$ & $2.62 \mathrm{E}-04$ & $2.40 \mathrm{E}-04$ & $2.41 \mathrm{E}-04$ & \\
\hline Methane & 0.53468 & 0.704368 & 0.617843 & 0.369656 & \\
\hline Ethane & $9.27 \mathrm{E}-02$ & 0.163631 & 0.142714 & $2.65 \mathrm{E}-02$ & \\
\hline Propane & $9.95 \mathrm{E}-02$ & $6.41 \mathrm{E}-02$ & $9.87 \mathrm{E}-02$ & $1.32 \mathrm{E}-02$ & \\
\hline iso-butane & 5.84E-02 & $1.91 \mathrm{E}-02$ & $4.08 \mathrm{E}-02$ & $9.23 \mathrm{E}-03$ & \\
\hline n-butane & $6.07 \mathrm{E}-02$ & $1.58 \mathrm{E}-02$ & $3.57 \mathrm{E}-02$ & $1.18 \mathrm{E}-02$ & \\
\hline iso-pentane & $4.58 \mathrm{E}-02$ & 8.31E-03 & $1.96 \mathrm{E}-02$ & $1.76 \mathrm{E}-02$ & \\
\hline n-pentane & $2.53 \mathrm{E}-02$ & 4.24E-03 & $1.01 \mathrm{E}-02$ & $1.31 \mathrm{E}-02$ & \\
\hline n-hexane & $2.97 \mathrm{E}-02$ & 4.30E-03 & $1.03 \mathrm{E}-02$ & $5.16 \mathrm{E}-02$ & \\
\hline n-heptane & 3.39E-02 & 4.71E-03 & $1.12 \mathrm{E}-02$ & 0.208331 & \\
\hline n-octane & $1.32 \mathrm{E}-02$ & $1.81 \mathrm{E}-03$ & 4.32E-03 & 0.248475 & \\
\hline n-nonane & $6.86 \mathrm{E}-04$ & $9.37 \mathrm{E}-05$ & $2.24 \mathrm{E}-04$ & $2.87 \mathrm{E}-02$ & \\
\hline
\end{tabular}


Table A.10: Results for 13-component natural gas in a nozzle with $A_{\text {out }} / A_{t}=3.0$, side stream at $163.7 \mathrm{~K}$ and $90 \%$ liquid recovery.

\begin{tabular}{|c|c|c|c|c|c|}
\hline Number of phases & 2 & 2 & 2 & 2 & 1 \\
\hline Area ratio & 1 & 1.548317 & 1.649342 & 1.649342 & 2.999782 \\
\hline Temperature $(K)$ & 216.69 & 169.29 & 164.52 & 231.10 & 246.00 \\
\hline Pressure $(\mathrm{MPa})$ & 4.6017 & 1.5925 & 1.4133 & 4.2376 & 5.2700 \\
\hline Molar entropy $(\mathrm{J} / \mathrm{mol} \cdot \mathrm{K})$ & -47.387 & -47.390 & -43.842 & -42.886 & -42.886 \\
\hline Molar volume $\left(\mathrm{m}^{3} / \mathrm{mol}\right)$ & $2.62 \mathrm{E}-04$ & $6.39 \mathrm{E}-04$ & 7.63E-04 & $3.55 \mathrm{E}-04$ & $3.04 \mathrm{E}-04$ \\
\hline Molar density $\left(\mathrm{mol} / \mathrm{m}^{3}\right)$ & 3811.7 & 1565.0 & 1311.2 & 2818.9 & 3284.4 \\
\hline Mass density $\left(\mathrm{kg} / \mathrm{m}^{3}\right)$ & 64.58662 & 26.51731 & 21.36391 & 45.92901 & $-1.76 \mathrm{E}-64$ \\
\hline Flow speed $(m / s)$ & 305.64 & 480.80 & 497.16 & 231.26 & 109.13 \\
\hline Sound speed $(\mathrm{m} / \mathrm{s})$ & 305.64 & 262.55 & 283.37 & 361.18 & 376.10 \\
\hline Mach number & 1 & 1.831319 & 1.754464 & 0.640286 & 0.290171 \\
\hline \multicolumn{6}{|c|}{ Gas phase } \\
\hline Gas phase fraction & 0.985633 & 0.908108 & 0.982282 & 0.999988 & 1 \\
\hline Carbon dioxide & $1.34 \mathrm{E}-03$ & 5.93E-04 & $5.21 \mathrm{E}-04$ & $6.80 \mathrm{E}-04$ & $6.80 \mathrm{E}-04$ \\
\hline Nitrogen & $2.01 \mathrm{E}-03$ & $2.16 \mathrm{E}-03$ & $2.17 \mathrm{E}-03$ & 2.14E-03 & $2.14 \mathrm{E}-03$ \\
\hline Methane & 0.966587 & 0.988287 & 0.989809 & 0.985252 & 0.985245 \\
\hline Ethane & 2.22E-02 & $8.62 \mathrm{E}-03$ & 7.33E-03 & $1.02 \mathrm{E}-02$ & $1.02 \mathrm{E}-02$ \\
\hline Propane & $5.56 \mathrm{E}-03$ & $3.15 \mathrm{E}-04$ & $1.62 \mathrm{E}-04$ & $1.03 \mathrm{E}-03$ & $1.03 \mathrm{E}-03$ \\
\hline iso-butane & $1.20 \mathrm{E}-03$ & $1.64 \mathrm{E}-05$ & $6.67 \mathrm{E}-06$ & 2.35E-04 & $2.35 \mathrm{E}-04$ \\
\hline n-butane & 8.09E-04 & $6.90 \mathrm{E}-06$ & 2.71E-06 & $1.88 \mathrm{E}-04$ & $1.88 \mathrm{E}-04$ \\
\hline iso-pentane & 2.20E-04 & $6.09 \mathrm{E}-07$ & $2.16 \mathrm{E}-07$ & $9.57 \mathrm{E}-05$ & $9.59 \mathrm{E}-05$ \\
\hline n-pentane & $8.43 \mathrm{E}-05$ & $1.66 \mathrm{E}-07$ & 5.74E-08 & $4.87 \mathrm{E}-05$ & 4.89E-05 \\
\hline n-hexane & $2.60 \mathrm{E}-05$ & $1.61 \mathrm{E}-08$ & 4.96E-09 & $4.87 \mathrm{E}-05$ & 4.93E-05 \\
\hline n-heptane & $7.88 \mathrm{E}-06$ & 1.70E-09 & $4.68 \mathrm{E}-10$ & $5.16 \mathrm{E}-05$ & $5.40 \mathrm{E}-05$ \\
\hline n-octane & 8.33E-07 & $6.36 \mathrm{E}-11$ & $1.56 \mathrm{E}-11$ & $1.77 \mathrm{E}-05$ & $2.07 \mathrm{E}-05$ \\
\hline n-nonane & $1.20 \mathrm{E}-08$ & $3.29 \mathrm{E}-13$ & $7.20 \mathrm{E}-14$ & $6.56 \mathrm{E}-07$ & $1.08 \mathrm{E}-06$ \\
\hline \multicolumn{6}{|c|}{ Liquid phase } \\
\hline Liquid phase fraction & $1.44 \mathrm{E}-02$ & $9.19 \mathrm{E}-02$ & $1.77 \mathrm{E}-02$ & $1.24 \mathrm{E}-05$ & \\
\hline Carbon dioxide & $4.95 \mathrm{E}-03$ & $9.29 \mathrm{E}-03$ & $9.51 \mathrm{E}-03$ & $1.87 \mathrm{E}-03$ & \\
\hline Nitrogen & $3.60 \mathrm{E}-04$ & $2.76 \mathrm{E}-04$ & $2.86 \mathrm{E}-04$ & $2.47 \mathrm{E}-04$ & \\
\hline Methane & 0.53468 & 0.684608 & 0.732223 & 0.378529 & \\
\hline Ethane & $9.27 \mathrm{E}-02$ & 0.16689 & 0.170009 & $3.20 \mathrm{E}-02$ & \\
\hline Propane & 9.95E-02 & $7.21 \mathrm{E}-02$ & 4.94E-02 & $1.44 \mathrm{E}-02$ & \\
\hline iso-butane & $5.84 \mathrm{E}-02$ & $2.18 \mathrm{E}-02$ & 1.29E-02 & $9.10 \mathrm{E}-03$ & \\
\hline n-butane & $6.07 \mathrm{E}-02$ & $1.81 \mathrm{E}-02$ & $1.05 \mathrm{E}-02$ & $1.15 \mathrm{E}-02$ & \\
\hline iso-pentane & $4.58 \mathrm{E}-02$ & $9.52 \mathrm{E}-03$ & $5.40 \mathrm{E}-03$ & $1.65 \mathrm{E}-02$ & \\
\hline n-pentane & $2.53 \mathrm{E}-02$ & $4.86 \mathrm{E}-03$ & $2.75 \mathrm{E}-03$ & $1.22 \mathrm{E}-02$ & \\
\hline n-hexane & $2.97 \mathrm{E}-02$ & 4.92E-03 & $2.78 \mathrm{E}-03$ & 4.77E-02 & \\
\hline n-heptane & 3.39E-02 & 5.39E-03 & $3.05 \mathrm{E}-03$ & 0.194322 & \\
\hline n-octane & $1.32 \mathrm{E}-02$ & $2.07 \mathrm{E}-03$ & $1.17 \mathrm{E}-03$ & 0.247829 & \\
\hline n-nonane & $6.86 \mathrm{E}-04$ & $1.07 \mathrm{E}-04$ & $6.07 \mathrm{E}-05$ & $3.38 \mathrm{E}-02$ & \\
\hline
\end{tabular}


Table A.11: Results for 13-component natural gas in a nozzle with $A_{\text {out }} / A_{t}=3.0$, side stream at $174.8 \mathrm{~K}$ and $90 \%$ liquid recovery.

\begin{tabular}{|c|c|c|c|c|c|}
\hline Number of phases & 2 & 2 & 2 & 2 & 1 \\
\hline Area ratio & 1 & 1.406763 & 1.696119 & 1.696119 & 2.999728 \\
\hline Temperature $(K)$ & 216.69 & 174.81 & 161.80 & 230.68 & 244.01 \\
\hline Pressure $(\mathrm{MPa})$ & 4.6017 & 1.8700 & 1.3274 & 4.3342 & 5.2700 \\
\hline Molar entropy $(\mathrm{J} / \mathrm{mol} \cdot \mathrm{K})$ & -47.387 & -47.390 & -44.466 & -43.204 & -43.204 \\
\hline Molar volume $\left(\mathrm{m}^{3} / \mathrm{mol}\right)$ & 2.62E-04 & $5.56 \mathrm{E}-04$ & $7.90 \mathrm{E}-04$ & $3.43 \mathrm{E}-04$ & $2.99 \mathrm{E}-04$ \\
\hline Molar density $\left(\mathrm{mol} / \mathrm{m}^{3}\right)$ & 3811.7 & 1800.0 & 1266.4 & 2917.3 & 3344.0 \\
\hline Mass density $\left(\mathrm{kg} / \mathrm{m}^{3}\right)$ & 64.58662 & 30.50034 & 20.67814 & 47.63512 & $-1.76 \mathrm{E}-64$ \\
\hline Flow speed $(m / s)$ & 305.64 & 460.08 & 506.90 & 220.04 & 108.54 \\
\hline Sound speed $(\mathrm{m} / \mathrm{s})$ & 305.64 & 265.40 & 274.79 & 359.36 & 372.98 \\
\hline Mach number & 1 & 1.733553 & 1.844669 & 0.612321 & 0.29101 \\
\hline \multicolumn{6}{|c|}{ Gas phase } \\
\hline Gas phase fraction & 0.985633 & 0.920872 & 0.9652 & 0.999989 & 1 \\
\hline Carbon dioxide & $1.34 \mathrm{E}-03$ & $7.26 \mathrm{E}-04$ & $4.85 \mathrm{E}-04$ & 7.98E-04 & $7.98 \mathrm{E}-04$ \\
\hline Nitrogen & $2.01 \mathrm{E}-03$ & $2.13 \mathrm{E}-03$ & $2.18 \mathrm{E}-03$ & $2.11 \mathrm{E}-03$ & $2.11 \mathrm{E}-03$ \\
\hline Methane & 0.966587 & 0.985766 & 0.990678 & 0.98304 & 0.983033 \\
\hline Ethane & 2.22E-02 & $1.08 \mathrm{E}-02$ & $6.56 \mathrm{E}-03$ & $1.21 \mathrm{E}-02$ & $1.21 \mathrm{E}-02$ \\
\hline Propane & $5.56 \mathrm{E}-03$ & $5.20 \mathrm{E}-04$ & $9.22 \mathrm{E}-05$ & $1.21 \mathrm{E}-03$ & $1.21 \mathrm{E}-03$ \\
\hline iso-butane & $1.20 \mathrm{E}-03$ & $3.09 \mathrm{E}-05$ & $3.00 \mathrm{E}-06$ & $2.45 \mathrm{E}-04$ & $2.45 \mathrm{E}-04$ \\
\hline n-butane & 8.09E-04 & $1.36 \mathrm{E}-05$ & $1.18 \mathrm{E}-06$ & $1.92 \mathrm{E}-04$ & $1.92 \mathrm{E}-04$ \\
\hline iso-pentane & $2.20 \mathrm{E}-04$ & $1.35 \mathrm{E}-06$ & 8.73E-08 & $9.52 \mathrm{E}-05$ & $9.54 \mathrm{E}-05$ \\
\hline n-pentane & $8.43 \mathrm{E}-05$ & $3.83 \mathrm{E}-07$ & 2.29E-08 & $4.83 \mathrm{E}-05$ & $4.85 \mathrm{E}-05$ \\
\hline n-hexane & $2.60 \mathrm{E}-05$ & 4.32E-08 & $1.87 \mathrm{E}-09$ & $4.82 \mathrm{E}-05$ & $4.87 \mathrm{E}-05$ \\
\hline n-heptane & 7.88E-06 & 5.30E-09 & $1.67 \mathrm{E}-10$ & $5.13 \mathrm{E}-05$ & $5.34 \mathrm{E}-05$ \\
\hline n-octane & 8.33E-07 & $2.32 \mathrm{E}-10$ & $5.25 \mathrm{E}-12$ & $1.78 \mathrm{E}-05$ & $2.05 \mathrm{E}-05$ \\
\hline n-nonane & $1.20 \mathrm{E}-08$ & $1.40 \mathrm{E}-12$ & $2.28 \mathrm{E}-14$ & $6.88 \mathrm{E}-07$ & $1.06 \mathrm{E}-06$ \\
\hline \multicolumn{6}{|c|}{ Liquid phase } \\
\hline Liquid phase fraction & $1.44 \mathrm{E}-02$ & 7.91E-02 & $3.48 \mathrm{E}-02$ & $1.11 \mathrm{E}-05$ & \\
\hline Carbon dioxide & 4.95E-03 & $9.15 \mathrm{E}-03$ & $9.47 \mathrm{E}-03$ & $2.23 \mathrm{E}-03$ & \\
\hline Nitrogen & $3.60 \mathrm{E}-04$ & 2.89E-04 & 3.01E-04 & $2.52 \mathrm{E}-04$ & \\
\hline Methane & 0.53468 & 0.664958 & 0.770976 & 0.387127 & \\
\hline Ethane & 9.27E-02 & 0.166952 & 0.166966 & $3.86 \mathrm{E}-02$ & \\
\hline Propane & 9.95E-02 & 8.13E-02 & $3.22 \mathrm{E}-02$ & $1.69 \mathrm{E}-02$ & \\
\hline iso-butane & 5.84E-02 & $2.52 \mathrm{E}-02$ & $6.96 \mathrm{E}-03$ & $9.46 \mathrm{E}-03$ & \\
\hline n-butane & 6.07E-02 & $2.09 \mathrm{E}-02$ & $5.48 \mathrm{E}-03$ & $1.16 \mathrm{E}-02$ & \\
\hline iso-pentane & $4.58 \mathrm{E}-02$ & $1.10 \mathrm{E}-02$ & $2.74 \mathrm{E}-03$ & $1.62 \mathrm{E}-02$ & \\
\hline n-pentane & 2.53E-02 & $5.64 \mathrm{E}-03$ & $1.39 \mathrm{E}-03$ & 1.19E-02 & \\
\hline n-hexane & $2.97 \mathrm{E}-02$ & $5.72 \mathrm{E}-03$ & $1.40 \mathrm{E}-03$ & $4.60 \mathrm{E}-02$ & \\
\hline n-heptane & 3.39E-02 & $6.26 \mathrm{E}-03$ & $1.53 \mathrm{E}-03$ & 0.186624 & \\
\hline n-octane & $1.32 \mathrm{E}-02$ & $2.40 \mathrm{E}-03$ & $5.89 \mathrm{E}-04$ & 0.23945 & \\
\hline n-nonane & $6.86 \mathrm{E}-04$ & $1.25 \mathrm{E}-04$ & $3.05 \mathrm{E}-05$ & $3.36 \mathrm{E}-02$ & \\
\hline
\end{tabular}


Table A.12: Results for 13-component natural gas in a nozzle with $A_{\text {out }} / A_{t}=3.0$, side stream at $179.7 \mathrm{~K}$ and $90 \%$ liquid recovery.

\begin{tabular}{|c|c|c|c|c|c|}
\hline Number of phases & 2 & 2 & 2 & 2 & 1 \\
\hline Area ratio & 1 & 1.305838 & 1.732013 & 1.732013 & 2.999774 \\
\hline Temperature $(K)$ & 216.69 & 179.70 & 160.47 & 230.08 & 242.38 \\
\hline Pressure $(\mathrm{MPa})$ & 4.6017 & 2.1336 & 1.2767 & 4.3972 & 5.2700 \\
\hline Molar entropy $(\mathrm{J} / \mathrm{mol} \cdot \mathrm{K})$ & -47.387 & -47.389 & -44.950 & -43.462 & -43.464 \\
\hline Molar volume $\left(\mathrm{m}^{3} / \mathrm{mol}\right)$ & $2.62 \mathrm{E}-04$ & $4.95 \mathrm{E}-04$ & 8.07E-04 & $3.34 \mathrm{E}-04$ & 2.94E-04 \\
\hline Molar density $\left(\mathrm{mol} / \mathrm{m}^{3}\right)$ & 3811.7 & 2018.5 & 1239.7 & 2993.8 & 3396.2 \\
\hline Mass density $\left(\mathrm{kg} / \mathrm{m}^{3}\right)$ & 64.58662 & 34.20277 & 20.28554 & 48.98968 & $-1.77 \mathrm{E}-64$ \\
\hline Flow speed $(m / s)$ & 305.64 & 441.99 & 512.39 & 212.17 & 107.99 \\
\hline Sound speed $(\mathrm{m} / \mathrm{s})$ & 305.64 & 268.25 & 270.71 & 357.47 & 370.27 \\
\hline Mach number & 1 & 1.647649 & 1.892769 & 0.593527 & 0.291639 \\
\hline \multicolumn{6}{|c|}{ Gas phase } \\
\hline Gas phase fraction & 0.985633 & 0.931651 & 0.950827 & 0.999987 & 1 \\
\hline Carbon dioxide & $1.34 \mathrm{E}-03$ & 8.44E-04 & $4.62 \mathrm{E}-04$ & $9.02 \mathrm{E}-04$ & 9.02E-04 \\
\hline Nitrogen & $2.01 \mathrm{E}-03$ & $2.11 \mathrm{E}-03$ & $2.19 \mathrm{E}-03$ & $2.09 \mathrm{E}-03$ & $2.09 \mathrm{E}-03$ \\
\hline Methane & 0.966587 & 0.983343 & 0.991132 & 0.980904 & 0.980896 \\
\hline Ethane & $2.22 \mathrm{E}-02$ & $1.28 \mathrm{E}-02$ & $6.14 \mathrm{E}-03$ & $1.39 \mathrm{E}-02$ & $1.39 \mathrm{E}-02$ \\
\hline Propane & $5.56 \mathrm{E}-03$ & 7.92E-04 & 7.37E-05 & $1.44 \mathrm{E}-03$ & $1.44 \mathrm{E}-03$ \\
\hline iso-butane & $1.20 \mathrm{E}-03$ & $5.34 \mathrm{E}-05$ & $2.05 \mathrm{E}-06$ & 2.63E-04 & 2.63E-04 \\
\hline n-butane & 8.09E-04 & $2.43 \mathrm{E}-05$ & $7.78 \mathrm{E}-07$ & $2.00 \mathrm{E}-04$ & $2.00 \mathrm{E}-04$ \\
\hline iso-pentane & $2.20 \mathrm{E}-04$ & $2.67 \mathrm{E}-06$ & $5.38 \mathrm{E}-08$ & $9.54 \mathrm{E}-05$ & $9.56 \mathrm{E}-05$ \\
\hline n-pentane & $8.43 \mathrm{E}-05$ & $7.85 \mathrm{E}-07$ & $1.40 \mathrm{E}-08$ & $4.82 \mathrm{E}-05$ & $4.83 \mathrm{E}-05$ \\
\hline n-hexane & $2.60 \mathrm{E}-05$ & $1.00 \mathrm{E}-07$ & $1.09 \mathrm{E}-09$ & 4.77E-05 & 4.83E-05 \\
\hline n-heptane & $7.88 \mathrm{E}-06$ & $1.40 \mathrm{E}-08$ & $9.41 \mathrm{E}-11$ & $5.05 \mathrm{E}-05$ & $5.28 \mathrm{E}-05$ \\
\hline n-octane & 8.33E-07 & $6.97 \mathrm{E}-10$ & $2.86 \mathrm{E}-12$ & $1.73 \mathrm{E}-05$ & $2.03 \mathrm{E}-05$ \\
\hline n-nonane & $1.20 \mathrm{E}-08$ & $4.78 \mathrm{E}-12$ & $1.20 \mathrm{E}-14$ & $6.49 \mathrm{E}-07$ & $1.05 \mathrm{E}-06$ \\
\hline \multicolumn{6}{|c|}{ Liquid phase } \\
\hline Liquid phase fraction & $1.44 \mathrm{E}-02$ & $6.83 \mathrm{E}-02$ & 4.92E-02 & $1.30 \mathrm{E}-05$ & \\
\hline Carbon dioxide & $4.95 \mathrm{E}-03$ & $8.87 \mathrm{E}-03$ & $9.42 \mathrm{E}-03$ & $2.56 \mathrm{E}-03$ & \\
\hline Nitrogen & $3.60 \mathrm{E}-04$ & 2.99E-04 & $3.03 \mathrm{E}-04$ & $2.56 \mathrm{E}-04$ & \\
\hline Methane & 0.53468 & 0.647398 & 0.782966 & 0.394462 & \\
\hline Ethane & $9.27 \mathrm{E}-02$ & 0.164037 & 0.164593 & 4.49E-02 & \\
\hline Propane & $9.95 \mathrm{E}-02$ & 9.04E-02 & 2.80E-02 & 2.04E-02 & \\
\hline iso-butane & $5.84 \mathrm{E}-02$ & $2.88 \mathrm{E}-02$ & $5.31 \mathrm{E}-03$ & $1.02 \mathrm{E}-02$ & \\
\hline n-butane & $6.07 \mathrm{E}-02$ & $2.41 \mathrm{E}-02$ & $4.05 \mathrm{E}-03$ & $1.21 \mathrm{E}-02$ & \\
\hline iso-pentane & $4.58 \mathrm{E}-02$ & $1.28 \mathrm{E}-02$ & $1.94 \mathrm{E}-03$ & $1.63 \mathrm{E}-02$ & \\
\hline n-pentane & $2.53 \mathrm{E}-02$ & $6.53 \mathrm{E}-03$ & 9.82E-04 & 1.19E-02 & \\
\hline n-hexane & $2.97 \mathrm{E}-02$ & $6.62 \mathrm{E}-03$ & $9.82 \mathrm{E}-04$ & $4.52 \mathrm{E}-02$ & \\
\hline n-heptane & 3.39E-02 & $7.25 \mathrm{E}-03$ & $1.07 \mathrm{E}-03$ & 0.181685 & \\
\hline n-octane & $1.32 \mathrm{E}-02$ & $2.78 \mathrm{E}-03$ & 4.12E-04 & 0.228958 & \\
\hline n-nonane & $6.86 \mathrm{E}-04$ & $1.44 \mathrm{E}-04$ & $2.14 \mathrm{E}-05$ & $3.10 \mathrm{E}-02$ & \\
\hline
\end{tabular}


Table A.13: Results for 13-component natural gas in a nozzle with $A_{\text {out }} / A_{t}=1.5$ and no side stream.

\begin{tabular}{|c|c|c|c|c|}
\hline Number of phases & 2 & 2 & 1 & 1 \\
\hline Area ratio & 1 & 1.347125 & 1.347125 & 1.5 \\
\hline Temperature $(K)$ & 258.99 & 204.73 & 280.16 & 285.33 \\
\hline Pressure $(M P a)$ & 1.8383 & 0.72293 & 2.2284 & 2.4000 \\
\hline Molar entropy $(\mathrm{J} / \mathrm{mol} \cdot \mathrm{K})$ & -28.623 & -28.622 & -27.412 & -27.414 \\
\hline Molar volume $\left(\mathrm{m}^{3} / \mathrm{mol}\right)$ & $1.09 \mathrm{E}-03$ & $2.22 \mathrm{E}-03$ & $9.77 \mathrm{E}-04$ & $9.23 \mathrm{E}-04$ \\
\hline Molar density $\left(\mathrm{mol} / \mathrm{m}^{3}\right)$ & 917.96 & 451.14 & 1023.6 & 1083.3 \\
\hline Mass density $\left(\mathrm{kg} / \mathrm{m}^{3}\right)$ & 15.55438 & 7.644362 & 17.34466 & $-1.83 \mathrm{E}-64$ \\
\hline Flow speed $(m / s)$ & 392.88 & 593.42 & 261.54 & 221.94 \\
\hline Sound speed $(\mathrm{m} / \mathrm{s})$ & 392.88 & 352.42 & 410.38 & 413.69 \\
\hline Mach number & 1 & 1.683862 & 0.637312 & 0.536483 \\
\hline \multicolumn{5}{|c|}{ Gas phase } \\
\hline Gas phase fraction & 0.999315 & 0.994563 & 1 & 1 \\
\hline Carbon dioxide & $1.39 \mathrm{E}-03$ & $1.38 \mathrm{E}-03$ & $1.39 \mathrm{E}-03$ & $1.39 \mathrm{E}-03$ \\
\hline Nitrogen & $1.98 \mathrm{E}-03$ & $1.99 \mathrm{E}-03$ & $1.98 \mathrm{E}-03$ & $1.98 \mathrm{E}-03$ \\
\hline Methane & 0.96095 & 0.964989 & 0.960381 & 0.960381 \\
\hline Ethane & $2.32 \mathrm{E}-02$ & $2.30 \mathrm{E}-02$ & 2.32E-02 & $2.32 \mathrm{E}-02$ \\
\hline Propane & $6.90 \mathrm{E}-03$ & $6.23 \mathrm{E}-03$ & $6.92 \mathrm{E}-03$ & $6.92 \mathrm{E}-03$ \\
\hline iso-butane & $2.00 \mathrm{E}-03$ & $1.34 \mathrm{E}-03$ & $2.02 \mathrm{E}-03$ & $2.02 \mathrm{E}-03$ \\
\hline n-butane & $1.65 \mathrm{E}-03$ & $8.51 \mathrm{E}-04$ & $1.67 \mathrm{E}-03$ & $1.67 \mathrm{E}-03$ \\
\hline iso-pentane & 8.42E-04 & $1.60 \mathrm{E}-04$ & $8.75 \mathrm{E}-04$ & $8.75 \mathrm{E}-04$ \\
\hline n-pentane & $4.23 \mathrm{E}-04$ & $5.13 \mathrm{E}-05$ & 4.47E-04 & $4.47 \mathrm{E}-04$ \\
\hline n-hexane & $3.72 \mathrm{E}-04$ & $7.76 \mathrm{E}-06$ & $4.52 \mathrm{E}-04$ & $4.52 \mathrm{E}-04$ \\
\hline n-heptane & $2.71 \mathrm{E}-04$ & $1.18 \mathrm{E}-06$ & $4.95 \mathrm{E}-04$ & 4.95E-04 \\
\hline n-octane & $4.64 \mathrm{E}-05$ & $6.37 \mathrm{E}-08$ & $1.90 \mathrm{E}-04$ & $1.90 \mathrm{E}-04$ \\
\hline n-nonane & $7.98 \mathrm{E}-07$ & $4.77 \mathrm{E}-10$ & $9.87 \mathrm{E}-06$ & $9.87 \mathrm{E}-06$ \\
\hline \multicolumn{5}{|c|}{ Liquid phase } \\
\hline Liquid phase fraction & $6.85 \mathrm{E}-04$ & $5.44 \mathrm{E}-03$ & & \\
\hline Carbon dioxide & $1.15 \mathrm{E}-03$ & $2.81 \mathrm{E}-03$ & & \\
\hline Nitrogen & $8.36 \mathrm{E}-05$ & $4.76 \mathrm{E}-05$ & & \\
\hline Methane & 0.131573 & 0.117488 & & \\
\hline Ethane & $2.44 \mathrm{E}-02$ & $5.57 \mathrm{E}-02$ & & \\
\hline Propane & $3.19 \mathrm{E}-02$ & 0.131492 & & \\
\hline iso-butane & $2.61 \mathrm{E}-02$ & 0.126888 & & \\
\hline n-butane & $3.28 \mathrm{E}-02$ & 0.151564 & & \\
\hline iso-pentane & $4.83 \mathrm{E}-02$ & 0.131666 & & \\
\hline n-pentane & $3.45 \mathrm{E}-02$ & $7.28 \mathrm{E}-02$ & & \\
\hline n-hexane & 0.117852 & $8.18 \mathrm{E}-02$ & & \\
\hline n-heptane & 0.328206 & $9.09 \mathrm{E}-02$ & & \\
\hline n-octane & 0.209931 & $3.50 \mathrm{E}-02$ & & \\
\hline n-nonane & $1.32 \mathrm{E}-02$ & $1.82 \mathrm{E}-03$ & & \\
\hline
\end{tabular}


Table A.14: Results for 13-component natural gas in a nozzle with $A_{\text {out }} / A_{t}=1.5$, side stream at. $210 \mathrm{~K}$ and $90 \%$ liquid recovery.

\begin{tabular}{|c|c|c|c|c|c|}
\hline Number of phases & 2 & 2 & 2 & 1 & 1 \\
\hline Area ratio & 1 & 1.282651 & 1.318316 & 1.318316 & 1.499951 \\
\hline Temperature $(K)$ & 258.99 & 210.01 & 206.67 & 280.87 & 287.39 \\
\hline Pressure $(M P a)$ & 1.8383 & 0.80046 & 0.75387 & 2.1875 & 2.4000 \\
\hline Molar entropy $(\mathrm{J} / \mathrm{mol} \cdot \mathrm{K})$ & -28.623 & -28.622 & -28.299 & -27.304 & -27.304 \\
\hline Molar volume $\left(\mathrm{m}^{3} / \mathrm{mol}\right)$ & $1.09 \mathrm{E}-03$ & $2.05 \mathrm{E}-03$ & $2.15 \mathrm{E}-03$ & $1.00 \mathrm{E}-03$ & 9.33E-04 \\
\hline Molar density $\left(\mathrm{mol} / \mathrm{m}^{3}\right)$ & 917.96 & 487.51 & 464.38 & 998.97 & 1072.1 \\
\hline Mass density $\left(\mathrm{kg} / \mathrm{m}^{3}\right)$ & 15.55438 & 8.260635 & 7.780403 & 16.73727 & $-1.81 \mathrm{E}-64$ \\
\hline Flow speed $(m / s)$ & 392.88 & 576.75 & 586.79 & 272.77 & 223.39 \\
\hline Sound speed $(\mathrm{m} / \mathrm{s})$ & 392.88 & 356.86 & 360.42 & 414.38 & 418.61 \\
\hline Mach number & 1 & 1.616183 & 1.628095 & 0.658257 & 0.533662 \\
\hline \multicolumn{6}{|c|}{ Gas phase } \\
\hline Gas phase fraction & 0.999315 & 0.995437 & 0.99934 & 1 & 1 \\
\hline Carbon dioxide & $1.39 \mathrm{E}-03$ & $1.39 \mathrm{E}-03$ & $1.39 \mathrm{E}-03$ & $1.39 \mathrm{E}-03$ & $1.39 \mathrm{E}-03$ \\
\hline Nitrogen & $1.98 \mathrm{E}-03$ & $1.99 \mathrm{E}-03$ & $1.99 \mathrm{E}-03$ & $1.99 \mathrm{E}-03$ & $1.99 \mathrm{E}-03$ \\
\hline Methane & 0.96095 & 0.964246 & 0.964417 & 0.963858 & 0.963858 \\
\hline Ethane & $2.32 \mathrm{E}-02$ & $2.30 \mathrm{E}-02$ & $2.30 \mathrm{E}-02$ & $2.31 \mathrm{E}-02$ & $2.31 \mathrm{E}-02$ \\
\hline Propane & $6.90 \mathrm{E}-03$ & $6.44 \mathrm{E}-03$ & $6.41 \mathrm{E}-03$ & $6.48 \mathrm{E}-03$ & $6.48 \mathrm{E}-03$ \\
\hline iso-butane & $2.00 \mathrm{E}-03$ & $1.52 \mathrm{E}-03$ & $1.48 \mathrm{E}-03$ & $1.57 \mathrm{E}-03$ & $1.57 \mathrm{E}-03$ \\
\hline n-butane & $1.65 \mathrm{E}-03$ & $1.04 \mathrm{E}-03$ & $9.96 \mathrm{E}-04$ & $1.10 \mathrm{E}-03$ & $1.10 \mathrm{E}-03$ \\
\hline iso-pentane & $8.42 \mathrm{E}-04$ & $2.38 \mathrm{E}-04$ & $2.04 \mathrm{E}-04$ & $3.02 \mathrm{E}-04$ & $3.02 \mathrm{E}-04$ \\
\hline n-pentane & 4.23E-04 & $8.11 \mathrm{E}-05$ & $6.47 \mathrm{E}-05$ & $1.18 \mathrm{E}-04$ & $1.18 \mathrm{E}-04$ \\
\hline n-hexane & $3.72 \mathrm{E}-04$ & $1.41 \mathrm{E}-05$ & $8.41 \mathrm{E}-06$ & $5.81 \mathrm{E}-05$ & $5.81 \mathrm{E}-05$ \\
\hline n-heptane & $2.71 \mathrm{E}-04$ & $2.35 \mathrm{E}-06$ & $1.20 \mathrm{E}-06$ & 5.19E-05 & $5.19 \mathrm{E}-05$ \\
\hline n-octane & $4.64 \mathrm{E}-05$ & $1.38 \mathrm{E}-07$ & $6.61 \mathrm{E}-08$ & $1.92 \mathrm{E}-05$ & $1.92 \mathrm{E}-05$ \\
\hline n-nonane & $7.98 \mathrm{E}-07$ & $1.11 \mathrm{E}-09$ & $5.08 \mathrm{E}-10$ & 9.92E-07 & 9.92E-07 \\
\hline \multicolumn{6}{|c|}{ Liquid phase } \\
\hline Liquid phase fraction & $6.85 \mathrm{E}-04$ & $4.56 \mathrm{E}-03$ & $6.60 \mathrm{E}-04$ & & \\
\hline Carbon dioxide & $1.15 \mathrm{E}-03$ & $2.48 \mathrm{E}-03$ & $2.69 \mathrm{E}-03$ & & \\
\hline Nitrogen & $8.36 \mathrm{E}-05$ & $5.01 \mathrm{E}-05$ & $4.88 \mathrm{E}-05$ & & \\
\hline Methane & 0.131573 & 0.117212 & 0.117935 & & \\
\hline Ethane & $2.44 \mathrm{E}-02$ & $4.97 \mathrm{E}-02$ & $5.37 \mathrm{E}-02$ & & \\
\hline Propane & $3.19 \mathrm{E}-02$ & 0.111245 & 0.125776 & & \\
\hline iso-butane & $2.61 \mathrm{E}-02$ & 0.111569 & 0.128334 & & \\
\hline n-butane & $3.28 \mathrm{E}-02$ & 0.139672 & 0.160129 & & \\
\hline iso-pentane & 4.83E-02 & 0.13983 & 0.148377 & & \\
\hline n-pentane & $3.45 \mathrm{E}-02$ & $8.02 \mathrm{E}-02$ & $8.04 \mathrm{E}-02$ & & \\
\hline n-hexane & 0.117852 & $9.61 \mathrm{E}-02$ & $7.53 \mathrm{E}-02$ & & \\
\hline n-heptane & 0.328206 & 0.108076 & 7.67E-02 & & \\
\hline n-octane & 0.209931 & $4.17 \mathrm{E}-02$ & $2.90 \mathrm{E}-02$ & & \\
\hline n-nonane & $1.32 \mathrm{E}-02$ & $2.16 \mathrm{E}-03$ & $1.50 \mathrm{E}-03$ & & \\
\hline
\end{tabular}


Table A.15: Results for 13-component natural gas in a nozzle with $A_{\text {out }} / A_{t}=1.5$, side stream at. $220 \mathrm{~K}$ and $90 \%$ liquid recovery.

\begin{tabular}{|c|c|c|c|c|c|}
\hline Number of phases & 2 & 2 & 2 & 1 & 1 \\
\hline Area ratio & 1 & 1.181444 & 1.326372 & 1.326372 & 1.5 \\
\hline Temperature $(K)$ & 258.99 & 220.00 & 205.41 & 280.76 & 286.88 \\
\hline Pressure $(\mathrm{MPa})$ & 1.8383 & 0.96286 & 0.74103 & 2.1997 & 2.4000 \\
\hline Molar entropy $(\mathrm{J} / \mathrm{mol} \cdot \mathrm{K})$ & -28.622 & -28.622 & -28.396 & -27.327 & -27.327 \\
\hline Molar volume $\left(\mathrm{m}^{3} / \mathrm{mol}\right)$ & $1.09 \mathrm{E}-03$ & $1.78 \mathrm{E}-03$ & $2.18 \mathrm{E}-03$ & 9.94E-04 & $9.30 \mathrm{E}-04$ \\
\hline Molar density $\left(\mathrm{mol} / \mathrm{m}^{3}\right)$ & 917.96 & 561.04 & 459.67 & 1005.8 & 1074.8 \\
\hline Mass density $\left(\mathrm{kg} / \mathrm{m}^{3}\right)$ & 15.55438 & 9.506526 & 7.720966 & 16.8932 & $-1.81 \mathrm{E}-64$ \\
\hline Flow speed $(\mathrm{m} / \mathrm{s})$ & 392.88 & 544.10 & 589.88 & 269.60 & 223.07 \\
\hline Sound speed $(m / s)$ & 392.88 & 365.06 & 356.55 & 413.51 & 417.47 \\
\hline Mach number & 1 & 1.490418 & 1.65442 & 0.651979 & 0.534333 \\
\hline \multicolumn{6}{|c|}{ Gas phase } \\
\hline Gas phase fraction & 0.999315 & 0.996753 & 0.99849 & 1 & 1 \\
\hline Carbon dioxide & $1.39 \mathrm{E}-03$ & $1.39 \mathrm{E}-03$ & $1.39 \mathrm{E}-03$ & $1.39 \mathrm{E}-03$ & $1.39 \mathrm{E}-03$ \\
\hline Nitrogen & $1.98 \mathrm{E}-03$ & $1.99 \mathrm{E}-03$ & $1.99 \mathrm{E}-03$ & $1.99 \mathrm{E}-03$ & $1.99 \mathrm{E}-03$ \\
\hline Methane & 0.96095 & 0.963126 & 0.964127 & 0.962851 & 0.962851 \\
\hline Ethane & 2.32E-02 & $2.31 \mathrm{E}-02$ & $2.31 \mathrm{E}-02$ & $2.31 \mathrm{E}-02$ & $2.31 \mathrm{E}-02$ \\
\hline Propane & $6.90 \mathrm{E}-03$ & $6.67 \mathrm{E}-03$ & $6.50 \mathrm{E}-03$ & $6.70 \mathrm{E}-03$ & $6.70 \mathrm{E}-03$ \\
\hline iso-butane & $2.00 \mathrm{E}-03$ & $1.76 \mathrm{E}-03$ & $1.57 \mathrm{E}-03$ & $1.78 \mathrm{E}-03$ & $1.78 \mathrm{E}-03$ \\
\hline n-butane & $1.65 \mathrm{E}-03$ & $1.32 \mathrm{E}-03$ & $1.08 \mathrm{E}-03$ & $1.35 \mathrm{E}-03$ & $1.35 \mathrm{E}-03$ \\
\hline iso-pentane & 8.42E-04 & $4.25 \mathrm{E}-04$ & $2.14 \mathrm{E}-04$ & $4.70 \mathrm{E}-04$ & 4.70E-04 \\
\hline n-pentane & $4.23 \mathrm{E}-04$ & $1.65 \mathrm{E}-04$ & $6.32 \mathrm{E}-05$ & $1.93 \mathrm{E}-04$ & $1.93 \mathrm{E}-04$ \\
\hline n-hexane & $3.72 \mathrm{E}-04$ & $4.01 \mathrm{E}-05$ & $5.07 \mathrm{E}-06$ & $8.14 \mathrm{E}-05$ & $8.14 \mathrm{E}-05$ \\
\hline n-heptane & $2.71 \mathrm{E}-04$ & $8.03 \mathrm{E}-06$ & $5.17 \mathrm{E}-07$ & 5.69E-05 & $5.69 \mathrm{E}-05$ \\
\hline n-octane & $4.64 \mathrm{E}-05$ & $5.46 \mathrm{E}-07$ & $2.55 \mathrm{E}-08$ & $1.96 \mathrm{E}-05$ & $1.96 \mathrm{E}-05$ \\
\hline n-nonane & $7.98 \mathrm{E}-07$ & $5.06 \mathrm{E}-09$ & $1.89 \mathrm{E}-10$ & 9.94E-07 & 9.94E-07 \\
\hline \multicolumn{6}{|c|}{ Liquid phase } \\
\hline Liquid phase fraction & $6.85 \mathrm{E}-04$ & $3.25 \mathrm{E}-03$ & $1.51 \mathrm{E}-03$ & & \\
\hline Carbon dioxide & $1.15 \mathrm{E}-03$ & $2.01 \mathrm{E}-03$ & $2.80 \mathrm{E}-03$ & & \\
\hline Nitrogen & $8.36 \mathrm{E}-05$ & $5.52 \mathrm{E}-05$ & $4.87 \mathrm{E}-05$ & & \\
\hline Methane & 0.131573 & 0.1177 & 0.11913 & & \\
\hline Ethane & $2.44 \mathrm{E}-02$ & $4.10 \mathrm{E}-02$ & $5.57 \mathrm{E}-02$ & & \\
\hline Propane & $3.19 \mathrm{E}-02$ & $8.19 \mathrm{E}-02$ & 0.134757 & & \\
\hline iso-butane & $2.61 \mathrm{E}-02$ & 8.31E-02 & 0.144755 & & \\
\hline n-butane & $3.28 \mathrm{E}-02$ & 0.109431 & 0.185836 & & \\
\hline iso-pentane & $4.83 \mathrm{E}-02$ & 0.139085 & 0.169523 & & \\
\hline n-pentane & $3.45 \mathrm{E}-02$ & $8.71 \mathrm{E}-02$ & 8.59E-02 & & \\
\hline n-hexane & 0.117852 & 0.127024 & $5.06 \mathrm{E}-02$ & & \\
\hline n-heptane & 0.328206 & 0.150132 & $3.73 \mathrm{E}-02$ & & \\
\hline n-octane & 0.209931 & $5.84 \mathrm{E}-02$ & $1.29 \mathrm{E}-02$ & & \\
\hline n-nonane & $1.32 \mathrm{E}-02$ & $3.04 \mathrm{E}-03$ & $6.58 \mathrm{E}-04$ & & \\
\hline
\end{tabular}


Table A. 16: Results for 13-component natural gas in a nozzle with $A_{\text {out }} / A_{t}=1.5$, side stream at. $230 \mathrm{~K}$ and $90 \%$ liquid recovery.

\begin{tabular}{|c|c|c|c|c|c|}
\hline Number of phases & 2 & 2 & 2 & 1 & 1 \\
\hline Area ratio & 1 & 1.103912 & 1.331963 & 1.331963 & 1.499925 \\
\hline Temperature $(K)$ & 258.99 & 229.99 & 204.91 & 280.64 & 286.48 \\
\hline Pressure $(M P a)$ & 1.8383 & 1.1474 & 0.73420 & 2.2082 & 2.4000 \\
\hline Molar entropy $(\mathrm{J} / \mathrm{mol} \cdot \mathrm{K})$ & -28.623 & -28.623 & -28.464 & -27.345 & -27.345 \\
\hline Molar volume $\left(\mathrm{m}^{3} / \mathrm{mol}\right)$ & $1.09 \mathrm{E}-03$ & $1.56 \mathrm{E}-03$ & 2.19E-03 & 9.89E-04 & $9.29 \mathrm{E}-04$ \\
\hline Molar density $\left(\mathrm{mol} / \mathrm{m}^{3}\right)$ & 917.96 & 641.00 & 456.89 & 1010.7 & 1076.9 \\
\hline Mass density $\left(\mathrm{kg} / \mathrm{m}^{3}\right)$ & 15.55438 & 10.86143 & 7.689632 & 17.00962 & $-1.82 \mathrm{E}-64$ \\
\hline Flow speed $(m / s)$ & 392.88 & 509.67 & 591.47 & 267.39 & 222.84 \\
\hline Sound speed $(m / s)$ & 392.88 & 372.89 & 354.67 & 412.80 & 416.57 \\
\hline Mach number & 1 & 1.366807 & 1.667674 & 0.647737 & 0.534926 \\
\hline \multicolumn{6}{|c|}{ Gas phase } \\
\hline Gas phase fraction & 0.999315 & 0.997692 & 0.997549 & 1 & 1 \\
\hline Carbon dioxide & $1.39 \mathrm{E}-03$ & $1.39 \mathrm{E}-03$ & $1.39 \mathrm{E}-03$ & $1.39 \mathrm{E}-03$ & $1.39 \mathrm{E}-03$ \\
\hline Nitrogen & $1.98 \mathrm{E}-03$ & $1.99 \mathrm{E}-03$ & 1.99E-03 & 1.99E-03 & $1.99 \mathrm{E}-03$ \\
\hline Methane & 0.96095 & 0.962326 & 0.964202 & 0.962131 & 0.962131 \\
\hline Ethane & $2.32 \mathrm{E}-02$ & 2.31E-02 & $2.31 \mathrm{E}-02$ & $2.31 \mathrm{E}-02$ & $2.31 \mathrm{E}-02$ \\
\hline Propane & $6.90 \mathrm{E}-03$ & $6.79 \mathrm{E}-03$ & $6.48 \mathrm{E}-03$ & $6.80 \mathrm{E}-03$ & $6.80 \mathrm{E}-03$ \\
\hline iso-butane & $2.00 \mathrm{E}-03$ & $1.89 \mathrm{E}-03$ & $1.54 \mathrm{E}-03$ & $1.90 \mathrm{E}-03$ & $1.90 \mathrm{E}-03$ \\
\hline n-butane & $1.65 \mathrm{E}-03$ & $1.49 \mathrm{E}-03$ & $1.05 \mathrm{E}-03$ & $1.51 \mathrm{E}-03$ & $1.51 \mathrm{E}-03$ \\
\hline iso-pentane & 8.42E-04 & $6.05 \mathrm{E}-04$ & 2.10E-04 & $6.32 \mathrm{E}-04$ & $6.32 \mathrm{E}-04$ \\
\hline n-pentane & 4.23E-04 & 2.63E-04 & $6.33 \mathrm{E}-05$ & 2.82E-04 & $2.82 \mathrm{E}-04$ \\
\hline n-hexane & 3.72E-04 & $9.65 \mathrm{E}-05$ & 4.98E-06 & $1.32 \mathrm{E}-04$ & $1.32 \mathrm{E}-04$ \\
\hline n-heptane & 2.71E-04 & $2.45 \mathrm{E}-05$ & 3.83E-07 & 7.17E-05 & $7.17 \mathrm{E}-05$ \\
\hline n-octane & $4.64 \mathrm{E}-05$ & $1.94 \mathrm{E}-06$ & $1.58 \mathrm{E}-08$ & $2.08 \mathrm{E}-05$ & $2.08 \mathrm{E}-05$ \\
\hline n-nonane & 7.98E-07 & $2.05 \mathrm{E}-08$ & $1.11 \mathrm{E}-10$ & $1.01 \mathrm{E}-06$ & $1.01 \mathrm{E}-06$ \\
\hline \multicolumn{6}{|c|}{ Liquid phase } \\
\hline Liquid phase fraction & $6.85 \mathrm{E}-04$ & $2.31 \mathrm{E}-03$ & $2.45 \mathrm{E}-03$ & & \\
\hline Carbon dioxide & $1.15 \mathrm{E}-03$ & $1.67 \mathrm{E}-03$ & $2.84 \mathrm{E}-03$ & & \\
\hline Nitrogen & $8.36 \mathrm{E}-05$ & $6.11 \mathrm{E}-05$ & $4.85 \mathrm{E}-05$ & & \\
\hline Methane & 0.131573 & 0.119424 & 0.119245 & & \\
\hline Ethane & $2.44 \mathrm{E}-02$ & $3.47 \mathrm{E}-02$ & $5.64 \mathrm{E}-02$ & & \\
\hline Propane & 3.19E-02 & $6.18 \mathrm{E}-02$ & 0.137046 & & \\
\hline iso-butane & 2.61E-02 & $6.04 \mathrm{E}-02$ & 0.146341 & & \\
\hline n-butane & $3.28 \mathrm{E}-02$ & 8.03E-02 & 0.186801 & & \\
\hline iso-pentane & 4.83E-02 & 0.117619 & 0.172209 & & \\
\hline n-pentane & $3.45 \mathrm{E}-02$ & 7.97E-02 & 8.92E-02 & & \\
\hline n-hexane & 0.117852 & 0.154332 & 5.19E-02 & & \\
\hline n-heptane & 0.328206 & 0.20411 & 2.91E-02 & & \\
\hline n-octane & 0.209931 & $8.16 \mathrm{E}-02$ & 8.49E-03 & & \\
\hline n-nonane & $1.32 \mathrm{E}-02$ & 4.27E-03 & $4.11 \mathrm{E}-04$ & & \\
\hline
\end{tabular}




\section{APPENDIX B}

FORTRAN CODE 
The following section of the code is the portion that simulates the diverging nozzle.

Packages for the calculations of thermodynamic parameter, EOS, flash calculations and sound of speed calculations are not reported. [1210 lines out of 57,400]

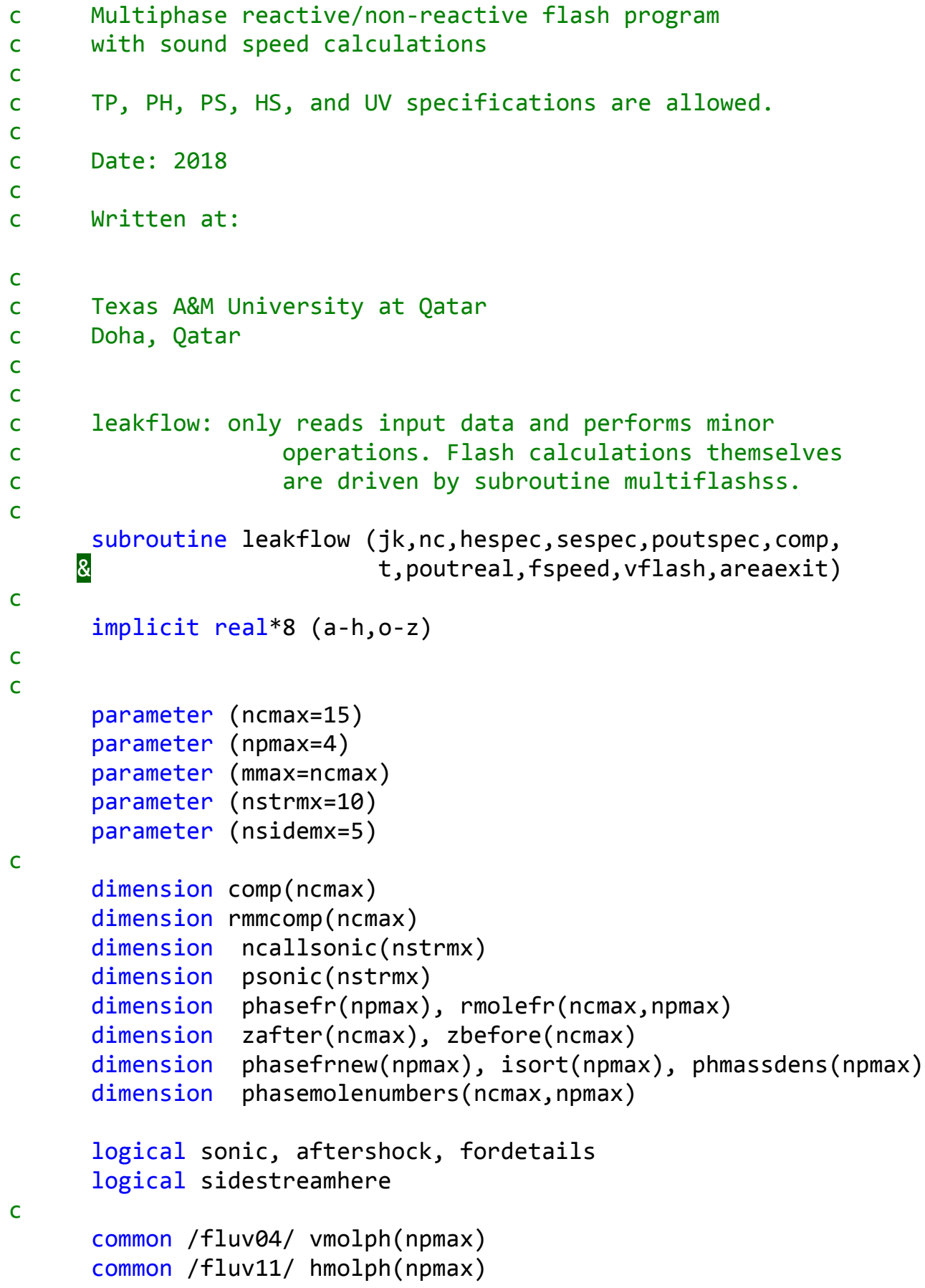


common /fluv12/ smolph(npmax)

c

common /flin17/ np

C

common /flio01/ in

common /flioo2/ iout

common /flio03/ iplot

common /flio04/ laval

common /flio05/ lavshock

common /flio06/ lavback

c

common /flrfo1/ po

common /flrf02/ tref

C

common /fluc01/ rem3bar

common /fluc02/ rjoule

C

C

C

change commons flfoel and flfoer in Petrobras version

common /flfoel/ fordat (ncmax, 2)

common /flfoo2/ cpval(ncmax,4)

C

common /flfoo3/ iforma(ncmax)

C

common /seleos/ kual_eos

C

common /limite/ xlim

C

c

common /molecw/ rmmcomp

common /memosonic04/ psonic

common /memosonic01/ ncallsonic

C

common /sidest01/ kountside

common /sidest02/ nsidestreams

dimension tside(nsidem $x$ )

common /sidest03/ tside

dimension alphaside(npmax, nsidemx)

common /sidest04/ alphaside

common /timeroo/ starto

common /timer01/ start

C

c $\quad$ write(iout, ${ }^{*}$ ) $1 \% \% \%$ inside leakflow pm', pm

c $\quad$ iplot $=8$

c

c

Reference pressure and temperature for formation data

$\mathrm{p} \theta=1 . \mathrm{d} 00$

tref $=298.15$ d00

tolside $=1 . d-04$

C 


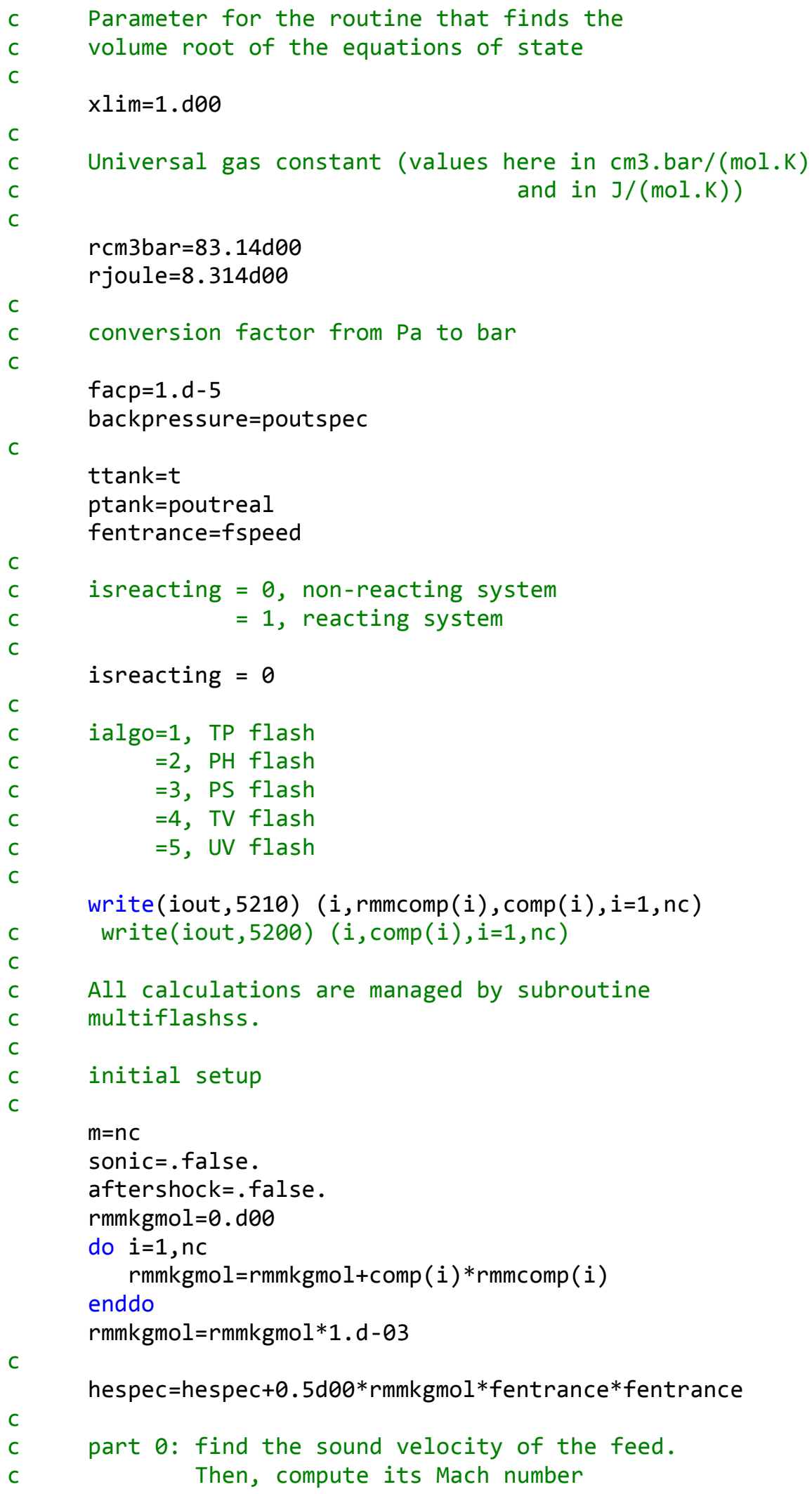


write(iout, *) 'hespec, sespec', hespec, sespec

write (iout, $*$ ) ' $t$, poutspec', $t$, poutspec

write(iout, ${ }^{*}$ ) 'beginning of part $\theta^{\prime}$

ialgo=1

call multiflashss ( $j k$, sonic, ialgo, nc, m, ttank, ptank, hespec, sespec, $\&$ uespec, vespec, comp, rmmcomp, asoundtank, htank, vtank, stank, phasefr, rmolefr)

rmachentrance $=$ fentrance $/$ asoundtank

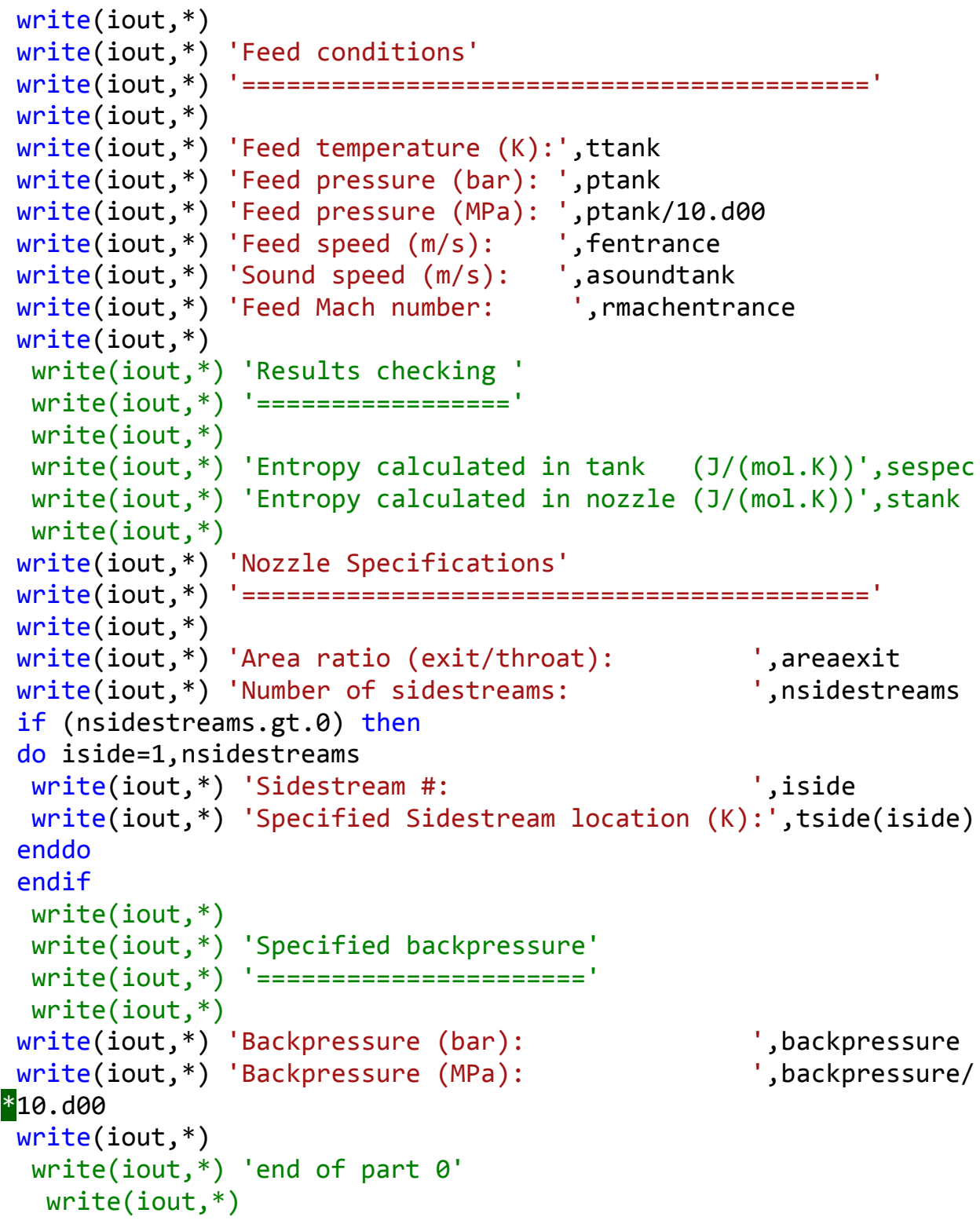




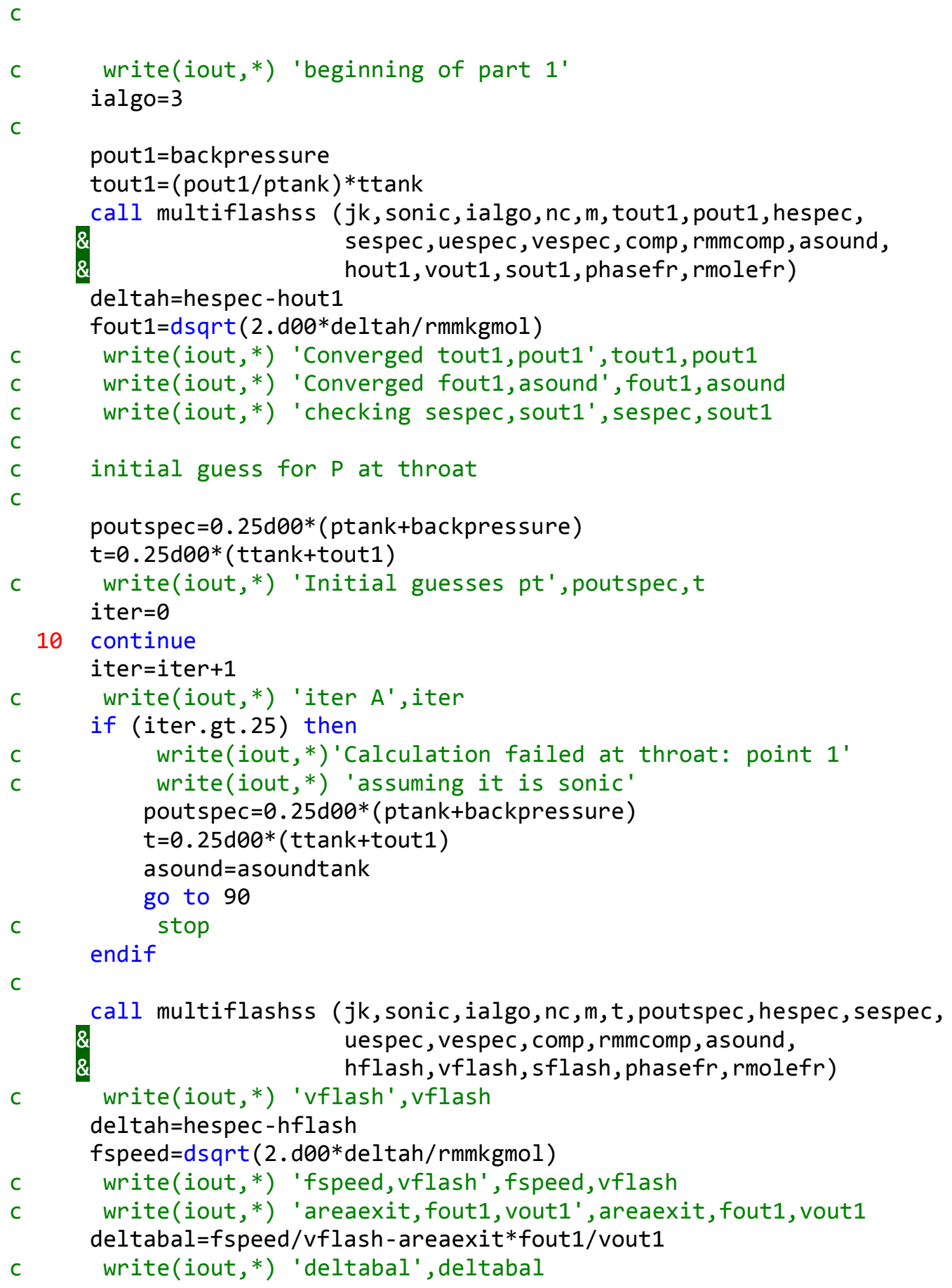


if (iter.eq.1) then poutspecold=poutspec deltabalold=deltabal poutspec $=0.99 \mathrm{~d} 00 *$ poutspec

else go to 10

secant $=($ deltabal - deltabalold $) /($ poutspec - poutspecold $)$ poutspecold=poutspec deltabalold=deltabal

C endif

stepsize $=1$. d00

delsec=deltabal/secant

dabsdelsec $=$ dabs $($ delsec $)$

sdel=dabsdelsec/delsec write (iout, *) 'sec, delsec, poutspecold', secant, delsec, poutspecold if (dabsdelsec/poutspecold.gt.0.2) delsec $=0.2 *$ sdel*poutspecold continue poutspec=poutspecold-stepsize*delsec if (stepsize.1t.1.d-2) then

else write(iout,*) 'Calculation failed at throat: point 2' write(iout, *) 'assuming it is sonic' poutspec $=0.25 \mathrm{d00} *($ ptank+backpressure $)$ $\mathrm{t}=0.25 \mathrm{d00} *$ (ttank+tout 1 ) asound=asoundtank go to 90

endif

if (poutspec.gt.backpressure.or.poutspec.1t.0.d00) then stepsize=stepsize*0.95d00 go to 40 endif

write (iout, *) 'end of part 1' 


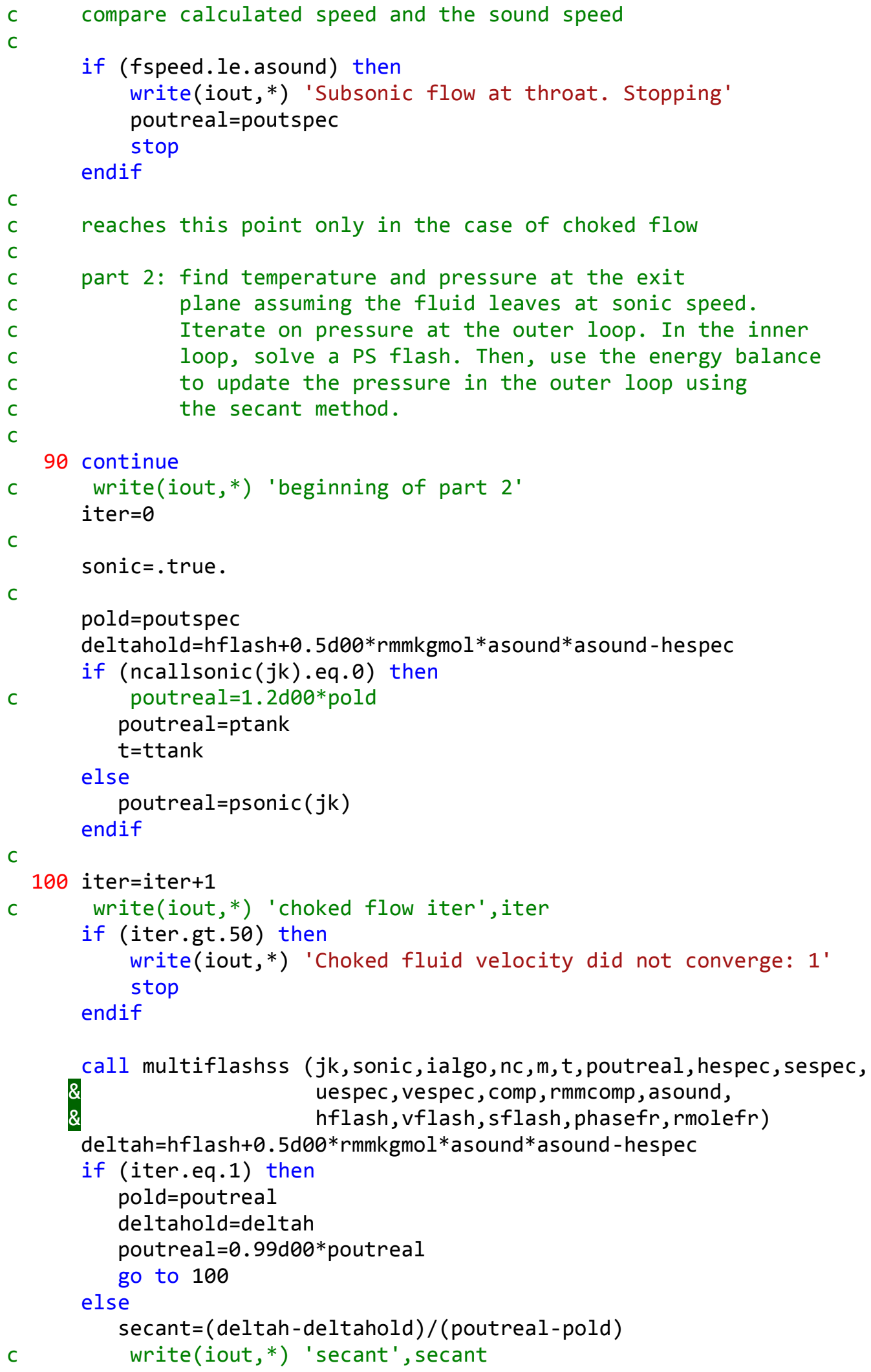




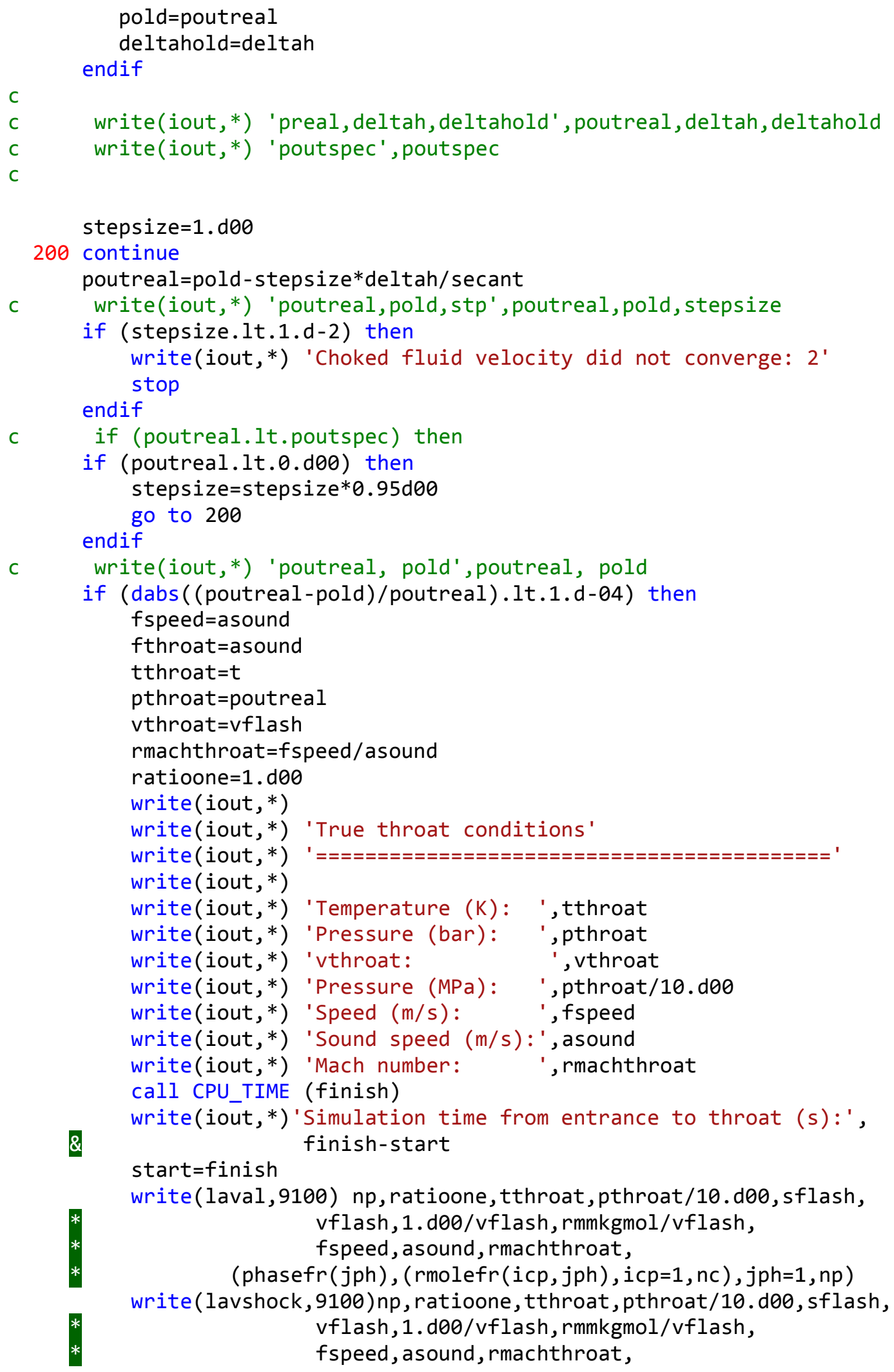




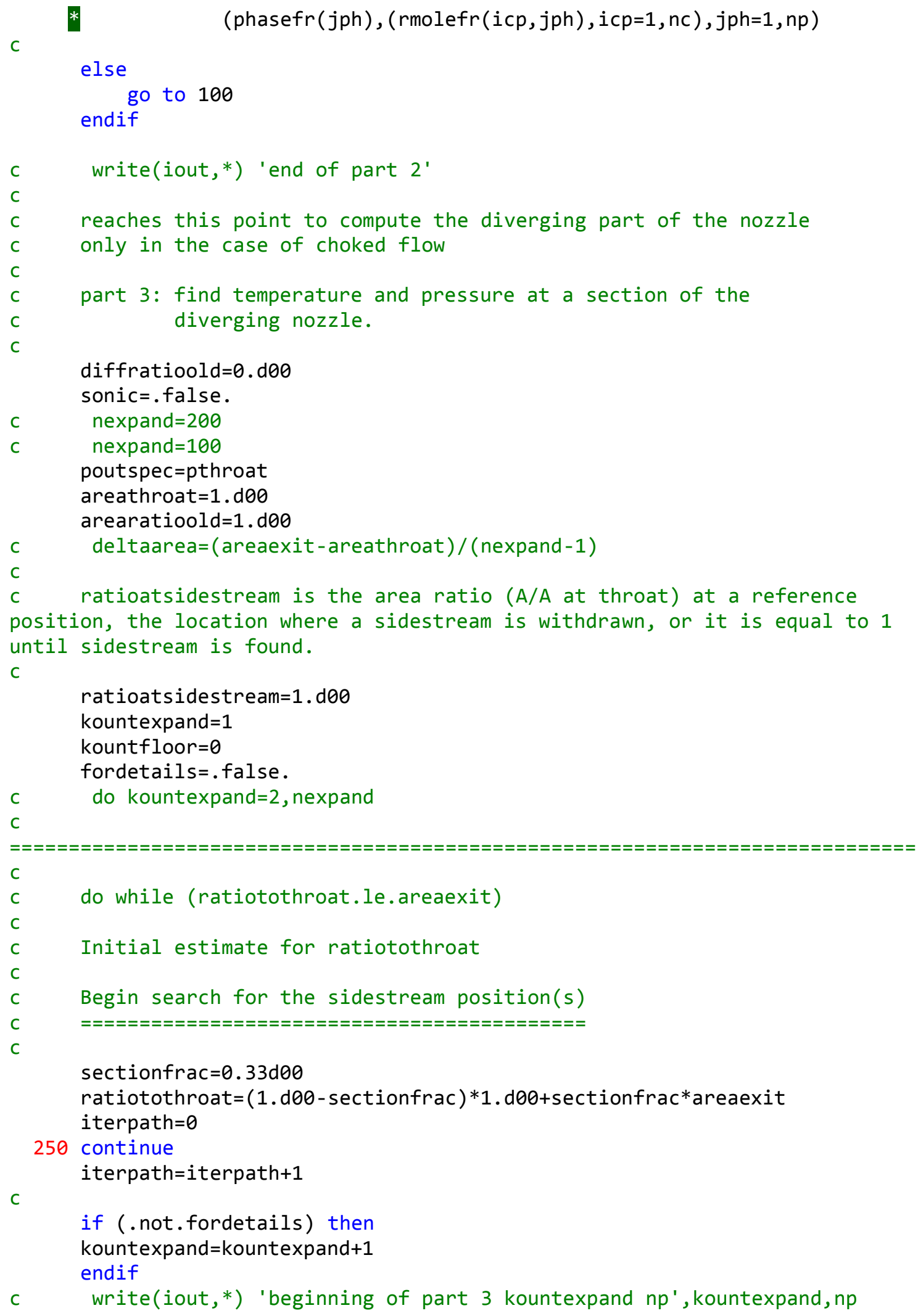




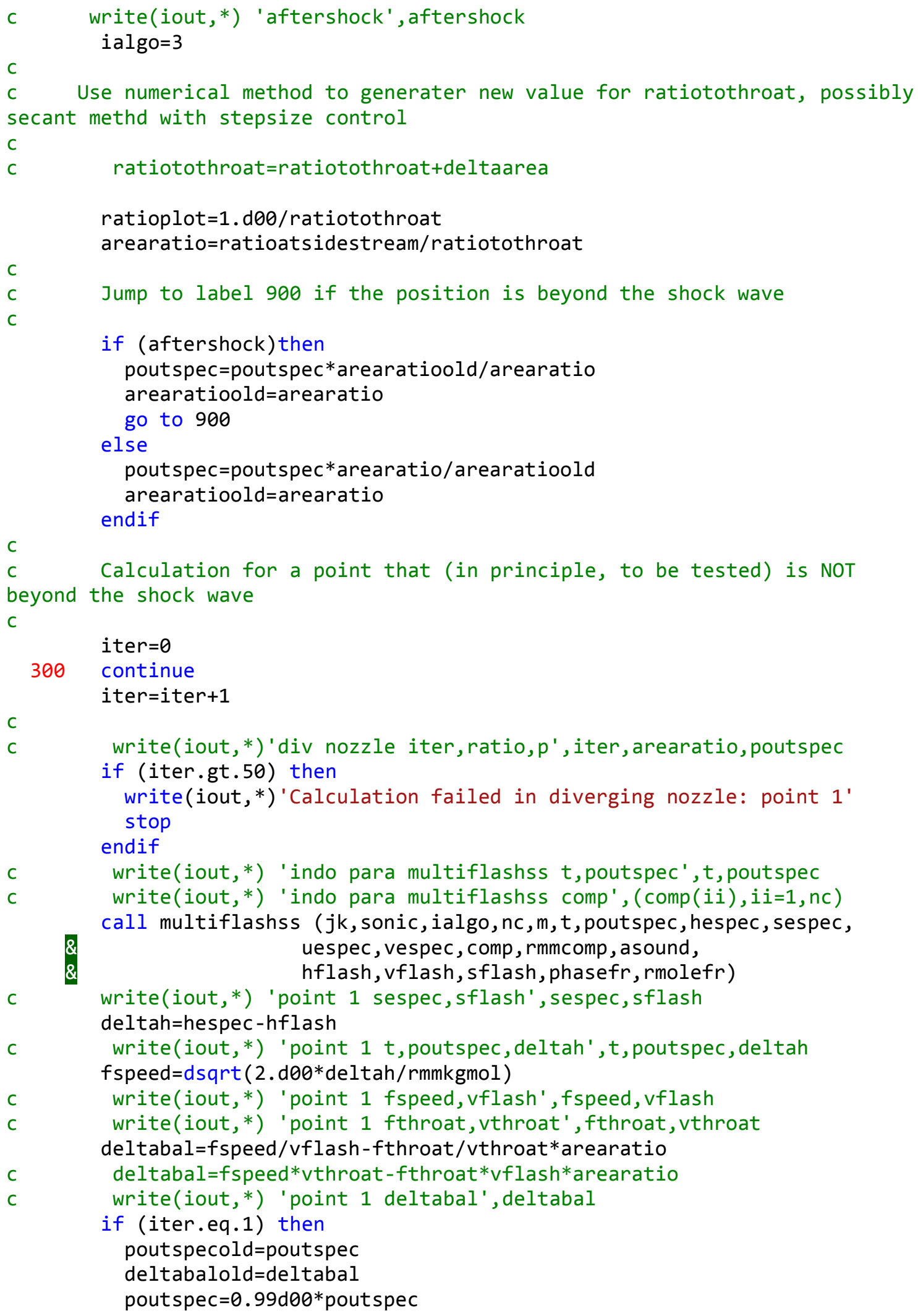




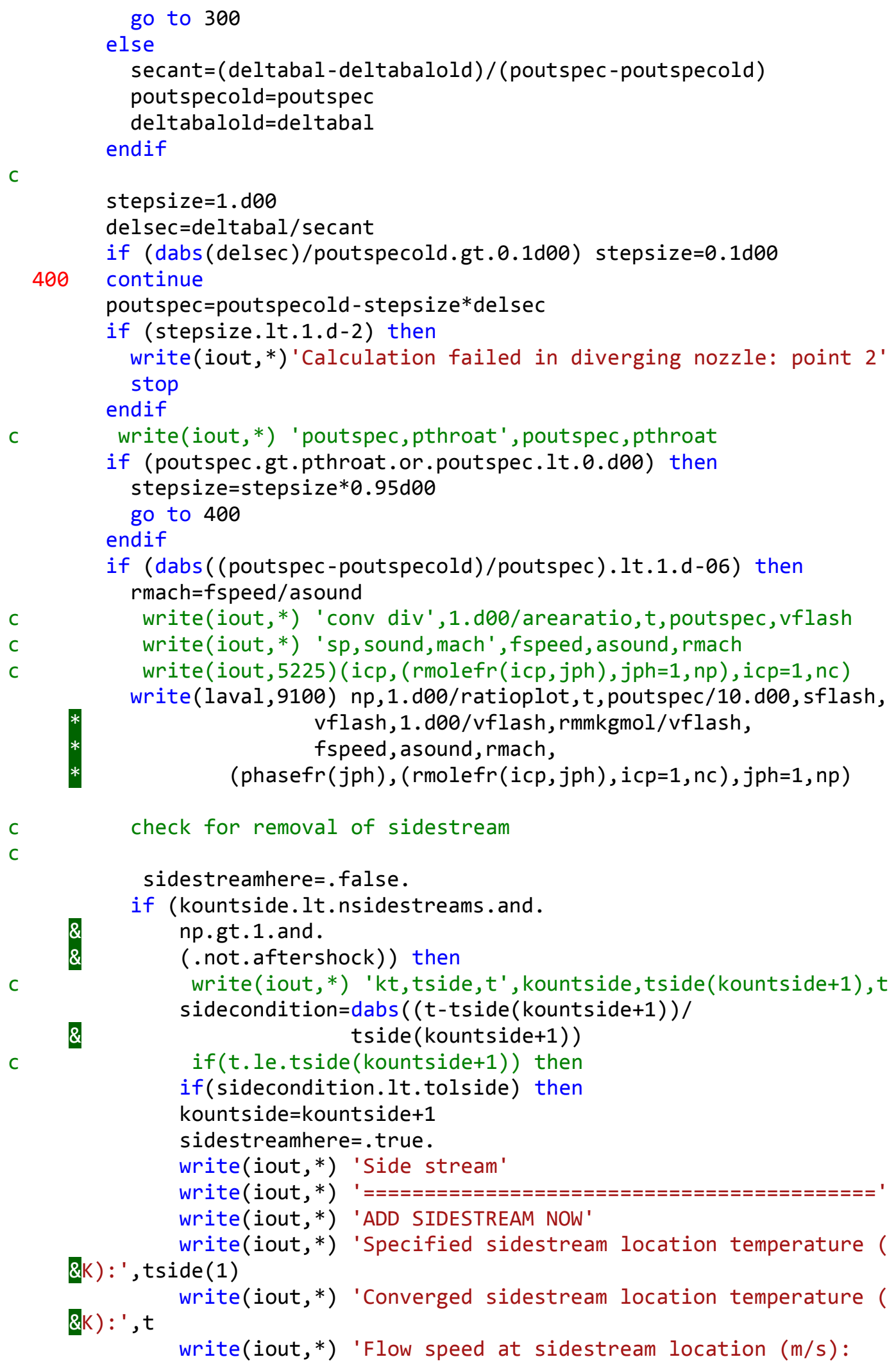




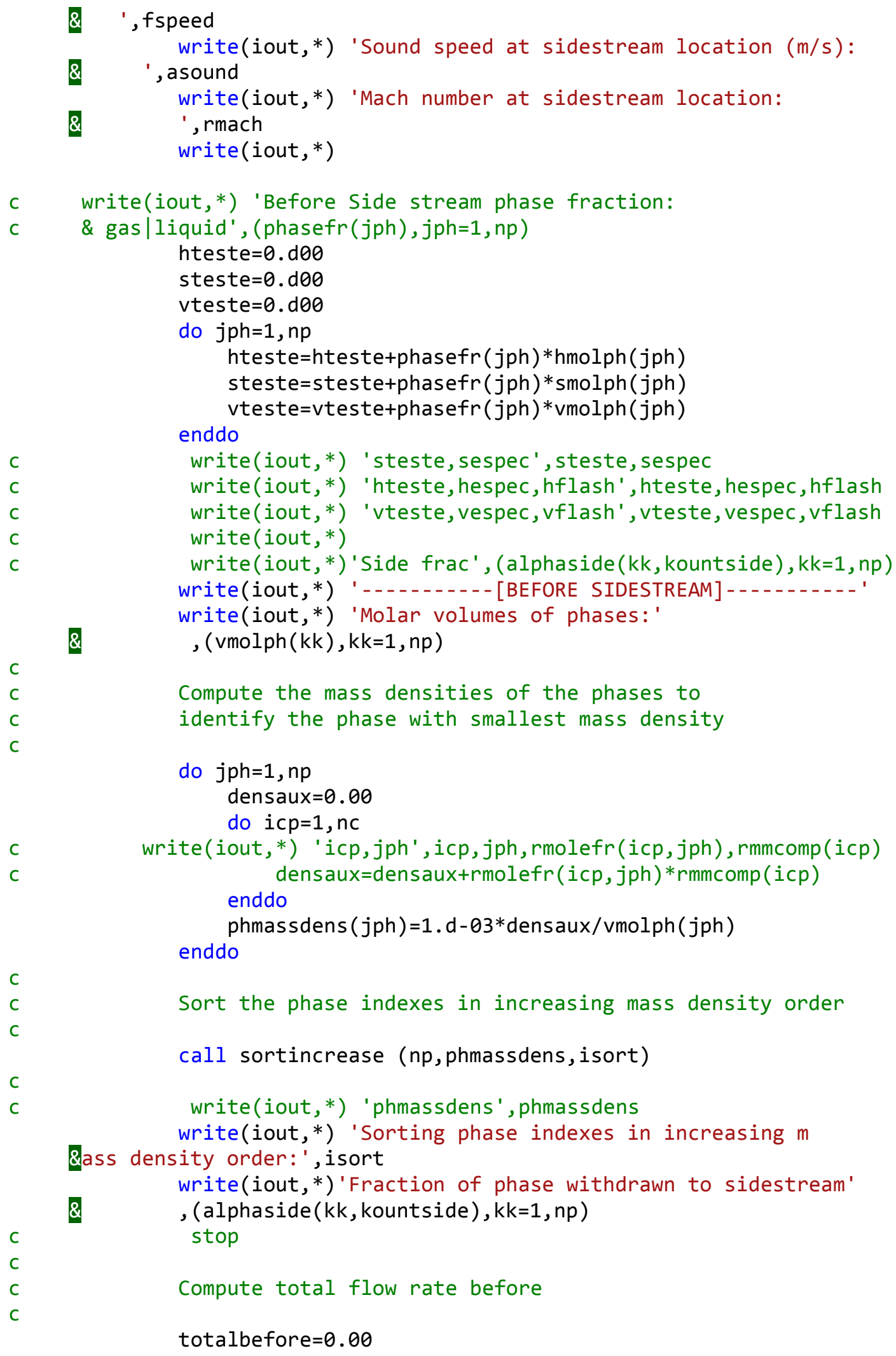




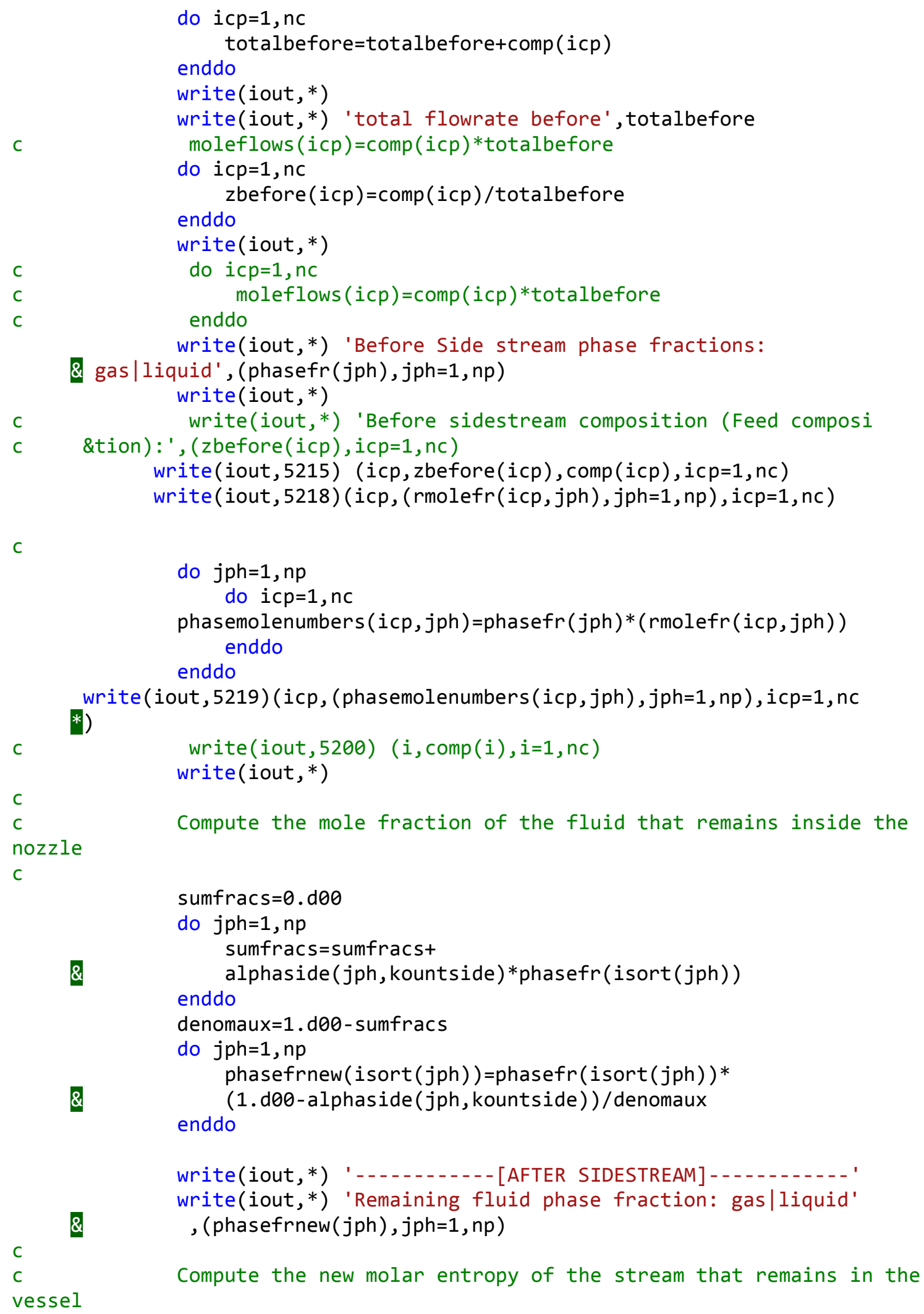




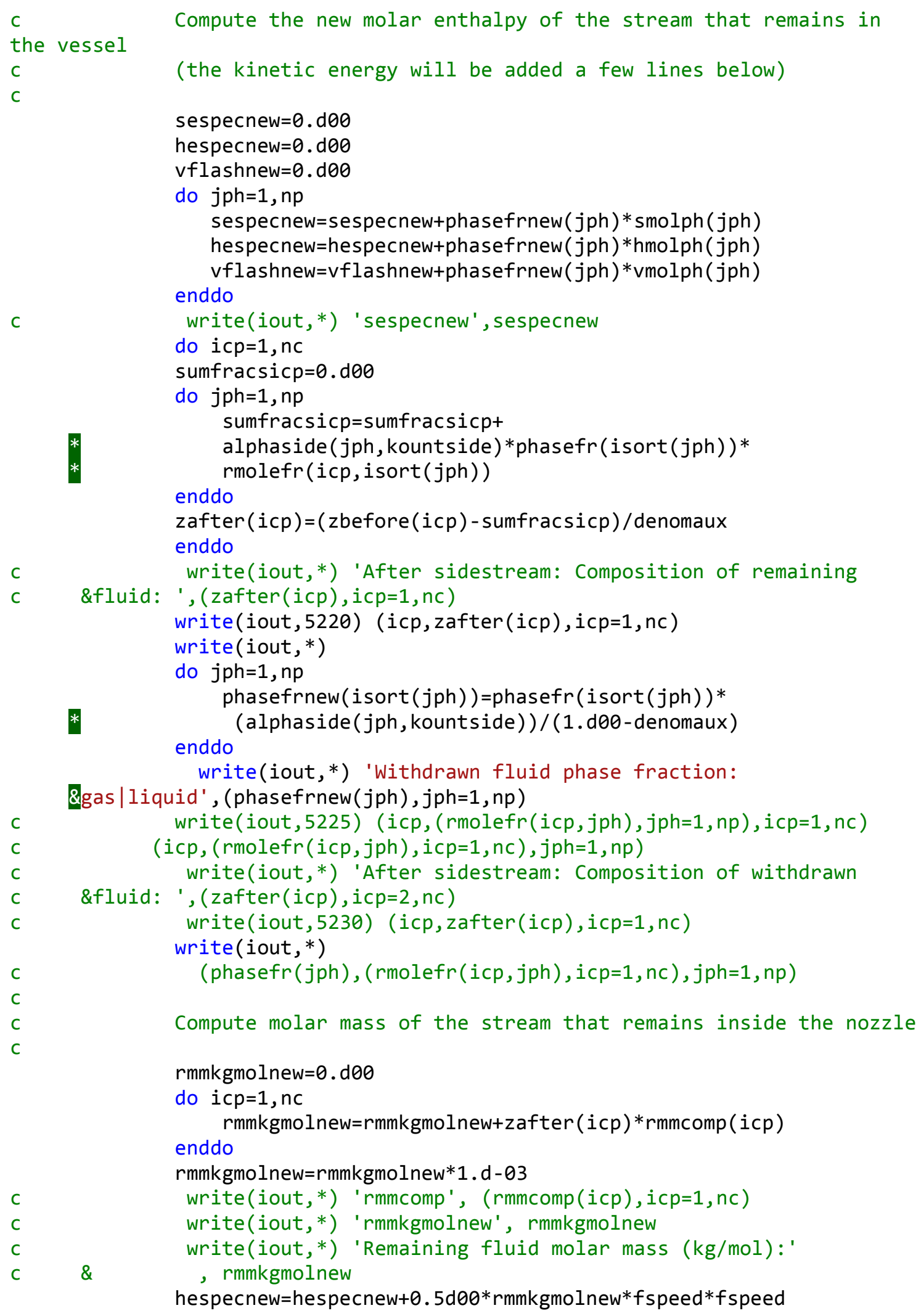

C

Compute the new molar enthalpy of the stream that remains in (the kinetic energy will be added a few lines below)

sespecnew $=0$. d 00

hespecnew $=0$. do0

vflashnew $=0 . d \theta 0$

do $\mathrm{jph}=1, \mathrm{np}$

sespecnew $=\operatorname{sespecnew}+$ phasefrnew $(j p h) * \operatorname{smolph}(j p h)$

hespecnew $=$ hespecnew+phasefrnew (jph)*hmolph (jph)

$v f l a s h n e w=v f l a s h n e w+p h a s e f r n e w(j p h) * v m o l p h(j p h)$

enddo

write(iout, $\left.{ }^{*}\right)$ ' sespecnew', sespecnew

do icp $=1, n c$

sumfracsicp $=0$. d00

do $\mathrm{jph}=1, \mathrm{np}$ sumfracsicp=sumfracsicp + alphaside(jph, kountside)*phasefr(isort (jph))*

enddo rmolefr(icp, isort (jph))

zafter $(i c p)=($ zbefore $(i c p)-\operatorname{sumfracsicp}) /$ denomaux

enddo

write(iout,*) 'After sidestream: Composition of remaining

\&fluid: ', (zafter(icp), icp=1,nc)

write (iout, 5220) (icp, zafter (icp), icp=1, nc)

write (iout, $*$ )

do $\mathrm{jph}=1, \mathrm{np}$

phasefrnew $($ isort $($ jph $))=$ phasefr $($ isort $($ jph $))$ *

enddo (alphaside(jph, kountside))/(1.d00-denomaux)

write(iout,*) 'Withdrawn fluid phase fraction:

\&gas|liquid' , (phasefrnew(jph), jph=1,np)

write(iout, 5225) (icp, (rmolefr (icp, jph), jph=1, np), icp=1, nc)

(icp, $(r m o l e f r(i c p, j p h), i c p=1, n c), j p h=1, n p)$

write(iout,*) 'After sidestream: Composition of withdrawn

\&fluid: ', (zafter (icp), icp=2,nc)

write (iout, 5230) (icp, zafter (icp), icp=1, nc)

write(iout, *)

(phasefr (jph), (rmolefr(icp,jph), icp=1,nc),jph=1, np)

Compute molar mass of the stream that remains inside the nozzle

rmmkgmolnew $=0$. do0

do icp $=1$, nc

enddo

rmmkgmolnew=rmmkgmolnew+zafter $($ icp $) *$ rmmcomp (icp)

rmmkgmolnew=rmmkgmolnew*1.d-03

write(iout, *) 'rmmcomp', ( $r m m c o m p(i c p), i c p=1, n c)$

write(iout, $*$ ) 'rmmkgmolnew', rmmkgmolnew

write $\left(\right.$ iout, $\left.{ }^{*}\right)$ 'Remaining fluid molar mass $(\mathrm{kg} / \mathrm{mol})$ :'

\& , rmmkgmolnew

hespecnew $=$ hespecnew $+0.5 \mathrm{~d} 00 *$ rmmkgmolnew*fspeed $*$ fspeed 


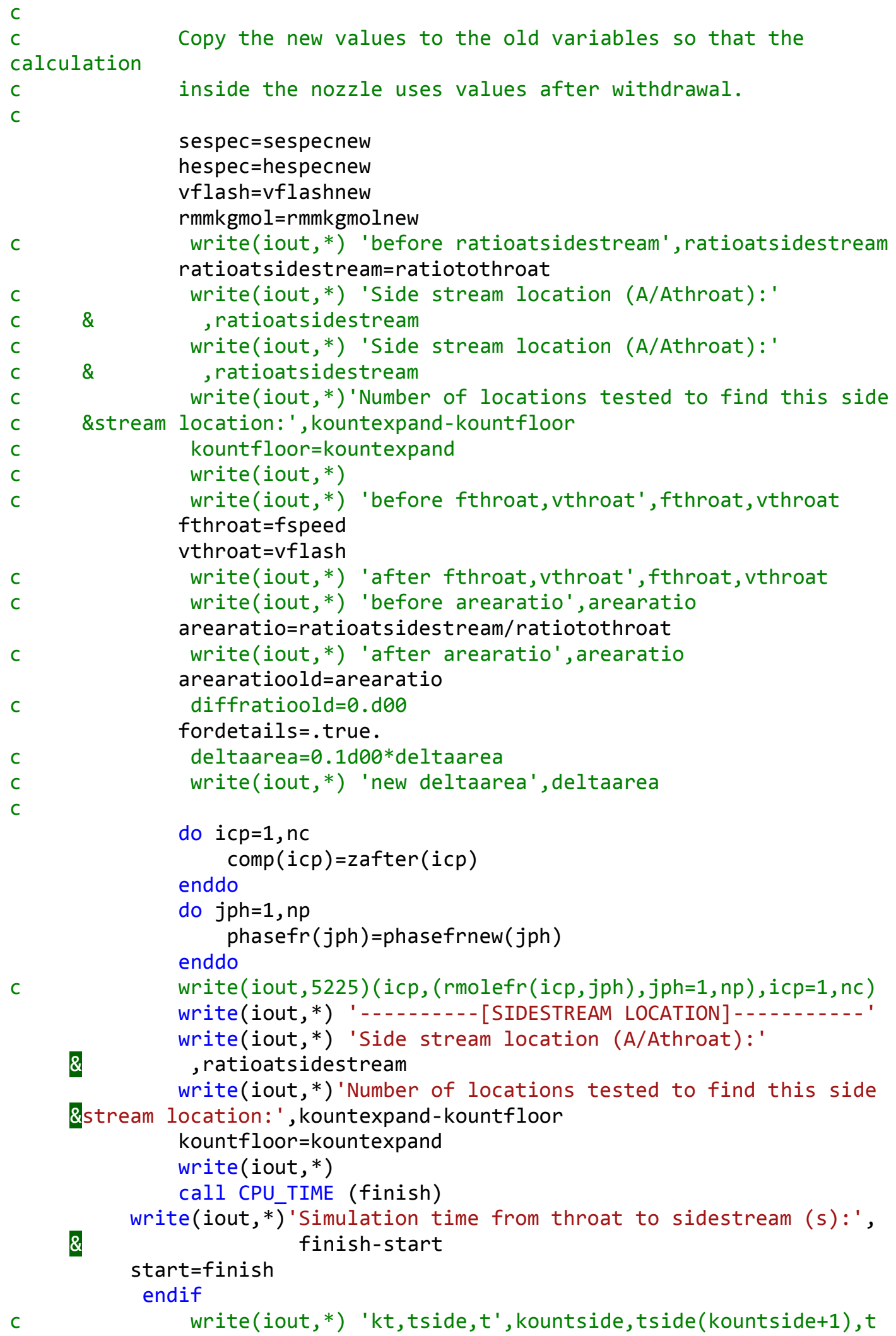




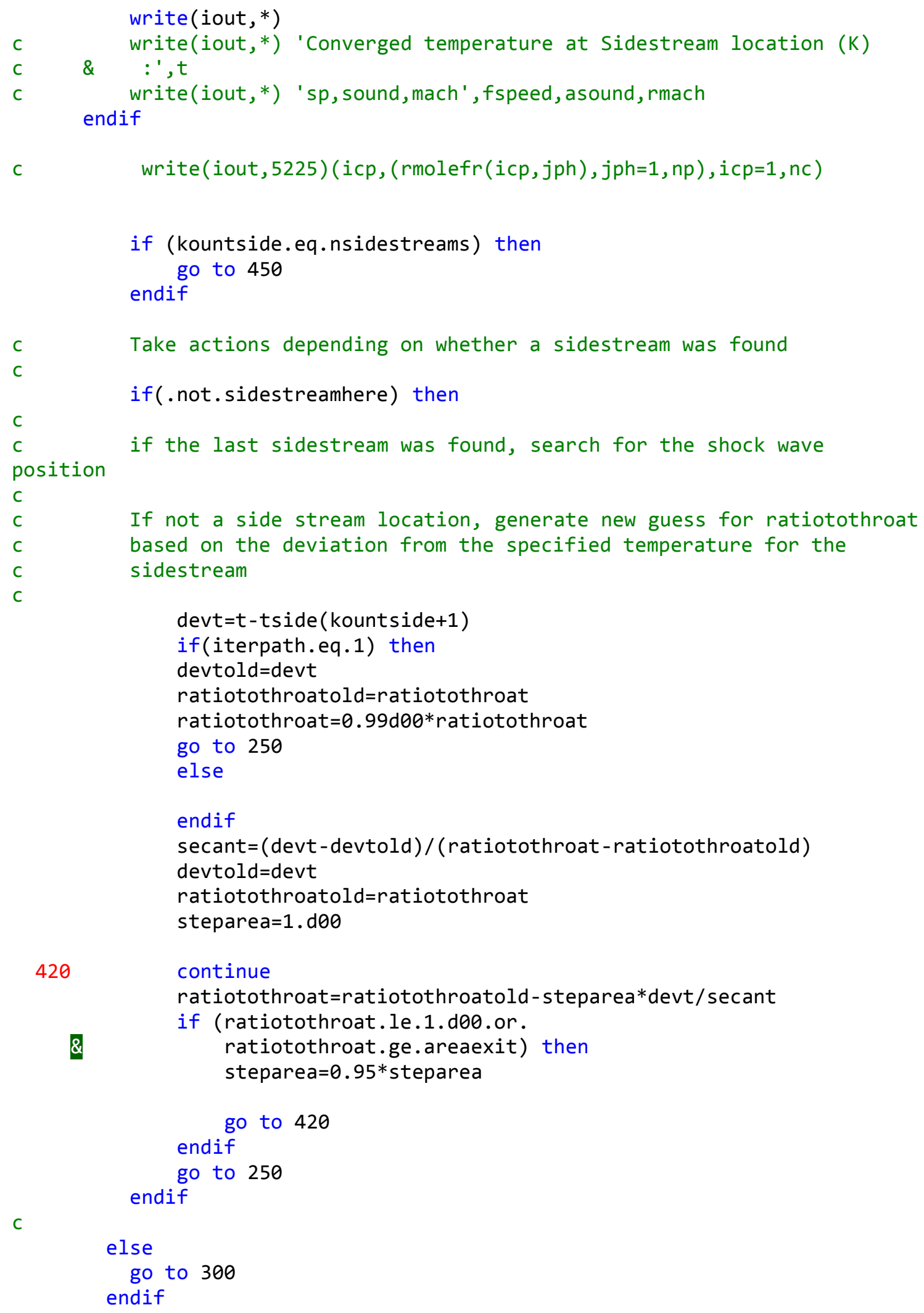




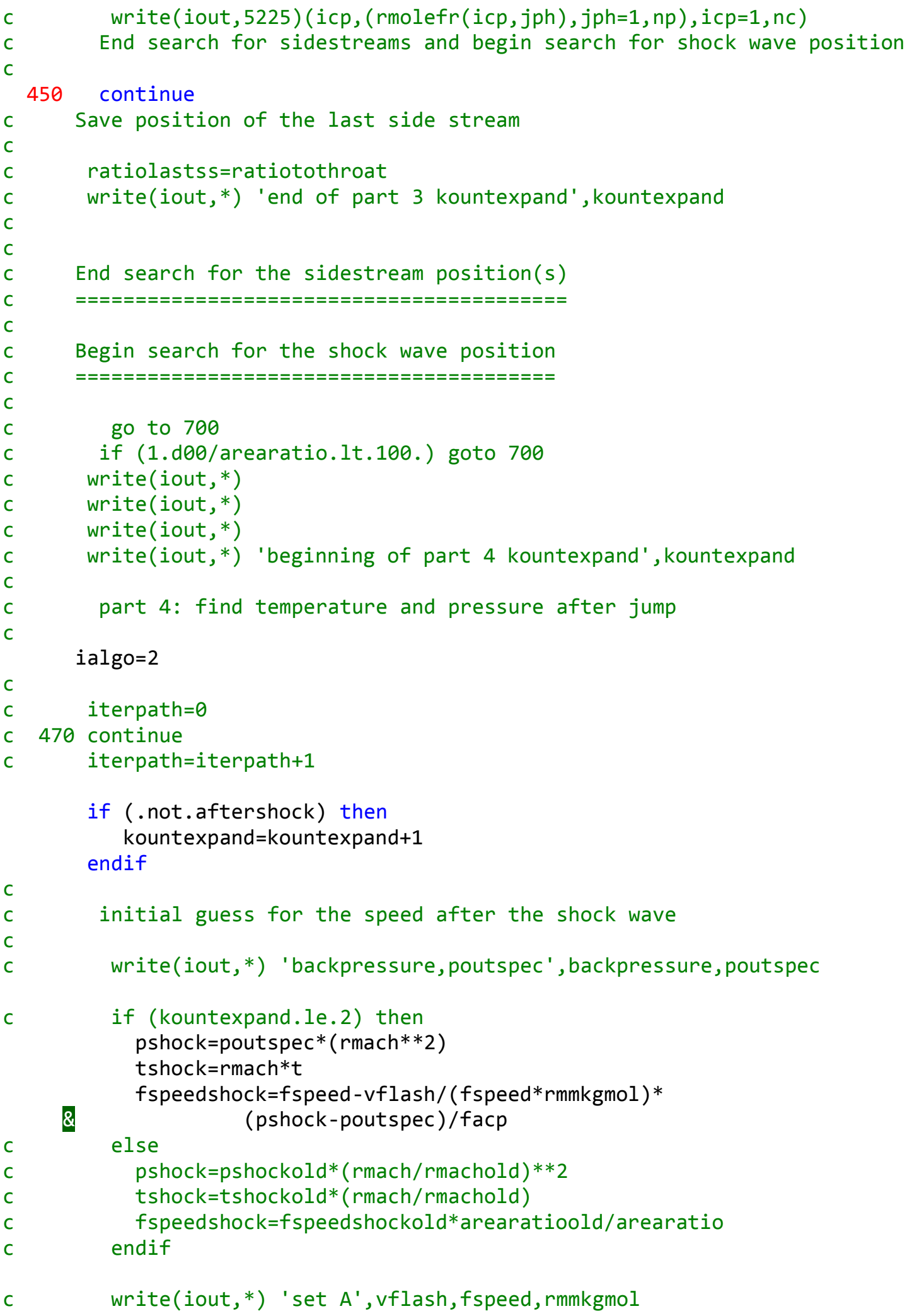


$c$

write(iout, *) 'set $B^{\prime}$ ', pshock, poutspec, facp

fspeedshock=fspeedshock $/ 1.2$

write(iout,*) 'initial pshock fspeedshock',pshock, fspeedshock iter $=0$

continue

iter $=$ iter +1

if (iter.gt.50) then

write(iout,*)'Calculation failed in diverging nozzle: point 3 ' stop

endif

write (iout, *) 'vari' , fspeed, vflash, fspeedshock, fspeed

write (iout, ${ }^{*}$ ) 'poutspec', poutspec

write(iout, *) 'correc', facp*fspeed/vflash*(fspeedshock-fspeed)

pshock=poutspec -facp*rmmkgmol ${ }^{*}$ fspeed/vflash* (fspeedshock-fspeed)

hshock=hespec $-0.5 \mathrm{~d} 00 *$ rmmkgmol*fspeedshock*fspeedshock

write(iout, *) 'iter, tshock, pshock', iter, tshock, pshock

write(iout, *) 'hshock', hshock

write(iout, *) 'sespec', sespec

ialgo $=2$ here $\Rightarrow \mathrm{PH}$ call to multiflashss

call multiflashss ( $j k$, sonic,ialgo, nc, m, tshock, pshock, hshock, sespec, uespec, vespec, comp, rmmcomp, asound, hflashock, vflashock, sflashock, phasefr, rmolefr)

write(iout, *) 'sflashock', sflashock

deltauv=fspeedshock/vflashock $-\mathrm{fspeed} / \mathrm{vflash}$

write(iout, *) 'deltauv', deltauv

asoundshockold=asound

if (iter.eq.1) then

fspeedshockold $=$ fspeedshock

deltauvold=deltauv

fspeedshock $=0.99 \mathrm{~d} 00 *$ fspeedshock

go to 500

else

secant=(deltauv-deltauvold)/(fspeedshock-fspeedshockold)

fspeedshockold=fspeedshock

deltauvold=deltauv

endif

stepsize $=1$. do0

delsec=deltauv/secant

if (dabs(delsec)/fspeedshockold.gt.0.1d00) stepsize=0.1d00

continue

fspeedshock=fspeedshockold-stepsize*delsec

if (stepsize.lt.1.d-2) then

write(iout,*)'Calculation failed in diverging nozzle: point 4 ' stop

endif 


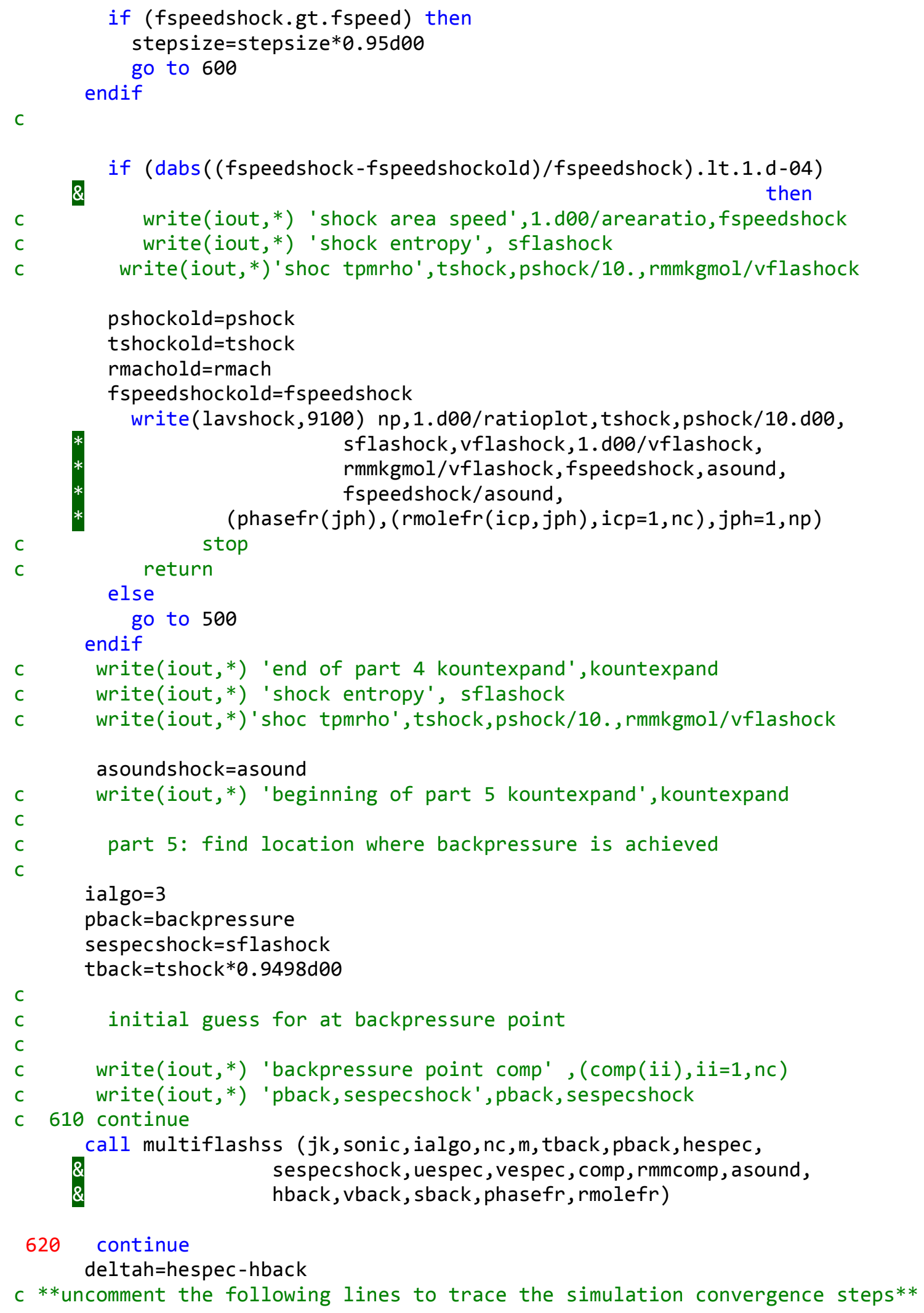




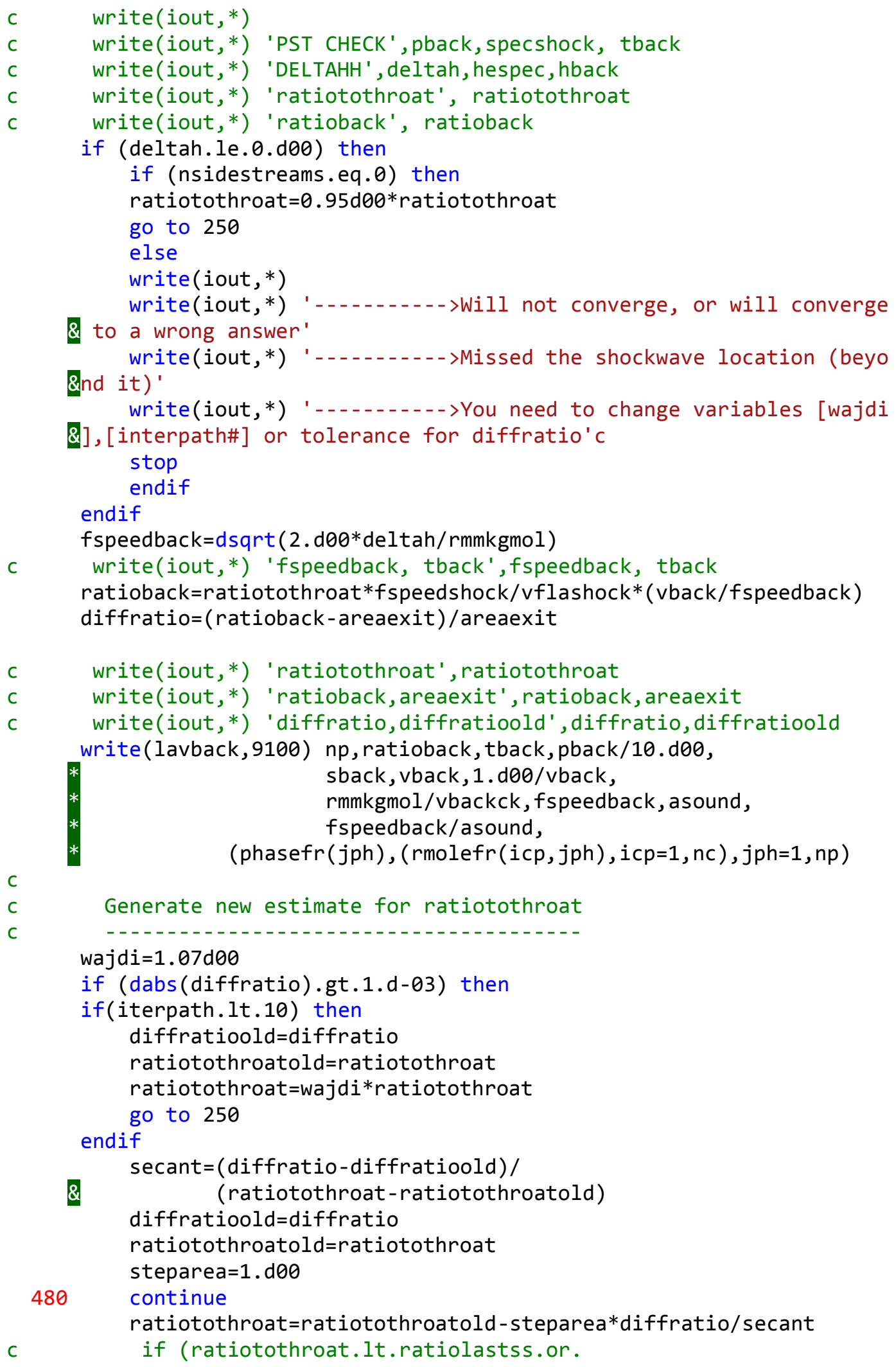




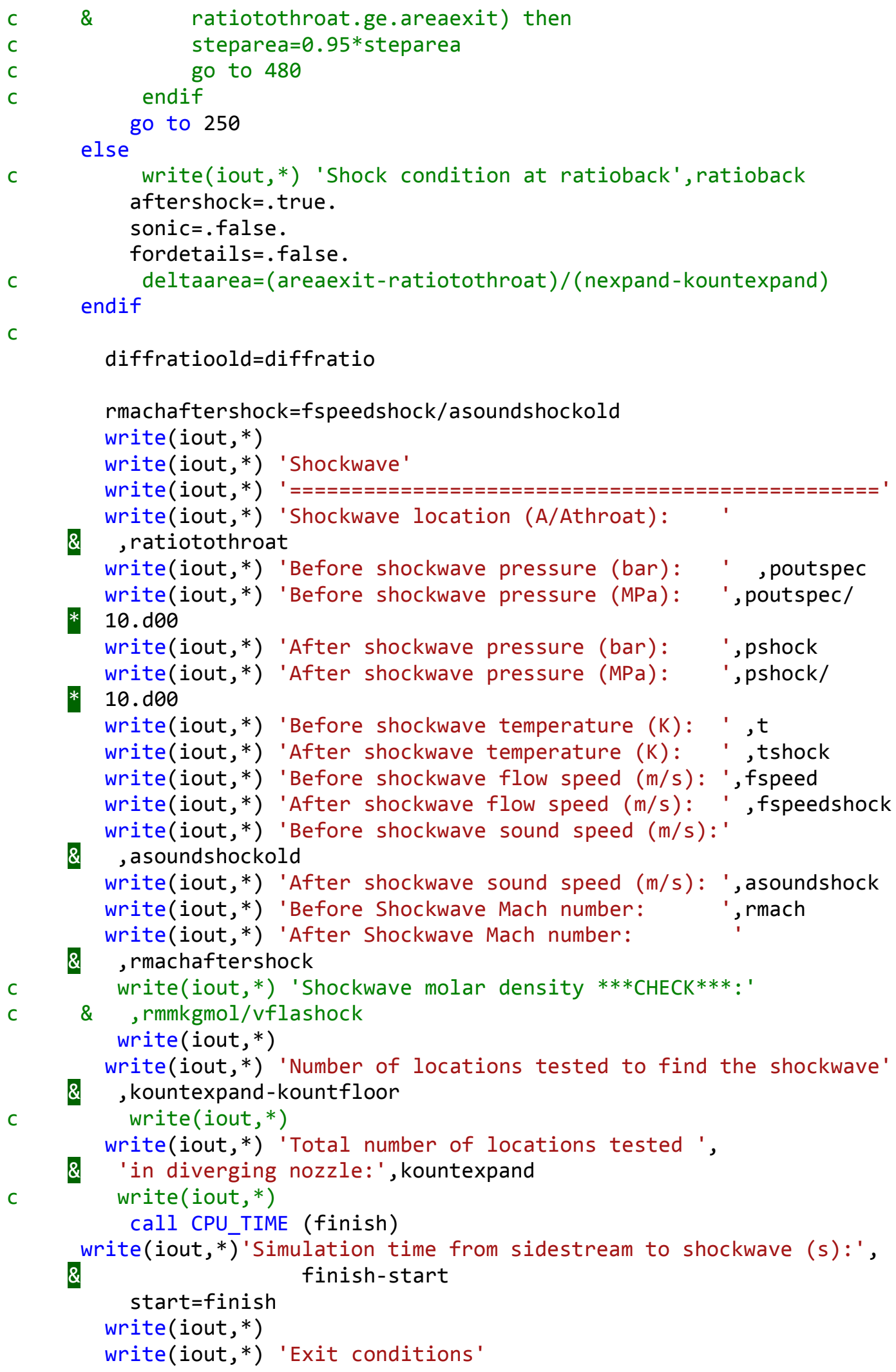




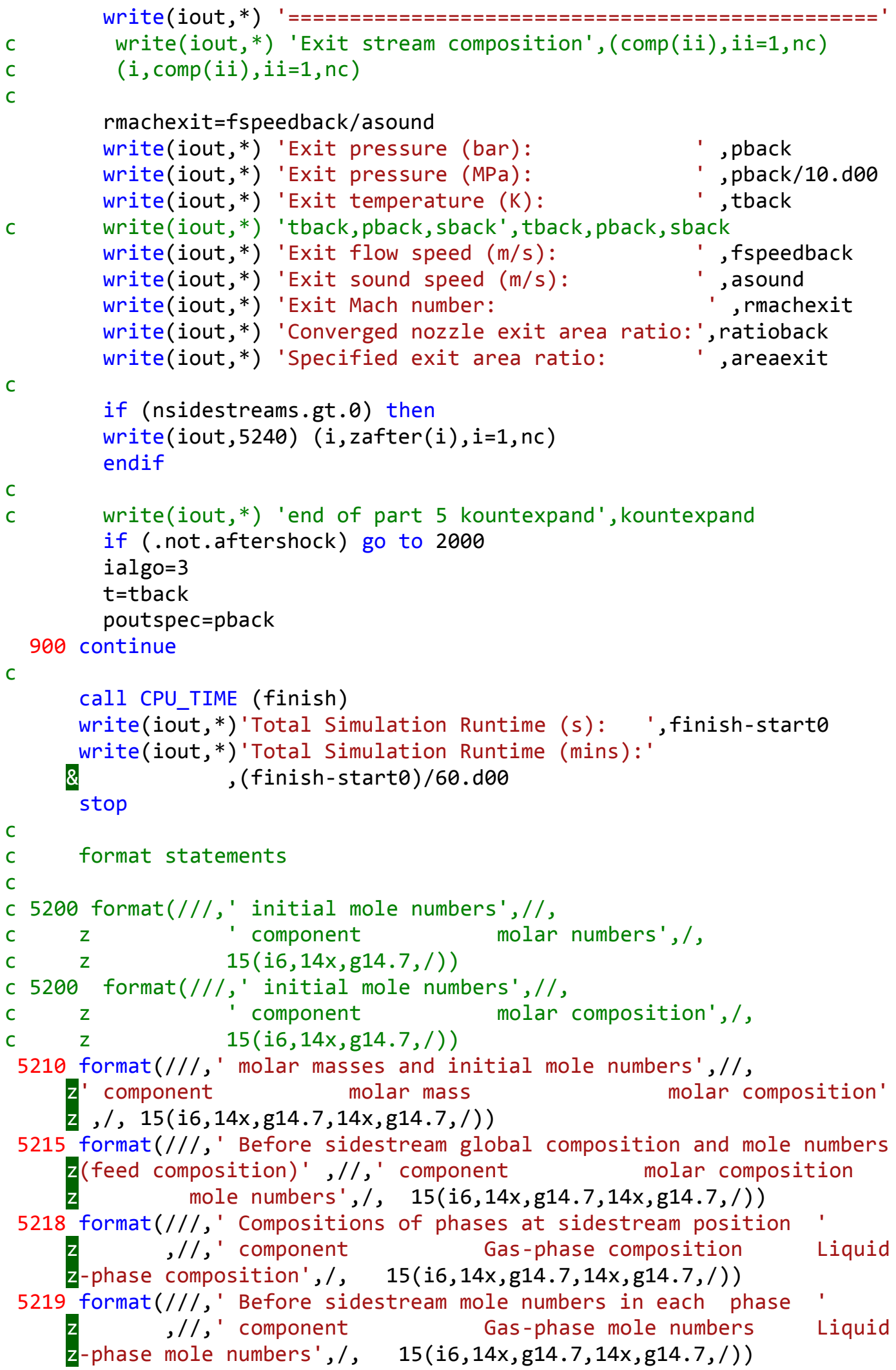




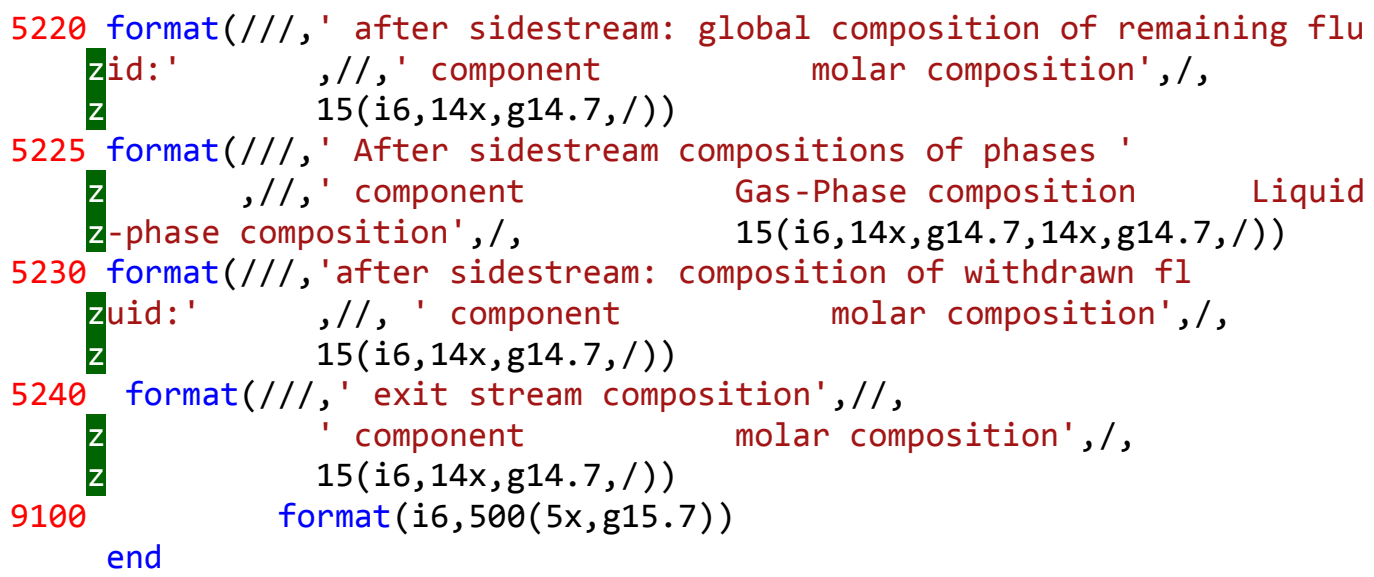

